Universidad de Lima

Facultad de Economía

Carrera de Economía

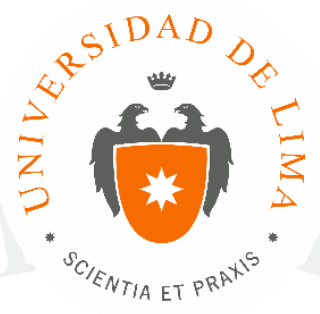

IMPAC TO DE LA NORMATIVA PESQUERA EN LA EFICIENCIA ECONÓMICA DE LA INDUSTRIA PERUANA DE LA ANCHOVETA (1990-2013)

Tesis para optar el título profesional de Economista

Vanessa Zegarra Roldán

Código 20091266

Asesor

Victor Luis Alberto Tokeshi Shirota

$$
\text { Lima - Perú }
$$

Diciembre de 2015 


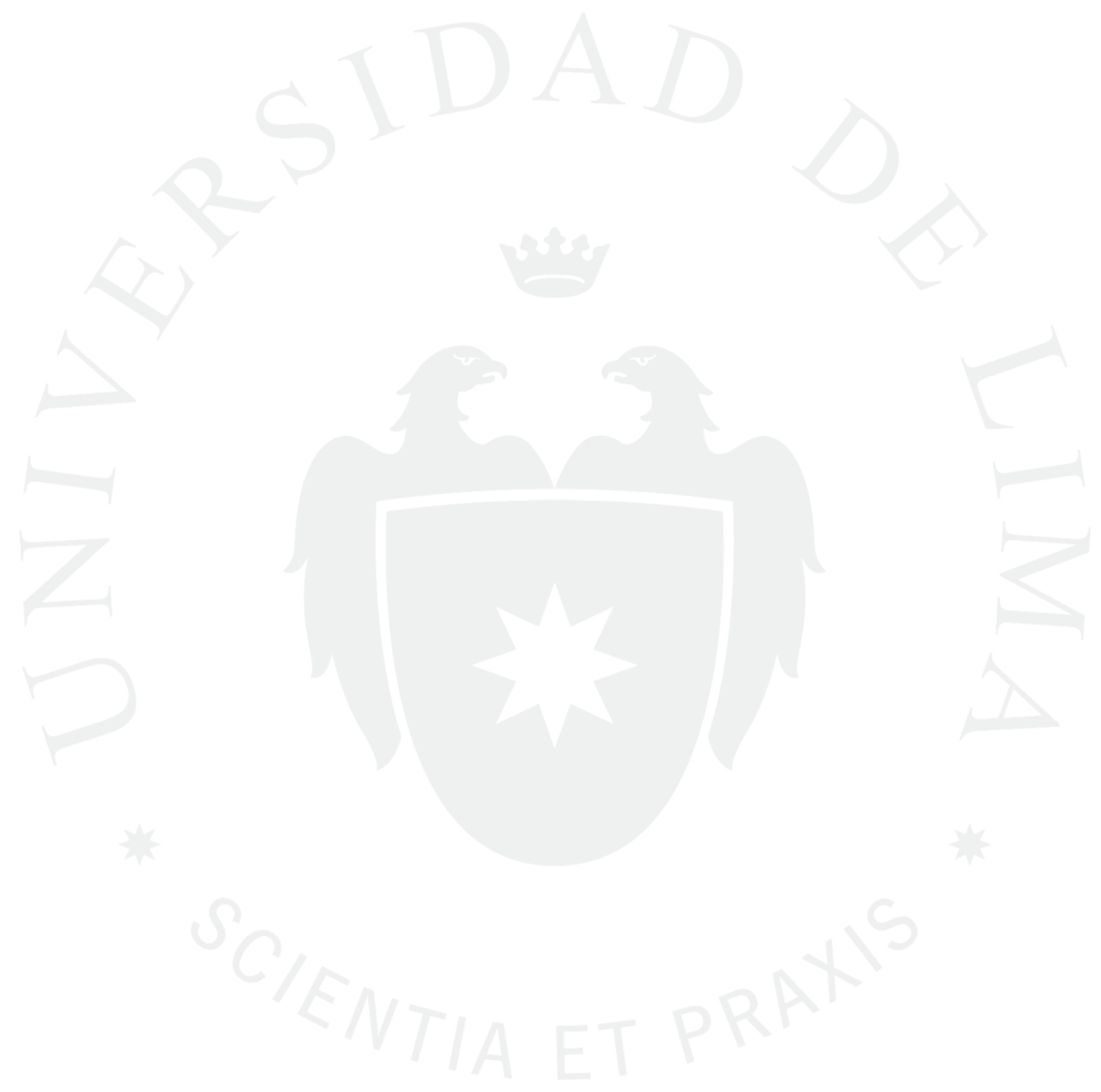




\section{IMPACTO DE LA NORMATIVA PESQUERA EN LA EFICIENCIA ECONÓMICA DE LA INDUSTRIA PERUANA DE LA ANCHOVETA (1990-2013)}




\section{ÍNDICE}

CAPÍTULO I: MARCO DE LA INVESTIGACIÓN.............................................15

1.1 Marco conceptual del problema.............................................15

1.2 Marco teórico de la eficiencia económica en el sector pesquero .21

1.2.1 Problemática del sector: propiedad común del recurso

1.2.2 Investigaciones relacionadas como sustento de las

hipótesis. 25

CAPÍtulo II: CONTEXTO de LA PESCA DE ANCHOVETA EN EL PERÚ 28

2.1 Importancia de la pesca en el Perú 28

2.2 Importancia de la anchoveta peruana ..................................30

2.3 Historia de la pesca de anchoveta en el Perú .......................40

2.4 Organización de la industria de la anchoveta ......................54

2.4.1 Organización institucional.........................................54

2.4.2 Organización industrial .............................................61

CAPÍTULO III: EVALUACIÓN DE EFICIENCIA EN LA DINÁMICA PESQUERA DE LA ANCHOVETA........................................................................72

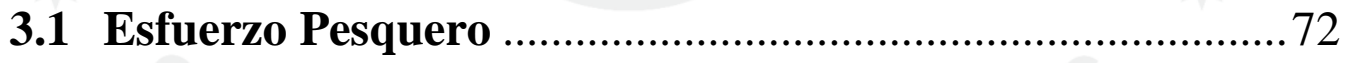

3.1.1 Desembarque por día de pesca....................................73

3.1.2 Planta: Promedio de capacidad por planta según tipo de producto .75

3.1.3 Embarcaciones: Capacidad promedio disponible de pesca por embarcación ................................................. 81

3.1.4 Nivel de efectividad del programa FONCOPES ......82

3.2 Distribución de la dotación inicial de anchoveta .................87

3.2.1 Racionalidad en la elección de un recurso escaso ....88 
3.2.2 Valor Agregado Bruto (VAB) y la relación con Empleo Generado. 91

3.3 Sostenibilidad del recurso …………………....................... 94

3.3.1 Varianza anual de pesca de juveniles .........................94 CAPÍTULO IV: PROSPECTIVA DE LA INDUSTRIA DE LA ANCHOVETA EN BASE A LA NORMATIVA PESQUERA ...................................................................97

4.1 Asignación de cuotas..............................................................97

4.2 Trazabilidad de la cadena productiva ................................102

4.2.1 Autoridades involucradas.........................................103

4.2.2 Herramientas para el control y fiscalización ............. 104 CONCLUSIONES ........................................................................................................113

RECOMENDACIONES ………………….....................................................................116

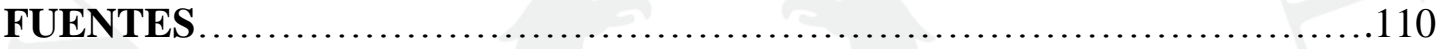

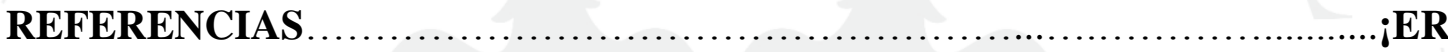

ROR! MARCADOR NO DEFINIDO. 1

ANEXOS 


\section{ÍNDICE DE FIGURAS}

\section{DIAGRAMAS:}

Diagrama 2.1: Dinámica de la anchoveta en el ecosistema marino y la pesca peruana ........................32

Diagrama 2.2: Composición del desembarque por localización, uso y especie al 2012 .........................33

Diagrama 2.3: Organigrama de produce relacionado con la gestión pesquera .....................................56

Diagrama 2.4: Relación de los elementos que componen la organización industrial del sector pesquero

\section{GRAFICOS:}

Gráfico 1.1: Relación del nivel de captura del recurso pesquero y su crecimiento .................................22

Gráfico1.2: Relación del esfuerzo pesquero y el costo y beneficios asociados a la actividad .................23

Gráfico 2.13: Evolución del PBI nacional y del PBI de Pesca ...............................................................28

Gráfico 2.24: Evolución de las exportaciones tradicionales y de productos pesqueros (millones de

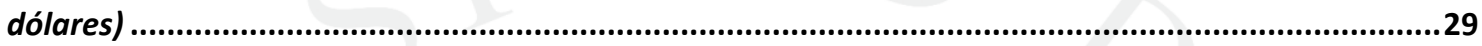

Gráfico 2.35: Evolución de la recaudación del Impuesto a la Renta (millones de nuevos soles)...........29

Gráfico 2.46: Composición del nivel de desembarque a 2012 .............................................................34

Gráfico 2.57: Participación del desembarque marítimo y del desembarque marítimo de pescados (al

2012 en porcentajes) ...............................................................................................................................34

Gráfico 2.68: Participación del desembarque marítimo de especies pelagágicas ...................................35

Gráfico 2.79: Distribución del desembarque de CHD y principales especies en el Congelado al 2011 ...35

Gráfico 2.810: Distribución del desembarque de CHD y principales especies en el Fresco al 2011 .........36

Gráfico 2.911: Distribución del desembarque de CHD y principales especies en el Enlatado al 2011 ....36

Gráfico 2.1012: Distribución del desembarque de CHD y principales especies en el Curado al 2011 .....37

Gráfico 2.1113: Participación del desembarque de recursos hidrobiológicos destinados a CHD y uso de

la anchoveta (al 2011 en porcentajes) ............................................................................................38

Gráfico 2.1214: Participación del desembarque de $\mathrm{CHI}$ por especie ....................................................38

Gráfico 2.1315: Participación en la producción mundial de harina de pescado .....................................39

Gráfico 2.1416: Evolución de las Exportaciones por tipo de producto (en millones de dólares) ...........42

Gráfico 2.1517: Evolución de las Exportaciones de productos tradicionales por tipo de producto (en

millones de dólares) .................................................................................................................42

Gráfico 2.1618: Evolución de las Exportaciones de productos pesqueros 1950-1970............................43

Gráfico 2.1719: Evolución de las exportaciones de productos pesqueros 1970-1990............................44

Gráfico 2.1820: Evolución de las exportaciones de productos pesqueros 1990-2013............................47

Gráfico 2.1921: Evolución de las exportaciones de productos (en millones de dólares)........................48

Gráfico 2.2022: Desembarque de anchoveta (miles de TMB) ........................................................48

Gráfico 2.2123: Evolución de la producción por CHI y CHD (en miles de TMB)......................................49

Gráfico 2.2224: Composición del desembarque de CHI (en miles de TMB) ...........................................50

Gráfico 2.2325: Composición del desembarque de CHD .....................................................................50

Gráfico 2.2426: Composición de las exportaciones pesqueras (en miles de dólares) ............................51

Gráfico 2.2527: Precio Harina de Pescado (US\$ / TM).....................................................................52

Gráfico 2.2628: Precio Aceite de Pescado (US\$ / TM) .....................................................................52

Gráfico 2.2729: Desembarques de anchoveta por puerto al 2013 (en TM y porcentajes) .....................68

Gráfico 2.2830: Desembarques de anchoveta por puerto al 2013 (en TM) ...........................................68

Gráfico 2.2931: Número de plantas de procesamiento por departamento y por tipo de producto.......69

Gráfico 2.3032: Evolución del número de armadores ......................................................................70

Gráfico 2.3133: Evolución del número de embarcaciones por armador .............................................71

Gráfico 3.134: Evolución de la Biomasa y Desembarque de anchoveta (en millones de toneladas).....74

Gráfico 3.235: Evolución del desembarque de anchoveta y los días de pesca .....................................74

Gráfico 3.336: Evolución del desembarque por día de pesca ............................................................75

Gráfico 3.437: Evolución del promedio de capacidad por planta de enlatado ........................................76

Gráfico 3.538: Evolución de la capacidad de planta y número de plantas de enlatado .........................76

Gráfico 3.639: Evolución del promedio de capacidad por planta de congelado (tonelada por día por

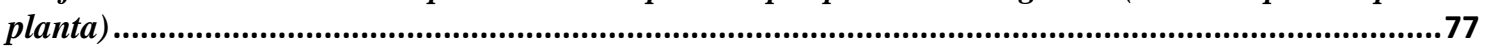

Gráfico 3.740: Evolución de la capacidad de planta y número de plantas de congelado .......................77 
Gráfico 3.841: Evolución del promedio de capacidad por planta de curado (tonelada por mes por planta)

Gráfico 3.942: Evolución de la capacidad de planta y número de plantas de curado

Gráfico 3.1043: Evolución del promedio de capacidad por planta de harina de pescado (tonelada por

hora por planta)

Gráfico 3.1144: Evolución de la capacidad de planta y número de plantas de harina de pescado .......79

Gráfico 3.1245: Evolución del promedio de capacidad por planta según producto ..............................80

Gráfico 3.1346: Capacidad promedio disponible de pesca por embarcación vs número de

embarcaciones

Gráfico 3.1447: Participación de Insumos para CHI (en \%) ........................88

Gráfico 3.1548: Participación de Insumos para CHD (en porcentajes) .................................................89

Gráfico 3.1649: Niveles de producción de CHI y CHD por tipo (en TM) ..........................................90

Gráfico 3.1750: Participación de desembarque de anchoveta por destino .........................................90

Gráfico 3.1851: VAB de CHI y CHD (en Millones de soles constantes del 2007) ...............................92

Gráfico 3.1952: Estructura del VAB y generación del empleo en el Sector Pesquero 2007 (\% del total) 93

Gráfico 3.2053: Porcentaje mensual de pesca de juveniles ................................................................96

Gráfico 3.2154: Varianza anual del porcentaje de pesca de juveniles ..................................................96 


\section{ÍNDICE DE TABLA}

Tabla 1.1: Una taxonomía de los problemas comunes en el reino de los Recursos Naturales y Medio Ambiente

Tabla 2.12: Nivel de embarcación nacional (2013)..........................................................................63

Tabla 2.23: Nivel De embarcación en la Zona Norte-Centro (2013) .....................................................64

Tabla 2.34: Nivel de embarcaciones por sistema de preservación en la ................................................64

Tabla 2.45: Nivel de embarcaciones en la Zona Sur (2013) ...............................................................66

Tabla 2.56: Nivel de embarcaciones por sistema de preservación en la Zona Sur (2013).....................66

Tabla 3.17: Relación de factores de producción e indicadores ............................................................73

Tabla 3.28: Tasa compuesta de crecimiento anual del promedio de capacidad por planta y sus

componentes según producto (1993-2013) .................................................................................80

Tabla 3.39: Fuerza laboral del sector pesquero..................................................................................84

Tabla 3.410: Características laborales de los trabajadores pesqueros .............................................85

Tabla 3.511: Trabajadores acogidos a programas de beneficios según empresas .................................86

Tabla 12: Esquema de una Matriz de Producción (a valores básicos) ................................................132 


\section{INTRODUCCIÓN}

El recurso pesquero presenta la condición de ser no excluyente, pero sí rival; es decir, no es un bien público puro y la falta de su regulación, dado un contexto de demanda por productos a base del recurso en mención, genera la depredación del mismo.

Dentro del sector de pesca, uno de los principales sectores extractivos del Perú, la anchoveta se ubica como uno de los principales recursos marítimos desde el punto de vista de la cadena alimentaria, calidad biológica-nutricional, nivel de desembarque y nivel de exportaciones.

La anchoveta, junto con la sardina y la caballa, representa un organismo planctónico, lo cual la convierte en la base de la cadena alimenticia de la mayoría de peces adultos (bonitos, atunes, barriletes, róbalos, corvinas, etc.), por lo que la importancia de la anchoveta trasciende a su relación con el resto del ecosistema marino.

Desde la perspectiva de nutrición, la anchoveta contiene mayor cantidad de nutrientes y grasas no saturadas (Omega 3 y Omega 6) que otras especies similares. Esto la ubica como una de las especies de pescado con mayor valor biológiconutricional, lo cual la vuelve idónea tanto para su comercialización en el Consumo Humano Directo (CHD) como en el en Indirecto (CHI).

Respecto al nivel de desembarque, al 2012 este alcanzó los 3’776,835 TMB; es decir, 93\% del desembarque de las especies pelagágicas, 90\% de desembarque marítimo de pescados y $79 \%$ del total de desembarque de recursos marítimos. Dentro del rubro de Consumo Humano Indirecto (CHI), la anchoveta representó un desembarque de 3,694 miles de TM (99.9\% del desembarque de pesca marítima de CHI) (INEI, 7 de mayo 2014).

En cuanto a las exportaciones, el $77 \%$ se basa en la harina y aceite de pescado al 2012, elaborado a base de la anchoveta por su alto valor nutritivo (INEI, 7 de mayo 2014). 
En el plano internacional, el Perú representa el 30\% de la exportación mundial de harina de pescado al 2012 según la Organización Internacional de Productores de Harina y Aceite de Pescado (IFFO), ubicándolo como el primer exportador de anchoveta.

Dada la importancia mencionada del recurso para la economía peruana y el mundo y que sufre la "tragedia de los comunes" (de propiedad común y de libre acceso), que incita rápida explotación, se produjo una crisis del sector en la década de 1970, causada por la ocurrencia del Fenómeno del Niño en 1973 y, sobre todo, por la sobrepesca asociada al deficiente manejo público del sector, expresado en la falta de instituciones que lo supervisen, ocasionando capturas masivas de anchoveta.

En respuesta a la toma de conciencia de este factor, el Estado inicia un proceso de regulación del sector, mediante la publicación de leyes y un reglamento de fiscalización para que se cumplan sus disposiciones.

Es así que el 7 de diciembre de 1992 y el 14 de marzo de 2001 se aprobó la Ley General de Pesca y su Reglamento, con el objetivo de promover el desarrollo sostenido del sector, enfatizando la necesidad de aprovechar su fortaleza nutritiva para el consumo humano directo (CHD), mediante el establecimiento de licencias de pesca otorgadas por el Ministerio de Producción. El 2007 se publica el Reglamento de Inspecciones y Sanciones Pesqueras-RISPAC, en el que se establecen las facultades y procedimiento del fiscalizador. El 2008 entra en vigencia la Ley sobre Límites Máximos de Captura por Embarcación y su Reglamento, que asigna a las embarcaciones con permiso vigente de pesca el umbral de captura correspondiente y otras disposiciones asociadas al permiso de pesca. El 14 de diciembre de 2013 se publica el Decreto Supremo 011-2013, el cual ratifica el D.S.005-2012, denominado "Establece Zona de Reserva para el Consumo Humanos Directo del recurso anchoveta y anchoveta blanca aplicable desde el extremo norte del dominio marítimo hasta los $16^{\circ} 00^{\prime} 00^{\prime \prime}$ Latitud Sur (10 millas marinas desde el extremo norte del dominio)”. En este se determina que la zona comprendida desde la línea de la costa hasta la milla marina 5 está reservada para uso exclusivo de las embarcaciones artesanales ${ }^{1}$ (destinadas a CHD), mientras que a partir de la milla marina 5 hasta la milla marina 10

\footnotetext{
${ }^{1}$ Embarcaciones de hasta 10 metros cúbicos de capacidad de bodega, en las que predomina el trabajo manual.
} 
se reserva para uso exclusivo de las embarcaciones de menor escala ${ }^{2}$ (destinadas a CHD); siempre que estas embarcaciones cuenten con el permiso de pesca correspondiente, emitido por la autoridad competente y conforme a la normativa aplicable.

El conjunto de esta normativa tiene un impacto sobre, la distribución del recurso preferiblemente hacia el CHD, el esfuerzo pesquero (factores de producción) y la sostenibilidad del sector; las cuales son variables clave que afectan a la eficiencia económica. Esta última variable se entiende como el estado en el que las decisiones de producción y consumo maximicen el valor del recurso sin afectar al resto de agentes. Sin embargo, para efectos de esta investigación, la variable "normativa" no abarcará la Zona de Reserva para Consumo Humano Directo, dado que su vigencia es demasiado reciente para determinar un impacto.

La problemática de la regulación del sector es que las normas emitidas están sujetas a objetivos políticos, los cuales no necesariamente se enfocan en la mejora de la eficiencia económica; sino que pueden seguir fines alternos como la mejora social. Políticas en las industrias extractivas han considerado por largos años reparticiones sociales que modifican el sector económico y la organización de estos. Tal es el caso de la reforma agraria, que sin hacer un análisis de su conveniencia, cambió considerablemente la estructura organizacional de la industria en el Perú.

Un sector económico, que se basa en fuentes naturales, puede contar con políticas que cambien toda la estructura organizacional, generando sobre costos, ya sea una concentración o atomización del mercado, o que regule la entrada y salida de agentes.

Además, se debe tomar en cuenta que aun cuando el objetivo de la Ley sea favorable para la eficiencia económica de sector, esta no necesariamente cumple su cometido, ya sea por deficiencias de la propia ley o de la organización institucional a cargo de su ejecución, conllevando a fuertes impactos en la economía y su estructura.

En este sentido, el propósito de este trabajo radica en evaluar el impacto de este marco regulatorio en el aspecto económico del sector. Este último se considera

\footnotetext{
${ }^{2}$ Embarcaciones de más de 10 y hasta 32.6 metros cúbicos de capacidad de bodega y no más de 15 metros de eslora, que pueden contar con modernos equipos y sistemas de pesca.
} 
como el aumento de la eficiencia económica de la industria. Por tanto, el análisis realizado por el presente trabajo de investigación busca brindar sustento de eficiencia económica a las normativas pesqueras, así como mostrar qué normas no ayudaron a este fin.

Entonces, el objetivo general es el de analizar el impacto de la normativa peruana del ordenamiento pesquero en la eficiencia económica de la industria de la anchoveta, en base a la evolución de esfuerzo pesquero, distribución y sostenibilidad del recurso durante el periodo 1990-2013, con la finalidad de evaluar si logró o no sus propósitos y determinar si apoyó a la mejora económica del sector.

Dado que la variable eficiencia económica está compuesta por las subvariables esfuerzo pesquero, distribución y sostenibilidad; la evaluación del impacto de la normativa en la variable mencionada se descompone en el impacto de dicha normativa sobre sus sub-variables.

Respecto al esfuerzo pesquero, el objetivo es conocer el efecto del ordenamiento pesquero sobre los factores de producción en la pesca de anchoveta durante el periodo 1990-2013, mediante indicadores, a fin de evaluar si la normativa benefició al sector empresarial en la administración de estos recursos.

En cuanto a la distribución, el objetivo es el de evaluar la influencia del ordenamiento pesquero sobre la decisión de destino de la dotación inicial del recurso de la anchoveta hacia consumo humano directo y/o a consumo humano indirecto durante el periodo 1990-2013, mediante el método de Valor Agregado y su comparación con la producción por tipo de consumo, a fin de establecer si la normativa incrementó significativamente la producción del consumo humano directo respecto al indirecto (conforme a lo promovido por la normativa) y si este objetivo es efectivamente beneficioso desde el punto de vista económico.

En el caso de la sostenibilidad, el objetivo es el determinar el efecto de la normativa sobre la sostenibilidad del recurso de la anchoveta durante el periodo 19902013, a través de la evolución de pesca de juveniles, con el fin de determinar si las medidas propuestas para asegurar no depredar el recurso han sido efectivas. 
A priori, la hipótesis fue que la normativa peruana del ordenamiento pesquero para el periodo 1990-2013 contribuyó al crecimiento de la eficiencia económica de la industria de la anchoveta.

Sobre la variable esfuerzo pesquero, la hipótesis que se planteó fue que la normativa ha contribuido a reducirlo mientras que el nivel de valor de la producción se mantenía o había incrementado, impactando positivamente en la eficiencia económica del sector, basado en que el establecimiento de cuotas por embarcaciones eliminó la competencia depredadora del mercado que existía previamente y posibilitó una mejor asignación de los insumos. Para su medición, se evaluó una serie de indicadores que miden la evolución de los niveles de dichos factores de producción.

Respecto a la distribución de la dotación de anchoveta, la hipótesis que se planteó fue que la normativa ha contribuido a orientar la distribución hacia el CHD; sin embargo, este resulta de menor valor agregado que el de CHI, por lo que el impacto en la eficiencia económica es negativo. Es decir, para el producto el destino de la dotación inicial de anchoveta hacia CHD, como lo busca promover la normativa, tienen un costo de oportunidad expresado en el valor agregado que deja de generar respecto al CHI. En este aspecto, se asume una economía de mercado, en la que el productor orienta su dotación inicial hacia aquel destino que ofrezca mayor valor. La teoría microeconómica señala que los empresarios redirigen sus recursos hacia el sector con mayor rendimiento; por tanto, se asume una economía de mercado, en la que el productor orienta su dotación inicial hacia aquel destino que ofrezca mayor valor. Cabe destacar que no se encontró un impacto concluyente de la normativa en la producción, pero sí se demostró que el CHI tiene mayor Valor Agregado y, por tanto, no es adecuado en términos de eficiencia económica intervenir en la oferta a favor del CHD.

En cuanto a la sostenibilidad, la hipótesis que se planteó fue que dicho impacto fue positivo, impactando positivamente en la eficiencia económica del sector, basado en que el sistema de sanciones apoyado en las inspecciones ha incentivado la protección de los juveniles. Su análisis se basa en la determinación en que debe existir una normativa, no solo que administre una propiedad común, sino que la administre continuamente. En base a esto, se analizó la evolución histórica de la descarga de anchovetas juveniles (menor a $12 \mathrm{~cm}$ ). Al respecto, cabe destacar que a partir del resultado no se puede realizar una afirmación absoluta, dada que una reducción de la volatilidad de dicho 
indicador no asegura que los juveniles no se hayan pescado y luego desechada al mar; es decir, la afirmación está limitado al hecho de que la data no recoge el completo de la realidad del sector.

Como se ha especificado, eficiencia económica en términos de esta investigación se ciñe a los conceptos de esfuerzo pesquero, distribución y sostenibilidad dentro del marco del sector de la pesca de anchoveta. En tal sentido, la evaluación de aspectos específicos como el ambiental no se abordará en forma directa.

En el capítulo 1, se establece la relación de la eficiencia económica con sus componentes (esfuerzo pesquero, distribución y sostenibilidad) y se explaya un marco teórico que abarca la problemática del sector e investigaciones previas que dan soporte a las hipótesis

En el capítulo 2, se establece un contexto al sector de pesca de la anchoveta en el Perú. Se realiza una descripción de la evolución histórica de la pesca y de la organización institucional, con una síntesis del marco normativo del sector, y su relación con la organización industrial.

En el capítulo 3, se realiza la evaluación del impacto de la normativa en la eficiencia económica, mediante una serie de indicadores que miden los aspectos claves de las tres sub-variables mencionadas.

En el capítulo 4, se desarrolla una prospectiva de la industria de la anchoveta relacionado a los aspectos de mejoras que podrían presentarse en el marco regulatorio del sector que promueva la mejora de la eficiencia económica.

Finalmente, en base a los resultados de los capítulos anteriores, se elabora en las principales conclusiones respecto al impacto de la normativa en la eficiencia económica y se realizan recomendaciones de mejora. 


\section{CAPÍTULO I: MARCO DE LA INVESTIGACIÓN}

\subsection{Marco conceptual del problema}

Uno de los grandes objetivos de la teoría económica es la búsqueda de la asignación eficiente de los recursos. La eficiencia económica en el sentido de Pareto se basa en llegar a un equilibrio entre diferentes agentes del mercado en el que optimizan su función de utilidad y no pueden llegar a un punto mejor sin perjudicar a otro agente (Hal R. Varian, 2007). Esta definición se basa en la teoría de la economía de bienestar, compuesta por dos teoremas que consideran supuestos bastante poderosos para que se cumpla un equilibrio eficiente en el sentido de Pareto, de lo cual se puede inferir que no siempre se puede llegar a este.

El primer teorema del bienestar, en el que se deduce que "cualquier equilibrio competitivo es eficiente en el sentido de Pareto", muestra dos supuestos muy fuertes. El primero es que el mercado deba ser competitivo, definido por Hal R. Varian (2007), como que debe ser un mercado privado en el que cada agente deba maximizar su utilidad independientemente del otro agente; mientras que el segundo supuesto es que esta solución llevará a un equilibrio de Pareto.

El segundo teorema del bienestar implica que, mediante el equilibrio competitivo, se puede llegar a todas las asignaciones eficientes en el sentido de Pareto. Lo cual implica, según Varian (2007), que se puede separar la evaluación de distribución del de la eficiencia. 
Este último punto es importante, tal como lo explica el autor, ya que dentro de la política económica se escuchan argumentos a favor de la intervención en la fijación de precios, imposición de impuestos o de subsidios por razones de equidad distributiva, lo cual afecta fuertemente a la eficiencia económica en el sentido de Pareto. Si bien esto implica que la participación del Estado en el desempeño del mercado puede distorsionar las decisiones de los agentes y así perjudicar su desenvolvimiento, en ocasiones es recomendable su intervención, aunque debe evitarse medidas como las mencionadas.

Un bien público puro desde el punto de vista económico es aquel que está disponible para todos y el uso de este por individuo no elimina el uso del mismo por otros; es decir, no es excluyente ni rival. Sin embargo, la mayoría de los bienes no cumplen con todas estas características; por tanto, generan fallos de mercado. Para poder asegurar el desempeño de una economía de mercado, se debe combatir dichos fallos, siendo la intervención del Estado mediante su regulación la metodología más común.

Tal es el caso del recurso pesquero, que aunque se encuentra en el mar peruano, por lo que sería de libre acceso para la población, posee la característica de ser limitado (sujeto a la reproducción de la especie); por lo que la pesca indiscriminada del recurso por parte de un agente afectaría la posibilidad de pesca por parte de otro. Esto quiere decir que la biomasa de anchoveta no es un bien público puro, sino que la característica de recurso renovable de la anchoveta se basa en la capacidad de reproducción de la especie, lo cual escapa de las decisiones de agentes privados en la industria para aumentar dicho stock.

Políticas económicas que no entiendan el significado de eficiencia económica pueden generar distorsiones en las decisiones de los agentes económicos, llegando a equilibrios sub-óptimos en el mercado; puesto que, la mejora del empleo, el incremento de los ingresos de las comunidades pesqueras y el aumento de los ingresos por producción de alimentos y por exportaciones nacionales son objetivos que compiten con la conservación y la eficiencia económica de la prioridad en la formulación de políticas pesqueras nacionales (Aguilar, Reid y Thorpe, 2000). 
Este argumento se ejemplifica en los comentarios de la historia del país vecino Chile por Julio Peña T. (1996) en Regulación Pesquera en Chile: Una perspectiva Histórica: "En el caso de la regulación pesquera chilena, parece claro que los objetivos de cuotas de pesca han sido dominados, durante la mayor parte de tiempo desde mediados de los 60, por objetivos con mayor prioridad política. Durante los sesenta las principales prioridades de política pesquera fueron promover el desarrollo industrial y adquirir conocimiento científico sobre el comportamiento de las poblaciones de peces (SUBPESVA_CORFO, 1989). En ocasiones, biólogos marinos y técnicos pesqueros de las agencias reguladoras intentaron promover estrategias de conservación del recurso pesquero, pero la mayoría de las veces no obtuvieron suficiente apoyo político para contrarrestar la oposición del sector privado. Esto es coherente con la opinión predominante de la época: que el recurso pesquero era muy abundante." (p. 382)

Por otro lado, la teoría del bienestar no considera las fallas de mercado, como por ejemplo las externalidades o información imperfecta, lo cual genera que el proceso de negociación entre los agentes incorpore el concepto de coste de transacción. Este influye significativamente en lo que se llama "fallas de coordinación"; es decir, estos costes afectan la interacción de los agentes dificultando el realizar un proceso de decisión basado en la cooperación para obtener el mejor resultado posible (Bowles, 2004). Esta falta de coordinación entre los agentes, se fundamenta en la "tragedia de los comunes" (Hardin, 1968). Generalmente el Estado es aquel que busca evitar o mitigar sus costosas consecuencias.

Respecto a la alternativa de la intervención gubernamental para atenuar estos fallos, existe un gran escepticismo dado que las instituciones y las políticas están sujetas a las mismas clases de fallas (Bowles, 2004). Es decir, también se cuenta con fallas de Estado, principalmente cuando este está compuesto de varias instituciones relacionadas a un mismo sector y deben coordinar entre estas.

Desde este punto de vista, la existencia de normas y regulaciones que definan derechos de propiedad (hacer que el bien no excluyente se convierta en privado) reduce los costos de transacción en el sector, dejando la negociación al agente privado en mejores condiciones. Al respecto, Oliver 
Williamson en su trabajo "La teoría de la firma como estructura gubernamental: de elección a contrato" comenta:

"Si los actores no sólo se enfrentan a la necesidad de adaptarse a imprevistos (por razones de racionalidad limitada), sino también por comportamiento estratégico (por razones de oportunismo) puede que se planteen costosos impases contractuales (denegación a la cooperación, mala adaptación, demandas de renegociación). En ese caso, tienen mérito los esfuerzos de ordenamiento privado para diseñar estructuras de apoyo gubernamental."

Una vez señalada los posibles impactos positivos y negativos de la regulación sobre la eficiencia económica, cabe destacar que, dentro del marco de la actividad pesquera, esta última variable se compone por las siguientes sub-variables:

\section{a. Esfuerzo pesquero}

El análisis de competencia de cualquier industria se basa en la eficiencia productiva, la cual se basa en la producción a mínimo costo y en que las decisiones del productor lo lleven a obtener economías de escala. Esta eficiencia productiva se complementa con la eficiencia asignativa. Formalmente esto se expresa como la función de producción con la que cuenta el productor para obtener el producto para vender.

Este dilema también lo tiene los pescadores a lo largo del tiempo que, al ser "price takers", tienen que reducir sus costos a menor medida para obtener los márgenes necesarios para contar con mayores utilidades.

\section{b. Distribución (CHD o CHI)}

La teoría económica ahonda mucho en la determinación y efectos de los costos de transacción dentro de las regulaciones económicas. Es así que regulaciones excesivas suelen elevar los costos de transacción de ciertas industrias afectando así el equilibrio de mercado. Teóricamente, la disminución de los costos de transacción 
lograría obtener mejores niveles eficientes de precios relativos entre productos competidores.

En este sentido, la teoría indica que dos productos competidores (anchoveta para consumo humano directo e indirecto) pueden estar afectados por regulaciones del sector que afecta a la distribución eficiente de la industria, dado el impacto en los precios relativos de estas. 


\section{c. Sostenibilidad}

Cuando las acciones de un agente económico afectan directamente a otro en su decisión más eficiente en la producción, se considera que se le ha causado una externalidad. Uno de los supuestos de la teoría del bienestar económico se basa en que no debería existir externalidades para llevar a un punto de eficiencia económica (Harl R. Varian, 2007). Análogamente, según el teorema de Coase, los agentes llegarán al punto óptimo en sus negociaciones, sujeto a reducidos niveles de costos de transacción y asimetrías de la información.

Las externalidades han sido abordadas exhaustivamente por la literatura económica en temas ambientales, aportando soluciones de derecho de propiedad y de impuestos Pigouvianos, con el fin de llegar a un punto de equilibrio de eficiencia económica.

La sostenibilidad de los recursos naturales cuenta con un fuerte impacto dentro de un análisis de teoría del bienestar y eficiencia económica en el sentido de Pareto. Víctor Aguilar (2008) muestra que en los modelos de generaciones traslapadas, con decisiones en las que cada agente maximiza utilidades, no se llega a un estado estacionario óptimo. La existencia de externalidades negativas intergeneracionales genera que no exista la sostenibilidad de las dotaciones futuras en los agentes posteriores, siendo necesaria la práctica de políticas económicas regulatorias en el sector con el fin de alcanzar la sostenibilidad en sus dimensiones económica, social y ambiental.

Como se detallará en el Capítulo 2 dentro del Marco Normativo, la normativa pesquera en el caso del Perú tiene implicancias en las decisiones de producción (de los niveles de factores de producción a emplear y distribución de la dotación inicial a CHD o CHI) y en la sostenibilidad del recurso, impactando los teoremas de bienestar antes mencionados y, por lo tanto, la eficiencia económica.

Por ejemplo, La Ley Orgánica para el Aprovechamiento Sostenible de los Recursos Naturales - Ley No 26821 sostiene: "el aprovechamiento sostenible implica el manejo racional de los recursos naturales teniendo en 
cuenta su capacidad de renovación, evitando su sobreexplotación y reponiéndolos cualitativa y cuantitativamente, de ser el caso". Sin embargo, estas intenciones gubernamentales por generar un ordenamiento pesquero pueden no haber sido las adecuadas a estos fines o puede que no lo hayan conseguido.

En tal sentido, el objetivo de este estudio es el de evaluar el impacto de la normativa peruana del ordenamiento pesquero en la eficiencia económica de la industria de la anchoveta, variable que será medida a través del impacto sobre las sub-variables esfuerzo pesquero, distribución hacia CHD o CHI y sostenibilidad.

\subsection{Marco teórico de la eficiencia económica en el sector pesquero}

\subsubsection{Problemática del sector: propiedad común del recurso}

El recurso pesquero se caracteriza por ser limitado, y por tanto posible de depredar, así como por ser de libre acceso. Por tanto, este no es excluyente, pero sí rival; es decir, no se puede imposibilitar su consumo a determinadas personas, pero el consumo de un individuo sí impide el uso del mismo por otros.

Tal como lo señala Robert N. Stavis (2011): "Desde mediados del siglo XIX, los recursos pesqueros de acceso abierto de especies numerosas han sido depredadas más allá de niveles sostenibles, a veces cerca de la extinción”. (p. 87)

Tabla 1.1: Una taxonomía de los problemas comunes en el reino de los Recursos Naturales y Medio Ambiente

\begin{tabular}{|c|c|c|}
\cline { 2 - 3 } \multicolumn{1}{c|}{ Rival } & $\begin{array}{c}\text { Excluible } \\
\text { Bienes privados puros } \\
\text { Algunos recursos renovables privatizados } \\
\text { (acuicultura) }\end{array}$ & $\begin{array}{c}\text { Necursos naturales renovables } \\
\text { caracterizados por libre acceso } \\
\text { (pesca marítima) }\end{array}$ \\
\hline $\begin{array}{c}\text { No } \\
\text { rival }\end{array}$ & $\begin{array}{c}\text { Blgunos recursos no renovables } \\
\text { (calidad del agua del estanque municipal) }\end{array}$ & $\begin{array}{c}\text { Bienes públicos puros } \\
\text { (aire limpio, cambio climático) }\end{array}$ \\
\hline
\end{tabular}


Sujeto a estas características, a medida que el tamaño de captura se incremente sin una regulación dada, los niveles de captura aumentarán hasta que la escasez del suministro del recurso y otras consecuencias de la sobreexplotación genere la caída de la renovación del recurso, haciendo que este disminuya. Como se puede apreciar en el gráfico 1.1, el crecimiento máximo se obtiene en el punto del rendimiento máximo sostenible SMSY.

Los otros puntos de equilibrio son el de extinción (punto origen) y el de la población mínima viable, descrito por los biólogos como "capacidad de carga" o "equilibrio natural" de la pesquería. Este último no es viable; puesto que, una vez que la población se encuentra por debajo de este nivel crítico, se procederá inevitablemente a la extinción (Stavins, 2011).

Gráfico 1.1: Relación del nivel de captura del recurso pesquero y su crecimiento

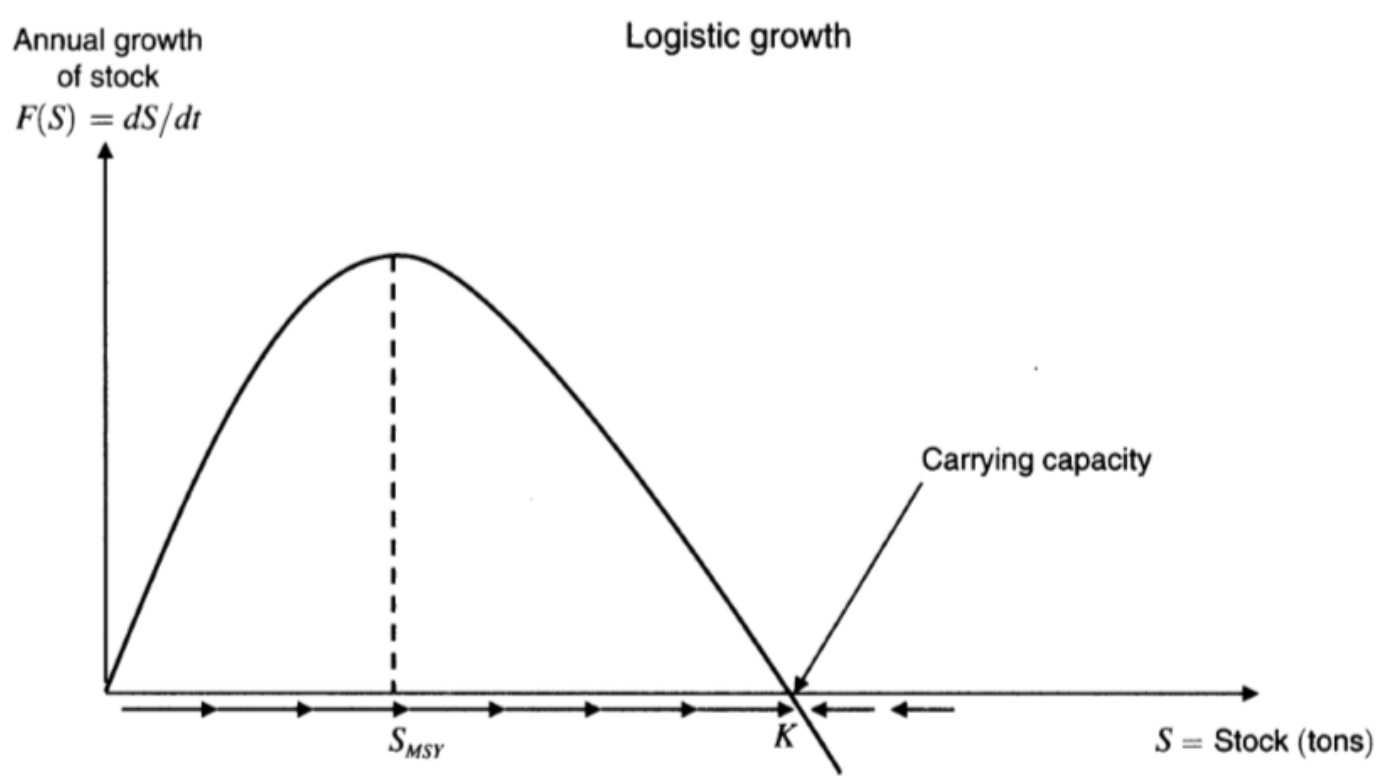

Fuente: "The Problem of the Commons: Still Unsettled after 100 Years" Robert N. Stavins 
En la actividad pesquera, cada pescador debe considerar su ingreso y costo marginal de extracción; sin embargo, ya que en el sector pesquero hay inexistencia de derechos de propiedad, la escasez de la renta es ignorada y cada pescador tiene el incentivo de intensificar su esfuerzo pesquero hasta que los beneficios de la actividad sean nulos. Es decir, se ubican en el punto Ec en el que el costo marginal es igual al ingreso promedio en vez que al ingreso marginal (Robert N. Stavins, 2011).

Esto se ejemplifica en la afirmación de Scott Gordon (1954): "En la pesca marina, el recurso natural no es de propiedad privada; por tanto, la renta que pueda producir no es capaz de ser apropiada por nadie. El pescador no tiene título legal de una sección del océano; es decir, cada pescador es más o menos libre de pescar donde le plazca. El resultado es un patrón de la competencia entre los pescadores (...)”. (p. 133)

Gráfico1.2: Relación del esfuerzo pesquero y el costo y beneficios asociados a la actividad

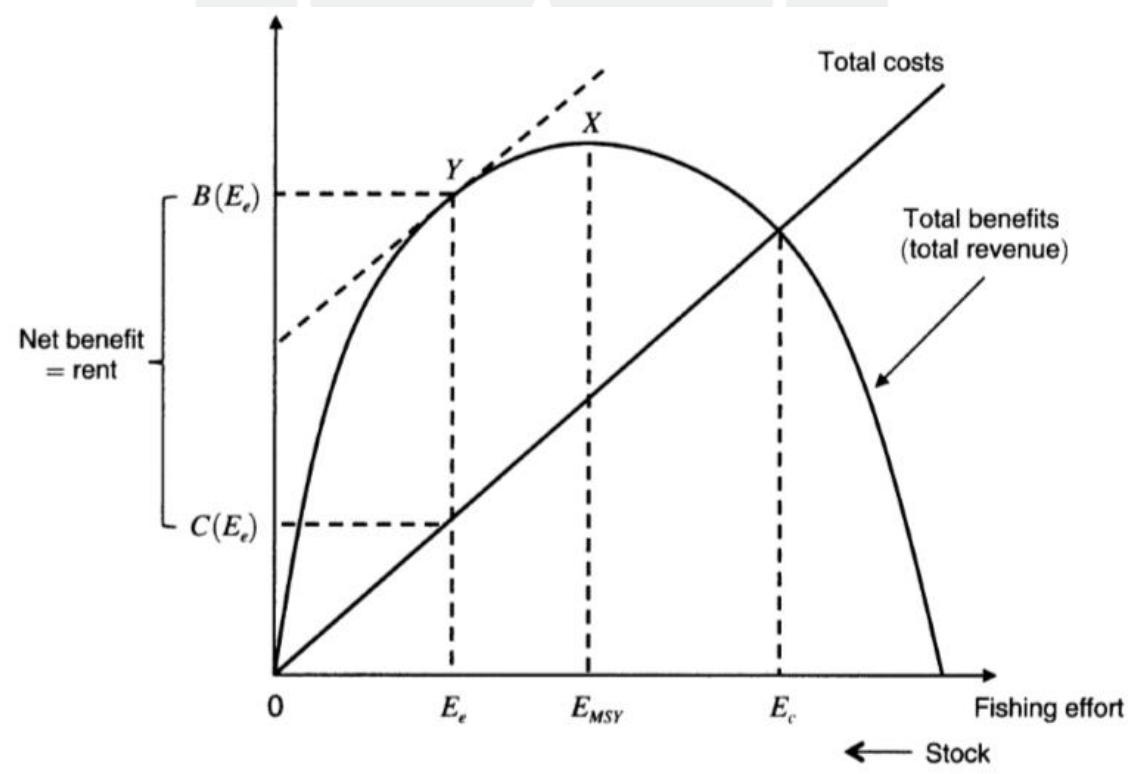

Fuente: "The Problem of the Commons: Still Unsettled after 100 Years" Robert N. Stavins 
Esto quiere decir que el acceso abierto al recurso propicia el que el pescador ignore de valor de los activos de la pesquería y que sus decisiones tienen efecto sobre el resto de pescadores, de esta generación y la siguiente. En tal sentido, en condiciones de libre acceso al recurso se presenta dos externalidades (Robert N. Stavins, 2011):

a. Contemporánea

Exceso de compromiso de recursos; por ejemplo, demasiados barcos, demasiados pescadores, y demasiado esfuerzo, ya que todos se apresuran para cosechar antes que otros.

b. Intertemporal

La pesca excesiva reduce la población del recurso y por lo tanto reduce los beneficios futuros de la pesca.

En otras palabras, el acceso libre al recurso genera la depredación del mismo, lo cual implica un esfuerzo pesquero desmedido y reduce el nivel de sostenibilidad del recurso en largo plazo, puesto que el equilibrio de la incontrolada pesca competitiva significa un mayor gasto de esfuerzo, mayores desembarques de peces, y una baja continua de población de peces en comparación al equilibrio óptimo. En tal sentido, bajo la explotación privada no regulada, no pueden producir ninguna renta. Sólo se podría lograr mediante métodos de propiedad privada o pública (gobierno). (H. Scott Gordo, 1954)

Así también lo afirma Robert N. Stavins (2011): “Las existencias de una variedad de recursos naturales renovables incluyendo agua, los bosques, la pesca, y otras numerosas especies de plantas y animales - se han agotado por debajo de niveles socialmente eficientes, principalmente por el régimen de derechos de propiedad mal definidos o incluso contraproducentes. Los problemas detrás de lo que Hardin (1968) caracterizó como la "tragedia de los comunes" podrían mejor ser descrito como el "fracaso de la regulación de bienes comunes". (p. 98) 


\subsubsection{Investigaciones relacionadas como sustento de las hipótesis}

a. Hipótesis general: Impacto de la normativa en la eficiencia económica

Entonces, tomando en cuenta que las normas evaluadas el presente trabajo de investigación, detalladas en el Capítulo 2, han generado un marco de ordenamiento del sector y que en investigaciones relacionadas a recursos con las mismas características de la anchoveta se concluye que la tragedia de los comunes está asociada a una falta de regulación sobre el recurso, la hipótesis inicial es que el impacto de la normativa en la eficiencia económica es positiva.

b. Hipótesis específica $\mathrm{N}^{\circ} 1$ : Impacto de la normativa en el esfuerzo pesquero

Las políticas industriales siempre han tenido como uno de sus principales pilares de acción la eficiencia dentro de los factores de producción. Dentro de estas industrias, la pesca ha sido evaluada como un sector bastante competitivo, siendo uno de los pocos gremios en el Perú que no cuenta con ninguna denuncia por concertación. En este sentido, es relevante la evaluación de las políticas del sector pesquero con respecto a la optimización de la capacidad instalada. Fred J. Prochaska (1978) realiza una investigación teórica y empírica de la racionalidad de las industrias pesqueras para la decisión de la capacidad instalada y, sobre todo, el nivel de utilización de esta. Teóricamente se basa en los fundamentos de una función de producción normal, lo cual incluye: precios de los insumos, la productividad del factor, restricciones en el mercado y factores exógenos a ella. Sin embargo, metodológicamente encuentra que hay obstáculos para formar una función de producción en el sector pesca que se adecúe a una función normal de producción óptima. Esto se asocia a que se registra una subutilización de la capacidad instalada, causada por una inversión en capacidad instalada mucho mayor respecto al nivel de captura que se dan anualmente, esperando oportunidades 
de pesca mayor. En base a esto, la Ley de Límites Máximos de Capturas por Embarcación (parte de las normas evaluadas detalladas en el Capítulo 2 dentro del Marco Normativo) sincera la capacidad instalada dentro del sector, al conocerse estos niveles de pesca que la industria antes desconocía.

Entonces, dado que la normativa asigna un máximo de captura por embarcación y emite disposiciones para evitar la depredación del recurso, la competencia por la captura que dio a lugar una crisis del sector en la década de los setenta no se repite. En tal sentido, los productores pueden destinar menor nivel de sus recursos hacia la cantidad de embarcaciones e invierten más en su calidad. Entonces, se evita este sobredimensionamiento de la capacidad instalada.

Por tanto, la hipótesis es que el impacto de la normativa en el esfuerzo pesquero, al disminuir inversiones que no conllevan a la mejora del valor del producto, es positivo.

\section{c. Hipótesis específica $\mathrm{N}^{\circ}$ 2: Impacto de la normativa en la distribución}

En el Perú, como se detalla en el Capítulo 2 dentro del Marco Normativo, la normativa analizada promueve el destino de la anchoveta hacia el CHD, aun cuando la preferencia revelada del sector empresarial es el de CHI.

Diane P. Dupont y Shelley A. Phipps (1991) realizan una evaluación del impacto de la imposición de un impuesto para el recurso pesquero de Salmón en Gran Bretaña como barrera de entrada. El contraste entre las pérdidas potenciales causadas por dicho impuesto (caída del empleo) contra los ingresos generados (monto de impuesto recaudado y la producción por la actividad alternativa que se genere) concluyó en que el efecto no se compensaba. En tal sentido, se comprueba la racionalidad de los agentes, quienes habían destinado sus factores de producción a la captura de la especie que más utilidad les rendía y así las rentas son superiores a las que el Estado buscaba incentivar. 
En base a los resultados de esta investigación, la hipótesis es que el impacto de la normativa distorsiona las decisiones de los productores y así a la distribución y, por tanto, afecta negativamente a la eficiencia económica.

d. Hipótesis específica $\mathrm{N}^{\circ}$ 3: Impacto de la normativa en la sostenibilidad

La Universidad Cayetano Heredia (2011) desarrolló un análisis de la normativa peruana en materia del recurso de la anchoveta. En este se concluye que, si bien aún subsisten puntos débiles en la legislación que atentan contra la sostenibilidad del recurso y el ecosistema peruano, en los últimos años ha habido un importante avance hacia un manejo sostenible del sector. Por tanto, la hipótesis es que la normativa tiene un impacto positivo en la sostenibilidad y así sobre la eficiencia económica. 


\section{CAPÍTULO II: CONTEXTO DE LA PESCA DE ANCHOVETA EN EL PERÚ}

\subsection{Importancia de la pesca en el Perú}

En el periodo 1990-2013, tanto el Producto Bruto Interno (PBI) del Perú como la actividad pesquera presentan tendencia positiva, con una tasa compuesta de crecimiento anual de $5 \%$ y $2 \%$ respectivamente. Cabe mencionar que esta última se ve perjudicada por eventos climatológicos.

Gráfico 2.1 : Evolución del PBI nacional y del PBI de Pesca (millones de nuevos soles 1994)

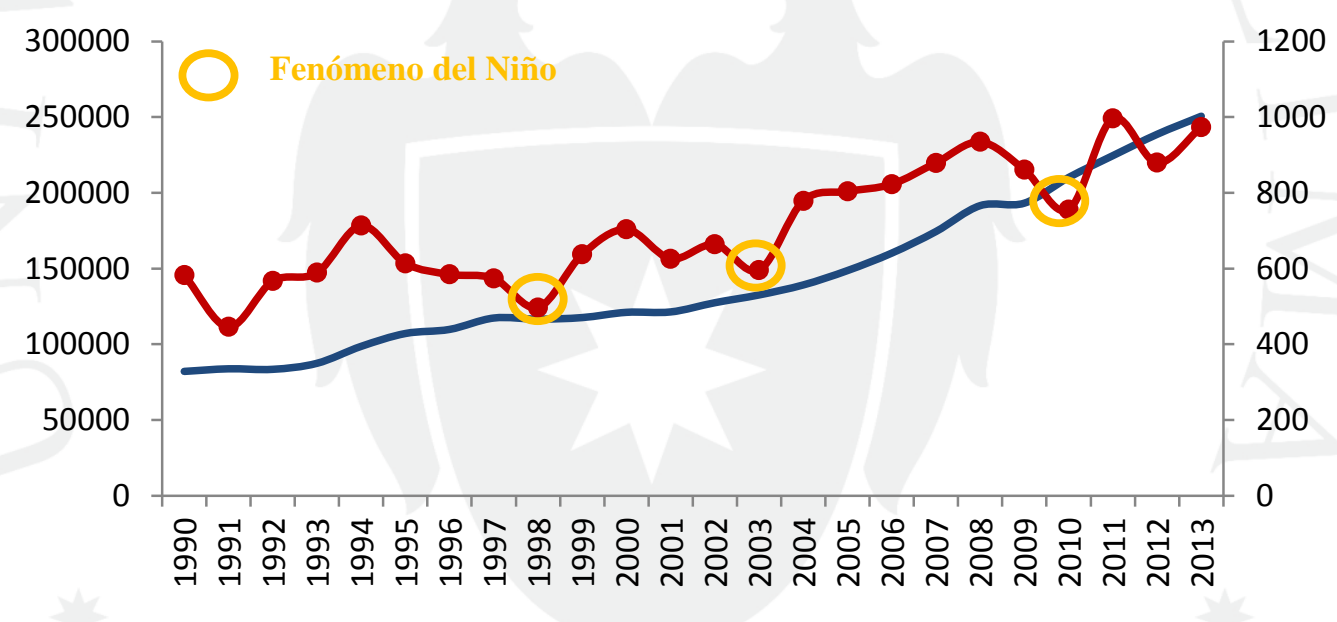

$\longrightarrow$ PBI $\longrightarrow$ PBI pesca (eje derecho)

Fuente: BCRP, http://estadisticas.bcrp.gob.pe/index.asp?sFrecuencia=A, revisado 01-mayo-2014 
En término de exportaciones, representa el tercer sector de la exportación de productos tradicionales con una participación de $6 \%$, superando la exportación de productos agrícolas.

Gráfico 2.2 : Evolución de las exportaciones tradicionales y de productos pesqueros (millones de dólares)

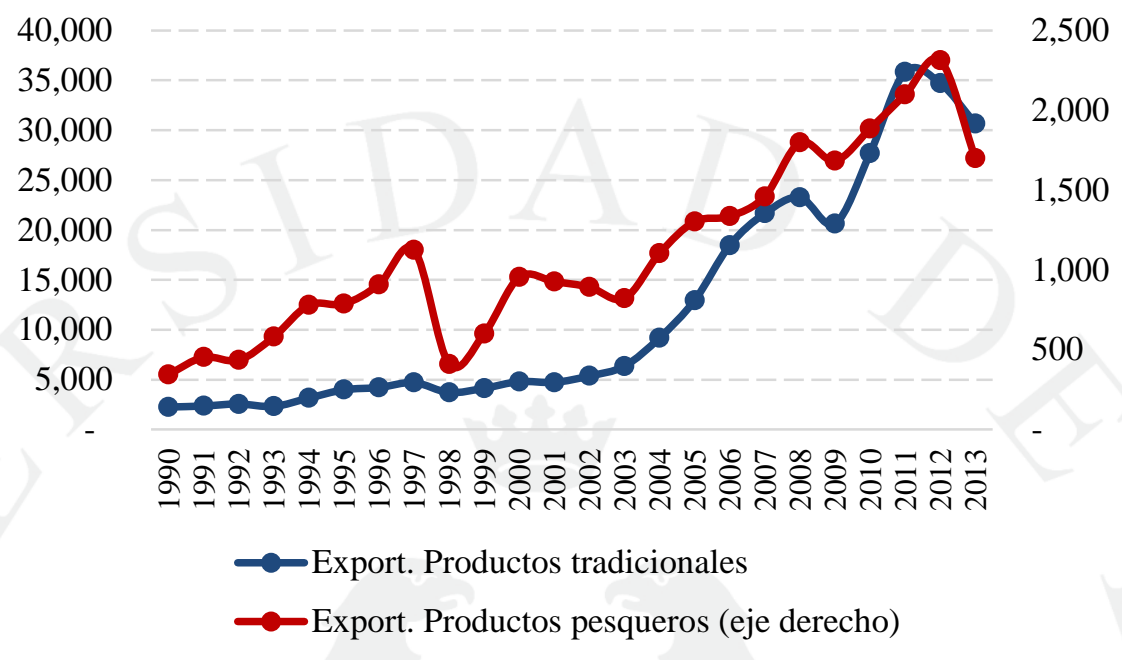

Fuente: BCRP, http://estadisticas.bcrp.gob.pe/index.asp?sFrecuencia=A, revisado 01-mayo-2014

Por otro lado, en término de aporte a la recaudación del Estado en el rubro de Impuesto a la Renta, el sector pesquero aporta al 201,364 millones de nuevos soles ( $0.3 \%$ de la recaudación total), superando al sector de agricultura.

Gráfico 2.3 : Evolución de la recaudación del Impuesto a la Renta (millones de nuevos soles)

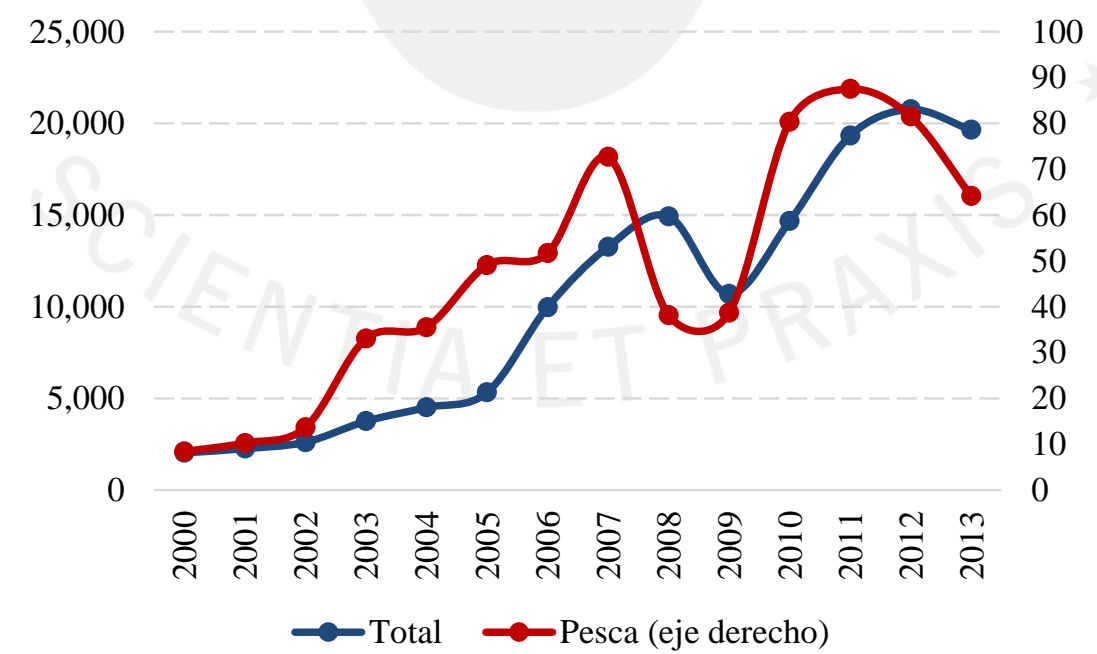

Fuente: BCRP, http://estadisticas.bcrp.gob.pe/index.asp?sFrecuencia=A, revisado 01-mayo-2014 


\subsection{Importancia de la anchoveta peruana}

Dentro del sector pesquero, una notable especie es la anchoveta. De acuerdo al Instituto del Mar del Perú (IMARPE), la Anchoveta (Engraulis ringens en Latín) se describe como una especie pelagágica ${ }^{3}$ marina cuya alimentación se basa en plancton (fitoplancton y zooplancton) y suele movilizarse en cardúmenes (facilitando su captura), ubicada en el Pacífico Sudeste a lo largo del litoral peruano y chileno entre $03^{\circ} 30^{\prime} \mathrm{S}$ y $37^{\circ} 00^{\prime} \mathrm{S}$ (Sociedad Nacional de Pesquería, 2003).

Al ser consumidor de plancton, se ubica en la base de la cadena alimenticia del Ecosistema Marino Peruano y su contenido se caracteriza por ser fuente de proteína animal de alta calidad, debido a su alto contenido de lisina y otros aminoácidos esenciales; su concentración en minerales como potasio, hierro, fósforo y calcio; la presencia de la vitamina A y D en su componente graso; y los altos contenidos de Omega-3 EPA y DHA. Estos contenidos fortalecen funciones claves del cuerpo humano; por ejemplo, los sistemas cardiovascular e inmunitario, así como funciones cerebrales.

Debido a estas propiedades, entre sus principales depredadores se encuentran las aves guaneras, bonitos, atunes, barriletes, róbalos, corvinas, defines, ballenas, lobos marinos y al hombre como sus principales depredadores. Por tanto, sirve como alimento para las especies comerciales, las aves marinas y mamíferos (Sociedad Nacional de Pesquería, 2003).

Análogamente, resulta de alta transcendencia para la nutrición humana con gran potencial en la reducción de los niveles de desnutrición infantil, por lo que se recomienda promover su uso en el rubro de Consumo Humano Directo.

\footnotetext{
${ }^{3}$ Animal u organismo que vive en el mar, con excepción del fondo y sus orillas
} 
Asimismo, su calidad biológica-nutricional la destaca dentro del rubro del Consumo Humano Indirecto (CHI), al ser el principal insumo de la harina de pescado ${ }^{4}$. Esto se debe a que la calidad de este producto dependerá no solo del tipo de procesamiento, sino de la calidad nutricional (concentración de aminoácidos) de su materia prima. A manera de ejemplo, las características mencionadas del recurso de la anchoveta coinciden con las consideraciones para seleccionar los insumos de este producto, especificadas por la Organización de las Naciones Unidas para la Alimentación y Agricultura (FAO): 1) las especies deben movilizarse en grandes concentraciones para una alta tasa de captura, 2) la base de la pesquería debe ser en más de una especie, 3) la abundancia total de especies de vida larga varía menos años tras año, y 4) las especies más rentables cuentan con alto contenido de grasas (se lleva a expensa del agua y no de proteínas).

En tal sentido, la anchoveta como fuente de alimento es importante desde el punto de vista de 1) base de la cadena trófica, impactando en las especies comerciales, aves marinas y mamíferos; y 2) calidad biológicanutricional, impactando al Consumo Humano Directo (enlatado, fresco, curado o congelado) y al Consumo Humano Indirecto (principalmente a través de la harina y aceite de pescado); siendo estos dos últimos factores los destinos de la pesca peruana.

${ }^{4}$ Según la FAO: producto sólido obtenido de la eliminación de la mayor parte del agua y una parte o todo del aceite de pescado o residuos de pescado a partir de pescado blanco o desechos de pescado blanco, utilizada en los alimentos compuestos para aves de corral, cerdos, peces de cultivo, entre otros. 
Diagrama 2.1: Dinámica de la anchoveta en el ecosistema marino y la pesca peruana

\section{Factores clave alimenticios}

Impacto sobre
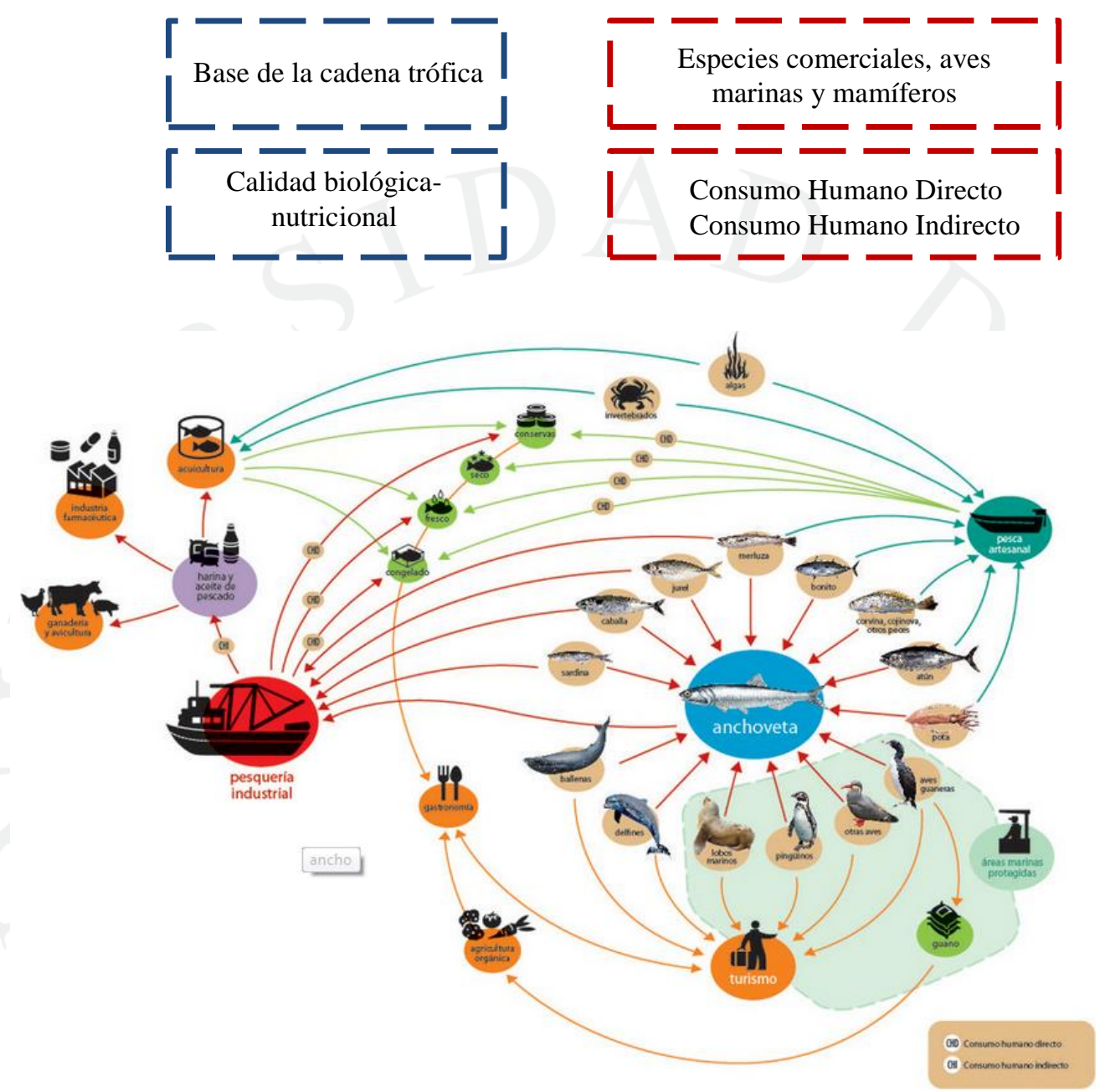

Fuente: Instituto del Mar del Perú, http://www.imarpe.pe/imarpe/archivos/informes/info_anal_pob_anchov_1.pdf, revisado 07 mayo-2014 
El grado de importancia mencionada de la anchoveta en el CHD y CHI se puede apreciar a través del nivel de desembarque de la actividad pesquera segmentada por estos tipos de destino del producto. A continuación, se exponen los niveles de desembarque por tipo de consumo.

Diagrama 2.2: Composición del desembarque por localización, uso y especie al 2012

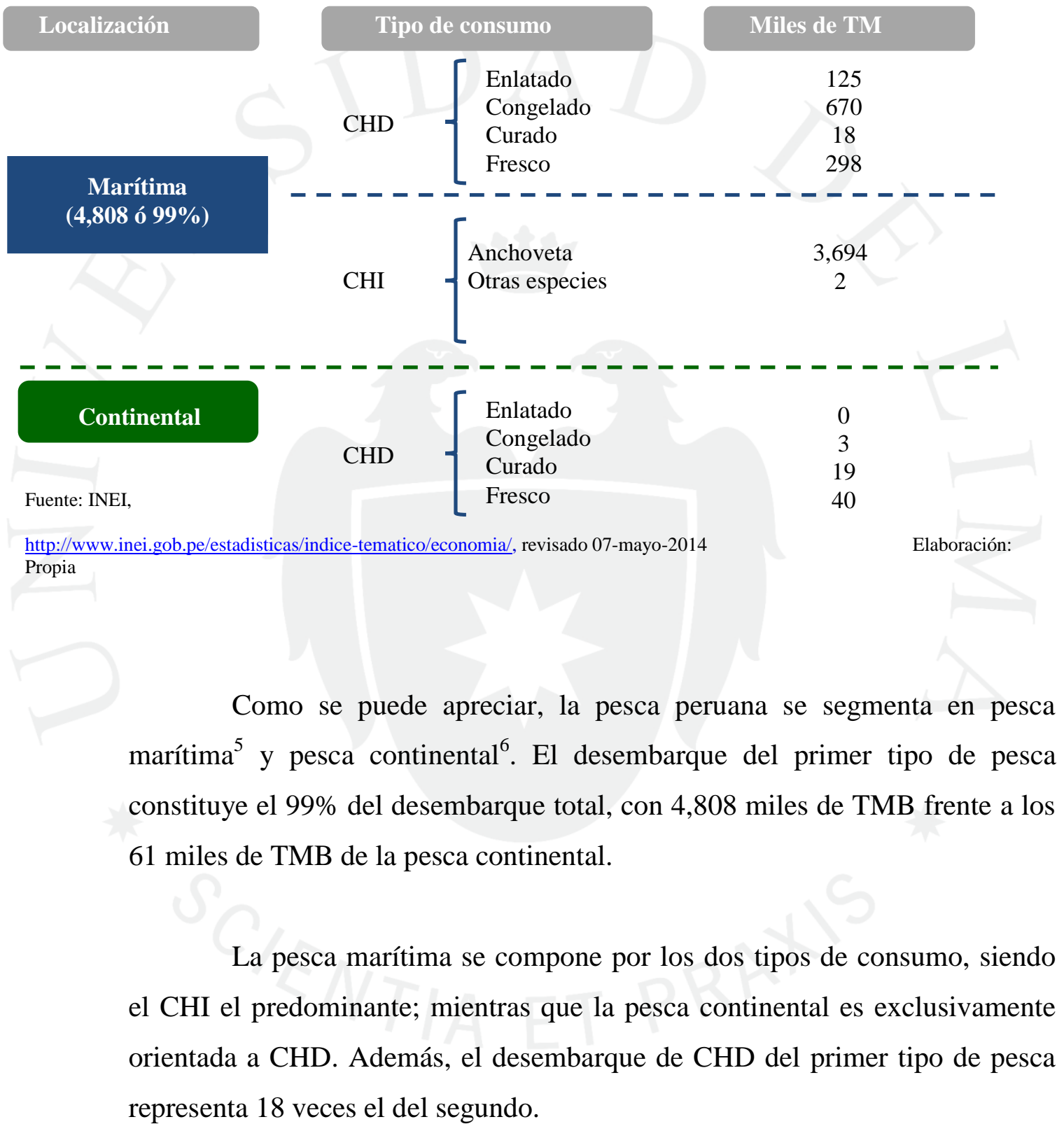

${ }^{5}$ Se realiza en aguas marinas, caracterizadas por ser saladas. Estas constituyen la mayor parte de la hidrósfera, comprendiendo mares y océanos.

${ }^{6}$ Se realiza en aguas continentales, caracterizadas por su ausencia de salinidad y se localizan en los continentes. Están constituidas por torrentes, ríos, lagos, glaciares y aguas subterráneas. 
Gráfico 2.4 : Composición del nivel de desembarque a 2012

Participación por tipo de pesca Destino del recurso por tipo de pesca
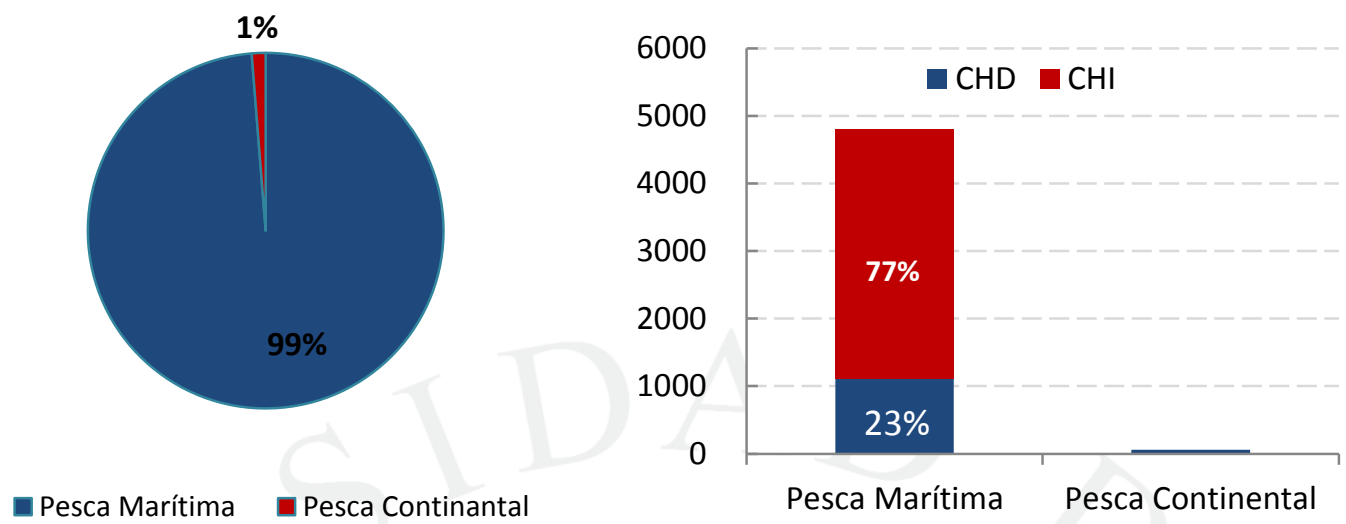

Fuente: INEI, http://www.inei.gob.pe/estadisticas/indice-tematico/economia/, revisado 07-mayo-2014

En la pesca marítima, el nivel de desembarque de pescados fue de 4,197 miles de TMB (87\% del desembarque marítimo y $86 \%$ del desembarque total). El desembarque de pescados está compuesto por tipos de especies, agrupadas en: pelagágicas, que evitan el fondo y las orillas del mar; desmersales, que habitan el fondo del mar; costeras, que habitan en las orillas; y otros grupos de peces. La primera clasificación representa un desembarque de 4,071 miles de TMB (97\% del desembarque marítimo de pescados, $85 \%$ del desembarque marítimo total y $84 \%$ del desembarque total).

Gráfico 2.5 : Participación del desembarque marítimo y del desembarque marítimo de pescados (al 2012 en porcentajes)

Desembarque marítimo Desembarque de pescados

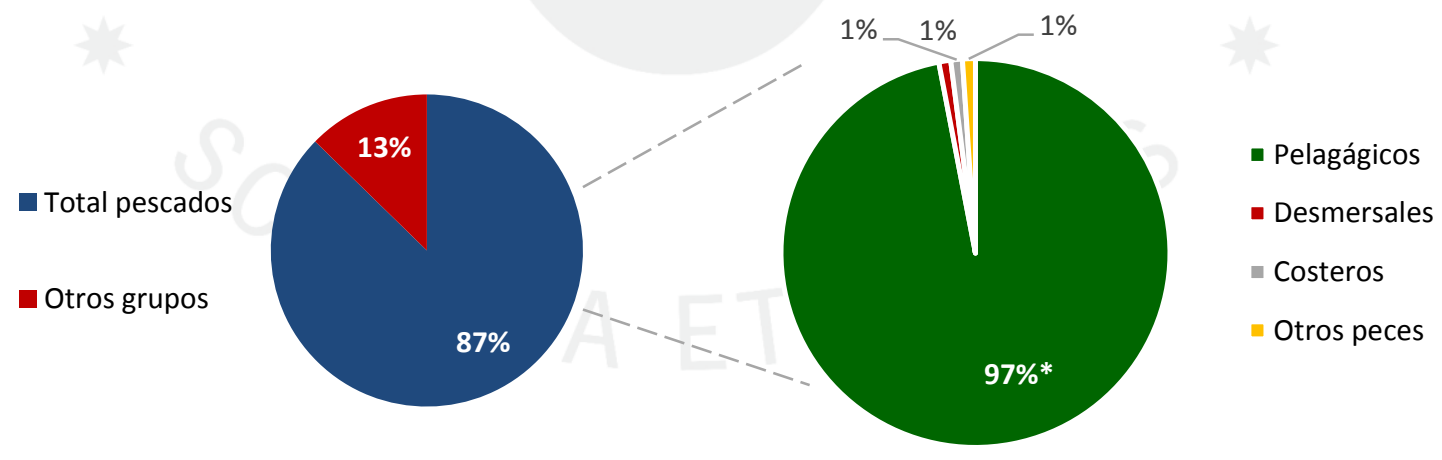

Fuente: INEI, http://www.inei.gob.pe/estadisticas/indice-tematico/economia/, revisado 07-mayo-2014 
Dentro del grupo de especies pelagágicas, la anchoveta representa 3,777 miles de TMB (93\% del desembarque de especies pelagágicas, 90\% del desembarque marítimo de pescados, $79 \%$ del desembarque marítimo total y $78 \%$ del desembarque total).

Gráfico 2.6 : Participación del desembarque marítimo de especies pelagágicas (al 2012 en porcentajes)

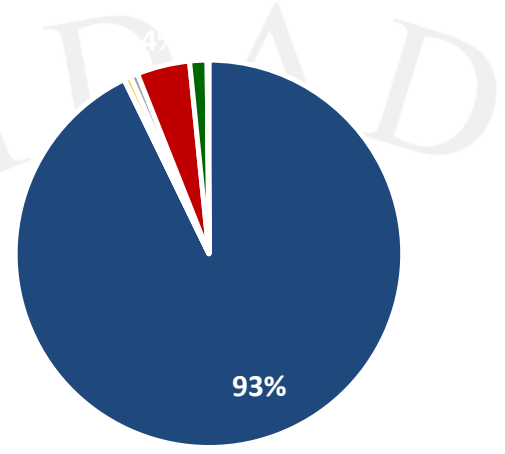

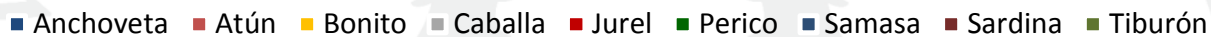

Fuente: INEI, http://www.inei.gob.pe/estadisticas/indice-tematico/economia/, revisado 07-mayo-2014

El rubro de CHD se segmenta en enlatado, congelado, curado y fresco. El sector de congelados (producto fresco e imperecedero) es el de mayor participación, con 637,636 TMB (51\% del CHD) al 2011. Las principales especies comercializadas fueron la concha de abanico con 51,575 TMB (8\%), el jurel con 96,538 TMB (15\%) y la pota con 365,133 TMB (57\%). La anchoveta sólo representó 14,690 TMB (2\%).

Gráfico 2.7 : Distribución del desembarque de CHD y principales especies en el Congelado al 2011

Desembarque del CHD Desembarque del sector congelado

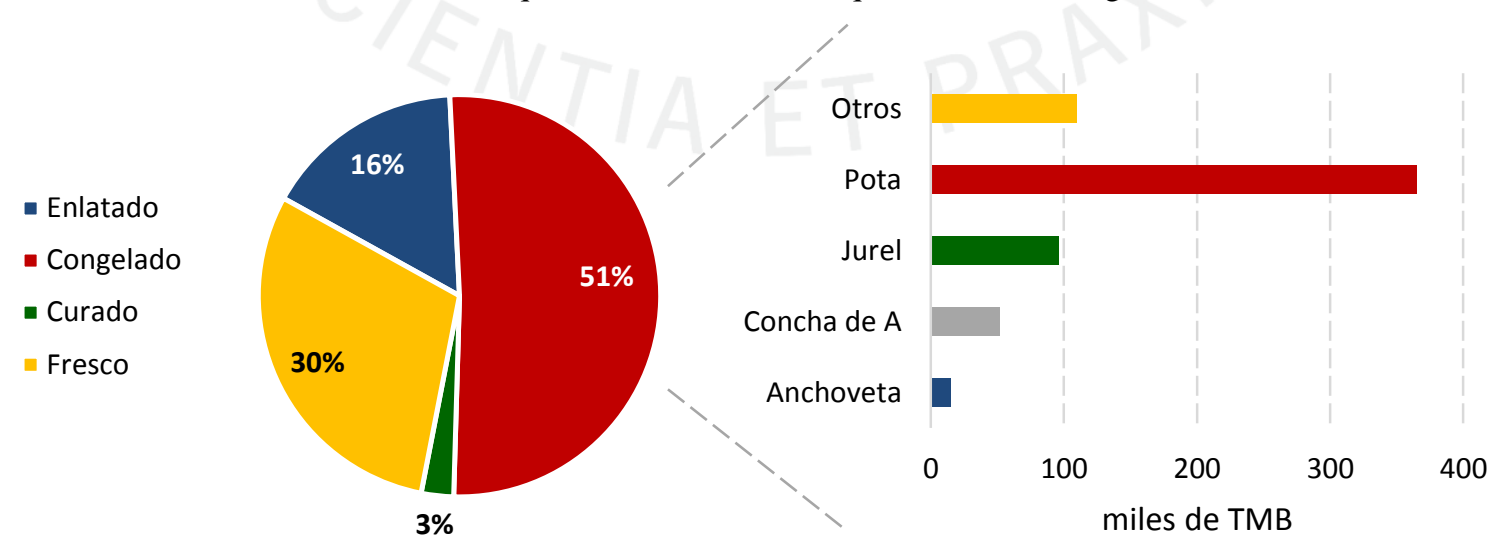

Fuente: PRODUCE,http://www.produce.gob.pe/index.php/estadistica/desembarque, revisado 07-mayo-2014 
En segundo lugar se encuentra el sector de fresco, con 373,313 TMB (30\% del CHD) al 2011. En el gráfico 2.8 se observa que las principales especies comerciales fueron el jurel con $81,760 \mathrm{TMB}(22 \%)$ y la pota con 30,353 TMB (8\%). La anchoveta sólo representó 44TMB (0.01\%).

\section{Gráfico 2.8 : Distribución del desembarque de CHD y principales especies en el Fresco al 2011}

\section{Desembarque del CHD Desembarque del sector fresco}

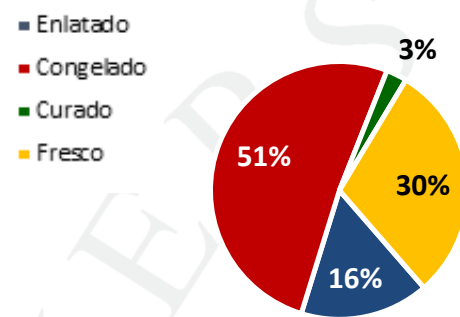

En tercer lugar se encuentra el sector de enlatados (proceso de limpieza, acondicionamiento y envase aséptico) con 201,293 TMB (16\% del CHD) al 2011. Las principales especies comercializadas fueron la anchoveta con 84,194 TMB (42\%), el jurel con 83,500 TMB (41\%) y la caballa con 20,810 TMB (10\%).

Gráfico 2.9 : Distribución del desembarque de CHD y principales especies en el Enlatado al 2011

Desembarque del CHD Desembarque del sector enlatado
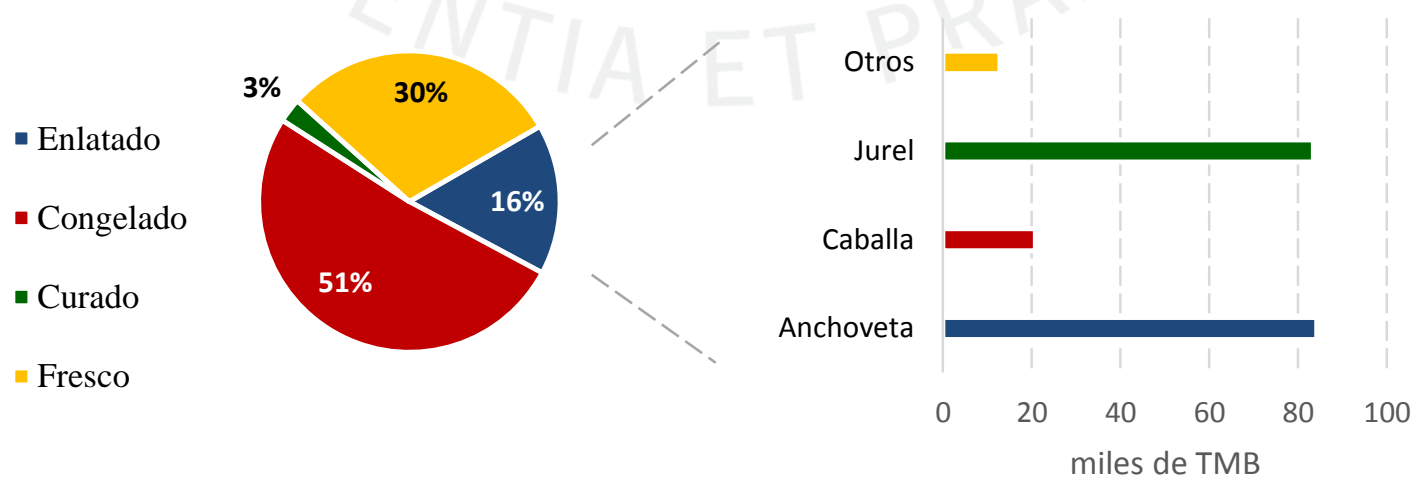

Fuente: PRODUCE,http://www.produce.gob.pe/index.php/estadistica/desembarque, revisado 07-mayo-2014 
Finalmente, el sector de curado (proceso de conservación y sazonado) presentó 32,337 TMB (3\% del CHD) al 2011. Las principales especies comercializadas fueron la anchoveta con 10,092 TMB (3\%) y el jurel con 1,273 TMB (0.3\%). Las demás especies individualmente no superaban las 57 TMB.

\section{Gráfico 2.10 : Distribución del desembarque de CHD y principales especies en el} Curado al 2011

Desembarque del CHD Desembarque del sector curado

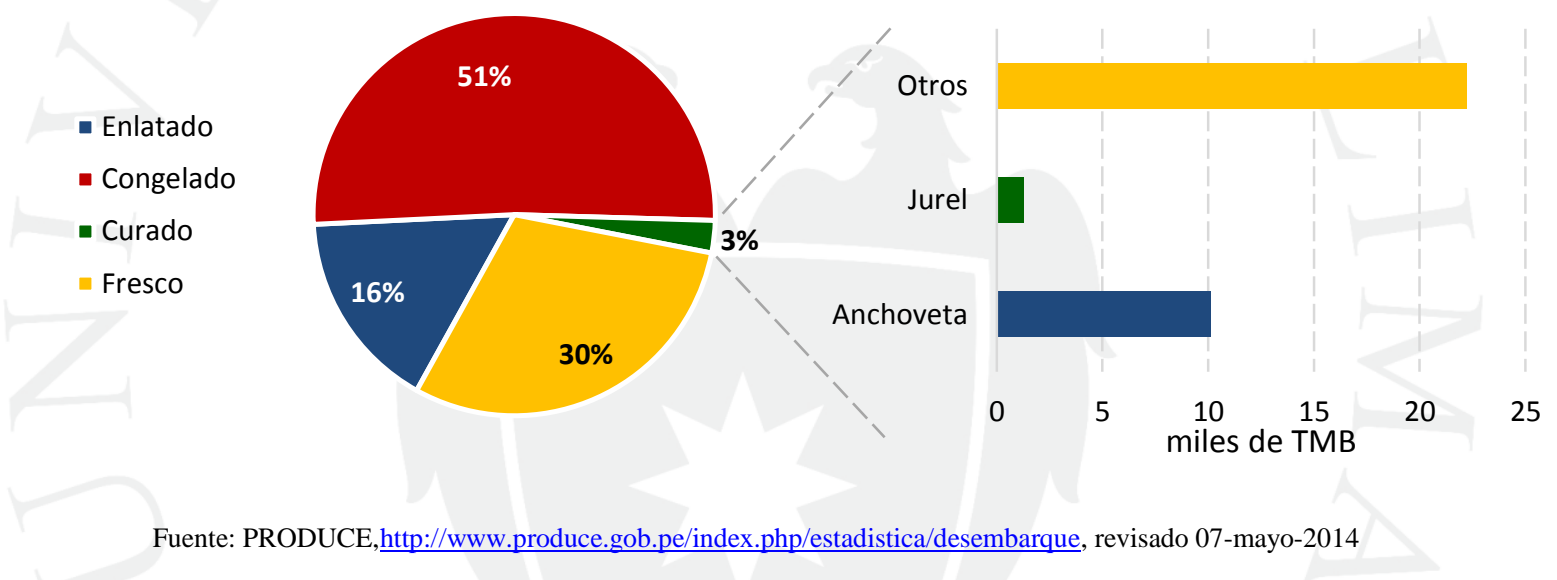

En síntesis, al 2011 la anchoveta es la tercera especie de mayor participación en el CHD con 109,010 TMB (9\%), superada por la Pota con 396,280 TMB (32\%) y el Jurel con 263,071 TMB (21\%). Dentro de este rubro, la anchoveta se destina principalmente a los enlatados registrando 84,194 TMB al 2011. Por otro lado, se destinó 14,680 TMB al congelado, 10,092 TMB al curado y $44 \mathrm{TMB}$ al fresco. 
Gráfico 2.11 : Participación del desembarque de recursos hidrobiológicos destinados a CHD y uso de la anchoveta (al 2011 en porcentajes)

Desembarque por especie Desembarque de anchoveta
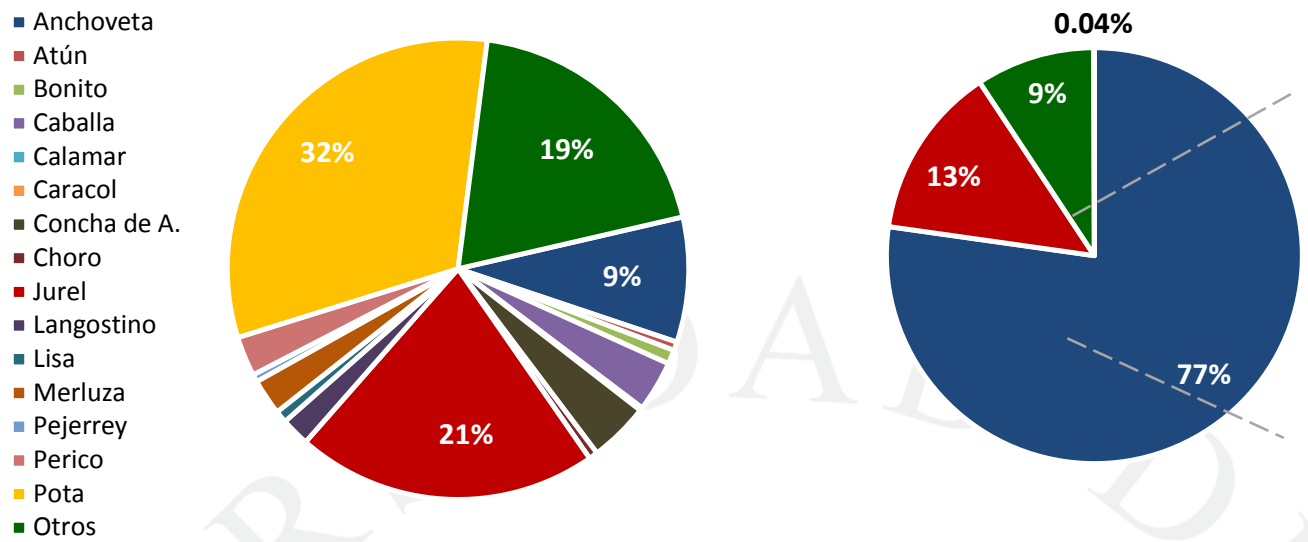

- Enlatado

- Congelado

- Curado

- Fresco

Otros

Fuente: PRODUCE,http://www.produce.gob.pe/index.php/estadistica/desembarque, revisado 07-mayo-2014

El rubro de CHI representó 3,696 miles de TMB al 2012 (76\% del desembarque de los productos pesqueros). La anchoveta representó 3,694 miles de TMB (99.99\% del CHI). En tal sentido, la anchoveta orientada al CHI representa aproximadamente $76 \%$ del desembarque total de la pesca.

Gráfico 2.12 : Participación del desembarque de CHI por especie (al 2012 en miles de TMB)

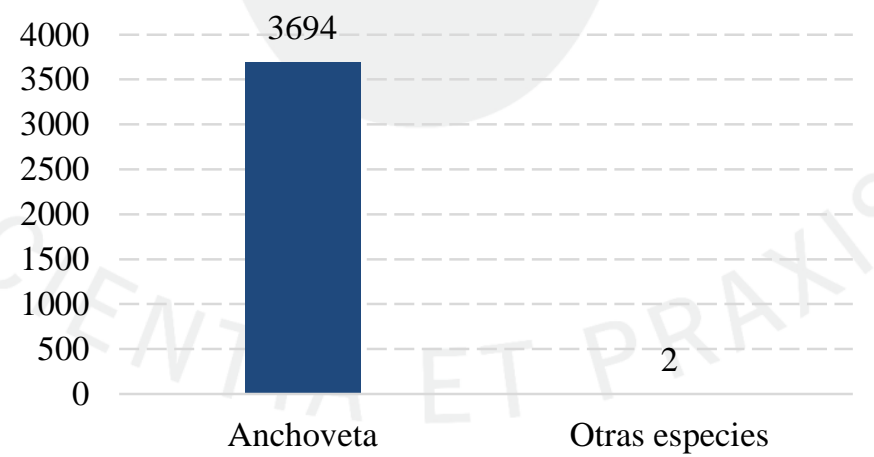

Fuente: INEI, http://www.inei.gob.pe/estadisticas/indice-tematico/economia/, revisado 07-mayo-2014 
El que la anchoveta sea el principal insumo para la elaboración de harina y aceite de pescado es de importancia internacional, puesto que esto ha convertido al Perú en el primer productor de harina de pescado (a base de anchoveta), con un nivel de 1,638 miles de TMB en la producción mundial de harina de pescado al 2012, equivalente a casi la mitad de la producción mundial.

Gráfico 2.13 : Participación en la producción mundial de harina de pescado (en porcentajes)

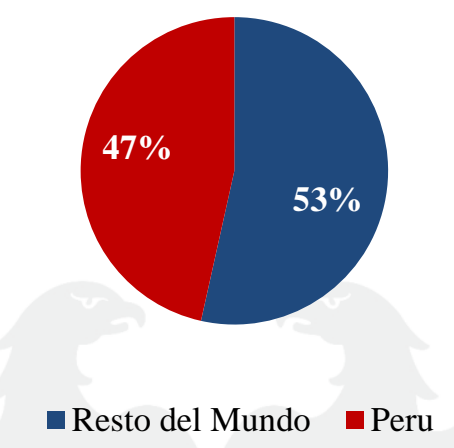

Fuente: FAO, http://www.fao.org/fishery/statistics/collections/en, revisado 10-mayo-2014

Es decir, el impacto de la calidad biológica nutricional de la anchoveta en el CHD a 2011 es de 9\% en términos de desembarque a nivel nacional; mientras en el CHI es de $99.9 \%$ en términos de desembarque a nivel nacional y de $47 \%$ en términos de producción de harina de pescado a nivel internacional.

El grado de impacto de la anchoveta sobre estas variables enfatiza la necesidad de la buena gestión del recurso en la actividad pesquera. En tal sentido, esta investigación busca evaluar si dicha gestión ha promovido la mejora de la eficiencia económica en el sector, en términos de esfuerzo pesquero (factores de producción), distribución (orientación del recurso a CHD o CHI) y sostenibilidad (preservación de la especie). 


\subsection{Historia de la pesca de anchoveta en el Perú}

Para poder realizar la evaluación mencionada, se describirá la evolución de la pesca de anchoveta y su gestión en la historia.

Según lo documentado por Arévalo (1995), previamente a 1943, el control del sector era realizado por diversas reparticiones públicas. Por la Ley $\mathrm{N}^{\circ} 9711$ del 2 de enero de 1943, se crea el Ministerio de Agricultura, el cual, mediante el D.S. del 2 de julio del mismo año, centraliza a la industria pesquera bajo la denominación de Dirección de Pesquería (Ley de Presupuesto 1946). Posteriormente se denominaría Dirección de Pesquería y Caza (D.S. del 9 de marzo de 1949) y ampliaría su rango de acción hacia el control y reglamentación de las actividades de caza en la República (D.S. del 10 de setiembre de 1949). Es decir, durante la década de 1940, el control del sector era relegado bajo el rubro de alimentación, lo cual implica que la perspectiva institucional de la época no valoraba al sector como fuente de exportaciones (Arévalo, 1995).

A inicios de la década de 1950, un grupo de pescadores españoles, en su mayoría expatriados producto de la Guerra Civil española, encontraron grandes cardúmenes de anchoveta que no habían sido aprovechadas para uso industrial; sino empleados como alimento de aves guaneras. Es así que, en la segunda mitad de los cincuentas, con la revolución tecnológica en la fabricación de harina de pescado a base de anchoveta, la compañía compradora de conservas Wilbur Ellis trajo desde California la primera planta para hacer harina de pescado. Esta fue vendida a Manuel Elguera, quien se convirtió en el primer productor de harina de pescado en el Perú en 1955 (Jaisuño, 1973). Es así que, con base en la abundancia del recurso de anchoveta y el desarrollo de la industria harinera, el Perú ascendió rápidamente en la producción mundial de harina de pescado, fuertemente apoyado por el impulso del empresario peruano.

Sin duda, en la década de 1950, el Perú se consolidó en el uso de anchoveta para harina de pescado y con el boom del sector en la década de 1960 las exportaciones del sector despegaron. 


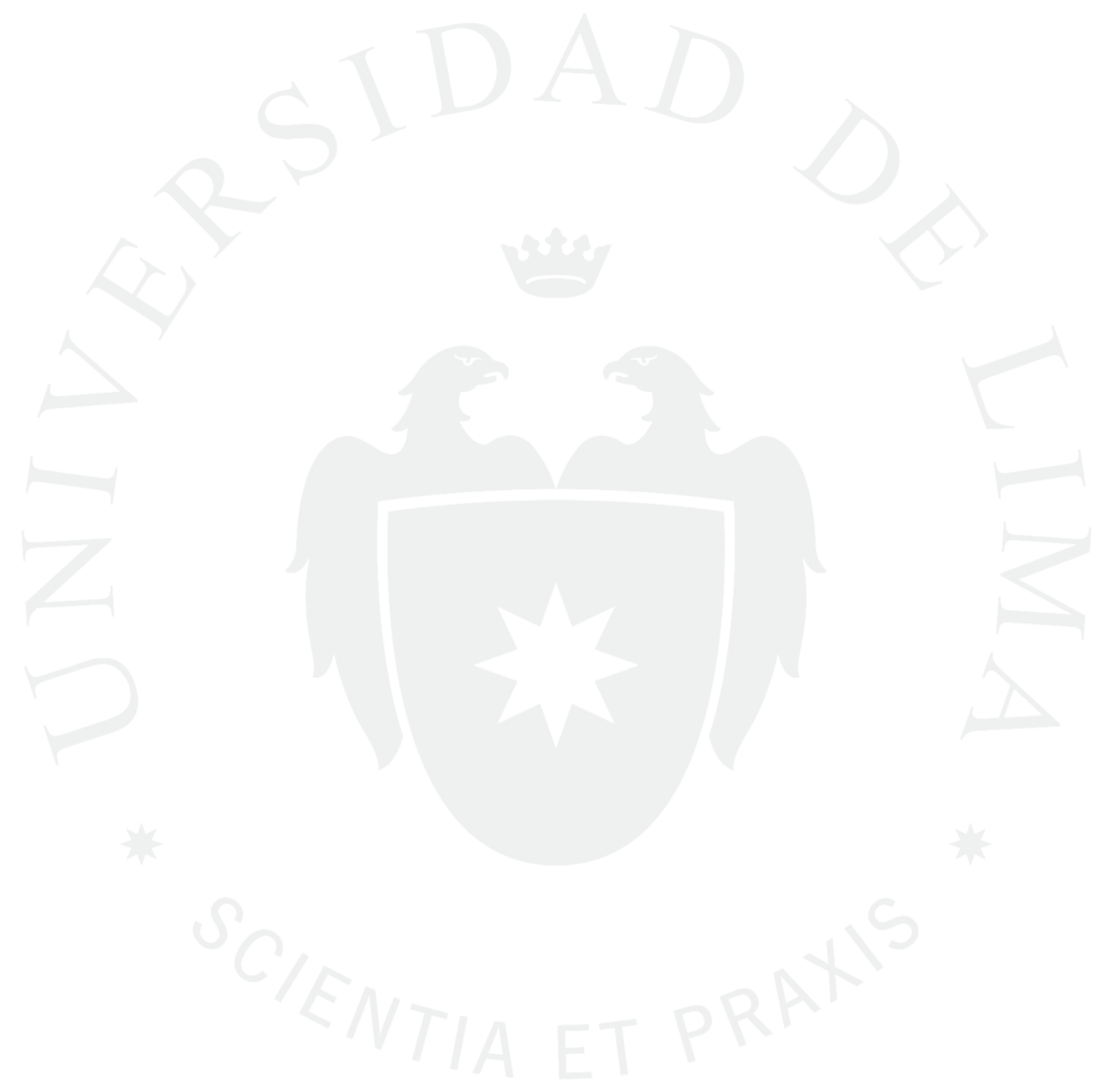


Si bien la exportación de productos tradicionales siempre primó frente a los no tradicionales, el crecimiento marcado a partir de la década de 1960 que experimentó fue apoyado principalmente por la expansión de la exportación de productos mineros y pesqueros. Este último sector a 1970 presentaba ocho veces el nivel de exportaciones presenciado en 1960.

Gráfico 2.14 : Evolución de las Exportaciones por tipo de producto (en millones de dólares)

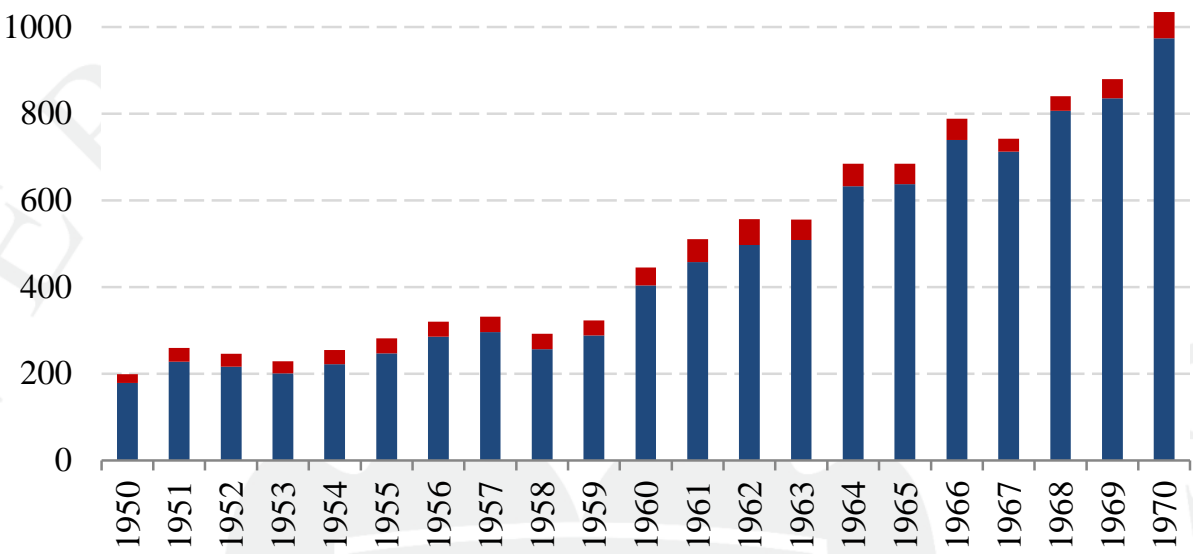

- Exportaciones tradicionales

- Export. no tradicionales

Fuente: BCRP, http://estadisticas.bcrp.gob.pe/index.asp?sFrecuencia=A, revisado 01-mayo-2014

Gráfico 2.15 : Evolución de las Exportaciones de productos tradicionales por tipo de producto (en millones de dólares)

1,200

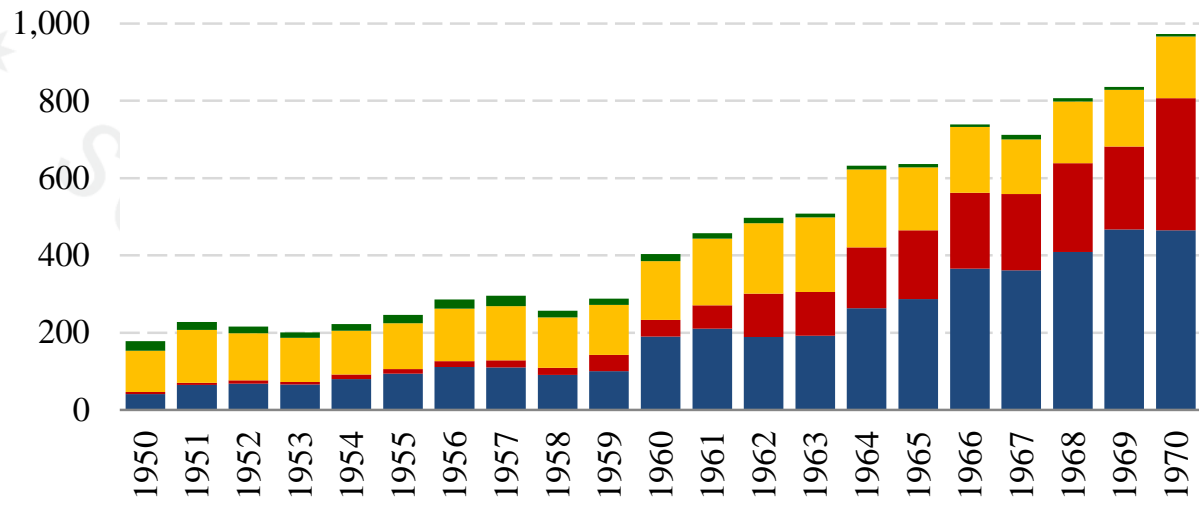

- Export. productos mineros

Export. prod. agrícolas
- Export. productos pesqueros

- Export. petróleo crudo y derivados

Fuente: BCRP, http://estadisticas.bcrp.gob.pe/index.asp?sFrecuencia=A, revisado 01-mayo-2014 
Gráfico 2.16 : Evolución de las Exportaciones de productos pesqueros 1950-1970

(en millones de dólares)

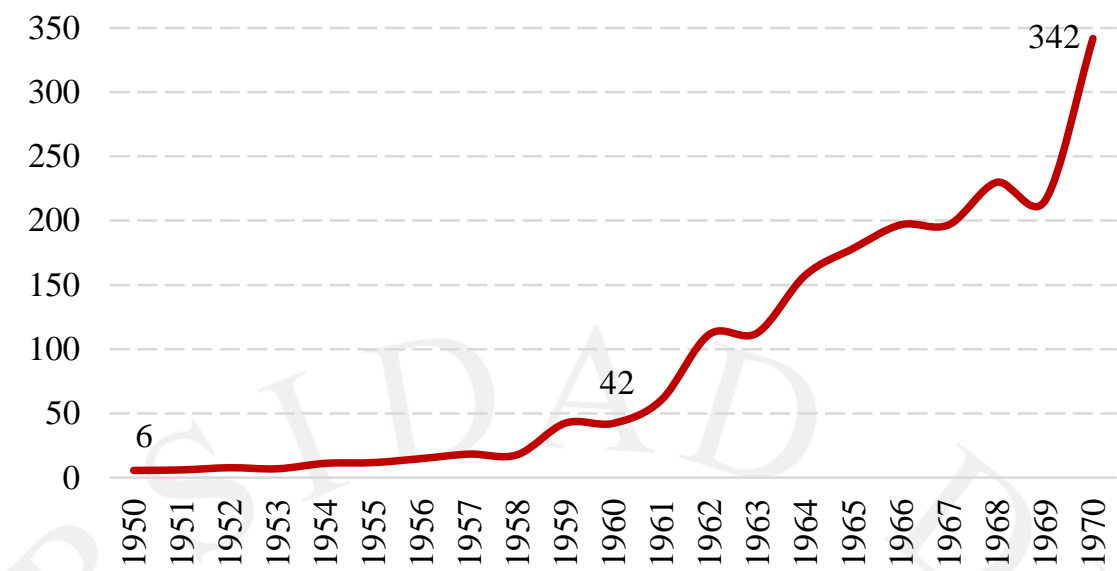

Fuente: BCRP, http://estadisticas.bcrp.gob.pe/index.asp?sFrecuencia=A, revisado 01-mayo-2014

Durante esta década, la Dirección de Pesquería y Caza fue transformada a Servicio de Pesquería (Ley de Presupuesto 1961) encargándose durante 10 años de los asuntos relacionados a la pesca en general y los correspondientes a la caza continental fueron transferidos al Servicio Forestal de Caza, perteneciente al Ministerio de Agricultura.

Por otro lado, se creó el Consejo Nacional de Pesquería (representantes del gobierno, investigación, industria, armadores y pescadores), encargado de estudiar los problemas de la actividad y proponer recomendaciones, no actuando en forma resolutiva. Análogamente, en 1963 se creó el Instituto del Mar del Perú (IMARPE), el cual a partir de 1964 consolidaría el Consejo Nacional de Investigaciones Hidrobiológicas y del Instituto de Investigaciones de los Recursos Marinos. Sin embargo, el boom del sector provocó la sobrepesca del recurso y la organización institucional desarrollada en esta época resultó insuficiente, conllevando a la captura masiva de anchoveta y la consecuente depredación del recurso.

Con el fin de normalizar el sector, en 1970 el Estado creó el Ministerio de Pesquería, así como la Empresa Pública de Servicios Pesqueros (EPSEP), para desarrollar la pesca para CHD compatible con la conservación de los recursos y contribuir con estos a elevar el nivel nutricional del pueblo peruano, y la Empresa Pública de Comercialización de Harina y Aceite de Pescado (EPCHAP). Un año después, se creó la Empresa Pública de Certificaciones Pesquera del Perú (CERPER) para dar lineamiento de calidad, 
seguridad, sanidad, entre otros, de los embarques; almacenajes de productos; y elementos técnicos del proceso de producción, transporte y distribución de productos hidrobiológicos. Asimismo, para verificar e informar el cumplimiento de normas y reglamentaciones de sanidad y calidad. En 1973, se creó Pesca Perú, para la administración de las fábricas de harina y aceite de pescado que habían sido estatizadas. Estas empresas estatales fueron luego privatizadas debido a su deficiente gestión y los impactos de la crisis del sector. Ese mismo año, se produce el Fenómeno del Niño, el cual, al complementarse con la continua sobrepesca ejercida producto de una escaza regulación, conllevó a una crisis en el sector. En 1980 se creó el Instituto Tecnológico de Pesquería, renombrado como Instituto Tecnológico de Producción (ITP) en 2013.

Para ilustrar el impacto de la crisis y su tardía recuperación, en el siguiente gráfico se puede apreciar como las exportaciones del sector a partir de 1972 se encuentran por debajo del promedio de exportación desde 1970 hasta 1990. No es hasta 1988 que se presencia una mejora significativa.

Gráfico 2.17 : Evolución de las exportaciones de productos pesqueros 1970-1990 (en millones de dólares)

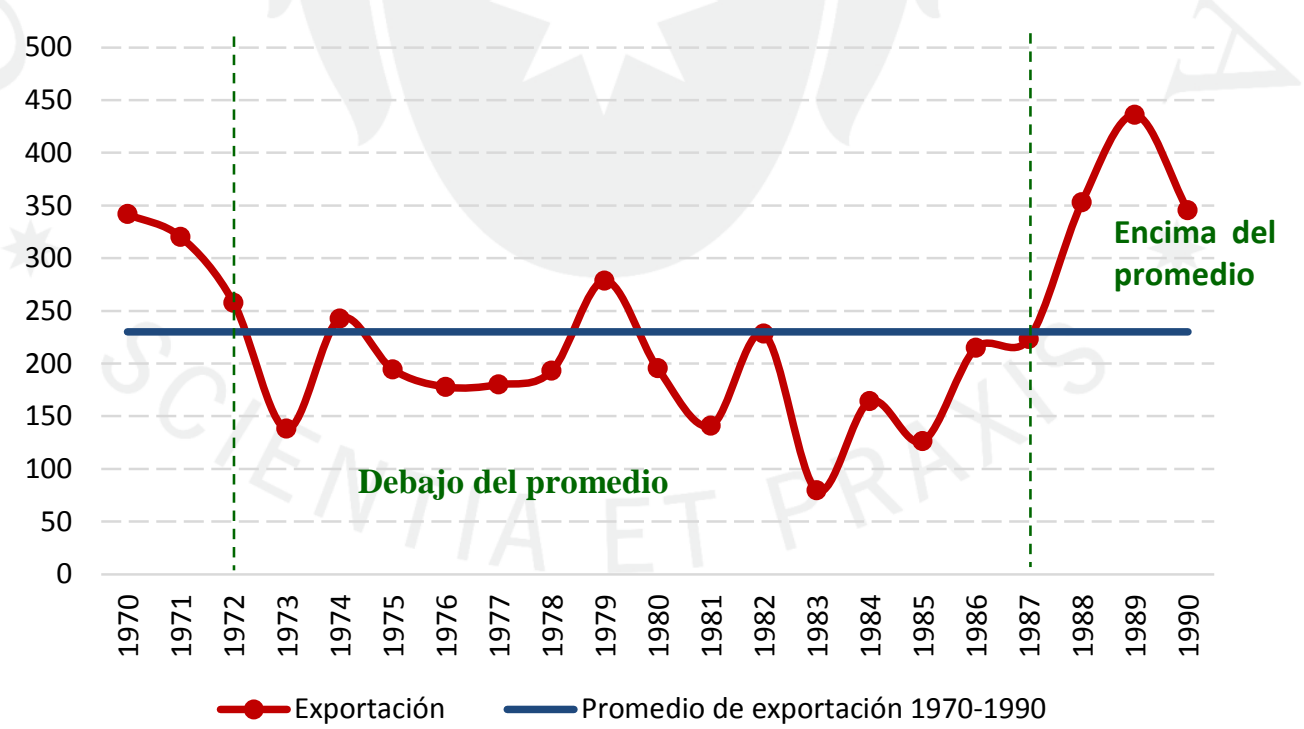

Fuente: BCRP,http://estadisticas.bcrp.gob.pe/index.asp?sFrecuencia=A, revisado 01-mayo-2014 Elaboración: Propia 


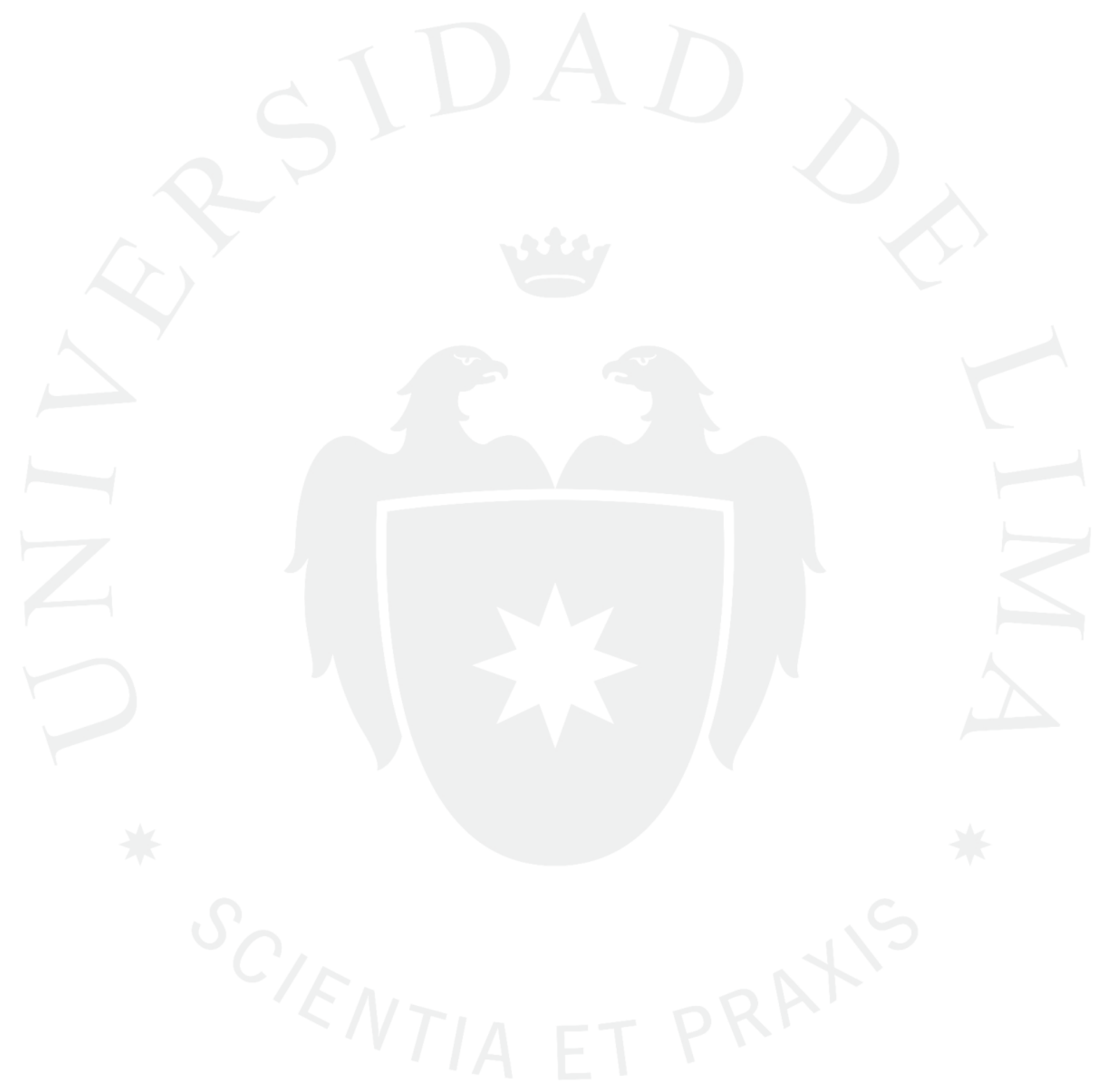


En 1992, se creó el Fondo Nacional de Desarrollo Pesquero (FONDEPES) por la fusión de los Fondos de Financiamiento de Infraestructura Pesquera (FOFIP), de Desarrollo Pesquero Artesanal (FONDEPA) y el Programa de Infraestructura Pesquera Artesanal (PDIPA), y asumió algunos activos y la cartera de recuperación del FONRESPE (entidad declarada en disolución). Además, se emite la Ley General de Pesca y su Reglamento, la cual constituye un hito en la regulación del sector y tiene por fin "normar la actividad pesquera con el fin de promover su desarrollo sostenido como fuente de alimentación, empleo e ingresos y de asegurar un aprovechamiento responsable de los recursos hidrobiológicos, optimizando los beneficios económicos, en armonía con la preservación del medio ambiente y la conservación de la biodiversidad.” En este sentido, establece el rol de las instituciones que regulan el sector, establece un ordenamiento inicial para la actividad pesquera en general, sujeto a la determinación de prohibiciones, infracciones y sanciones.

En este contexto, la industria pesquera se recuperó e inició una etapa de modernización; sin embargo, en 1998 El Niño vuelve a presentarse, pero esta vez en magnitud fuerte tal que, al combinarse con un contexto de crisis asiática y el endeudamiento de las empresas pesqueras producto del proceso de privatización, determina una nueva etapa de crisis. No obstante, un mejor control de la biomasa permitió que en la década del 2000 se experimentara crecimiento y expansión de las inversiones. A inicios de la década en 2002, se creó el Ministerio de la Producción, el cual incorpora actualmente el Viceministerio de Pesquería; en el 2007 se publicó el Reglamento de Inspecciones y Sanciones Pesqueras y Acuícolas (RISPAC), que permitió regularizar las inspecciones sobre el cumplimiento de la normativa emitida en el sector; en el 2008 se emitió la Ley sobre Límites Máximos de Captura por Embarcación y su Reglamento, que regulariza la pesca destinada a CHI; y en 2013 se emitió la Ley Zona de Reserva para la extracción del recurso de anchoveta(Engraulis ringens) y anchoveta blanca (anchoa nasus) destinado al consumo humano directo (detalle en el Capítulo 2 Marco Normativo). 
Gráfico 2.18 : Evolución de las exportaciones de productos pesqueros 1990-2013 (en millones de dólares)

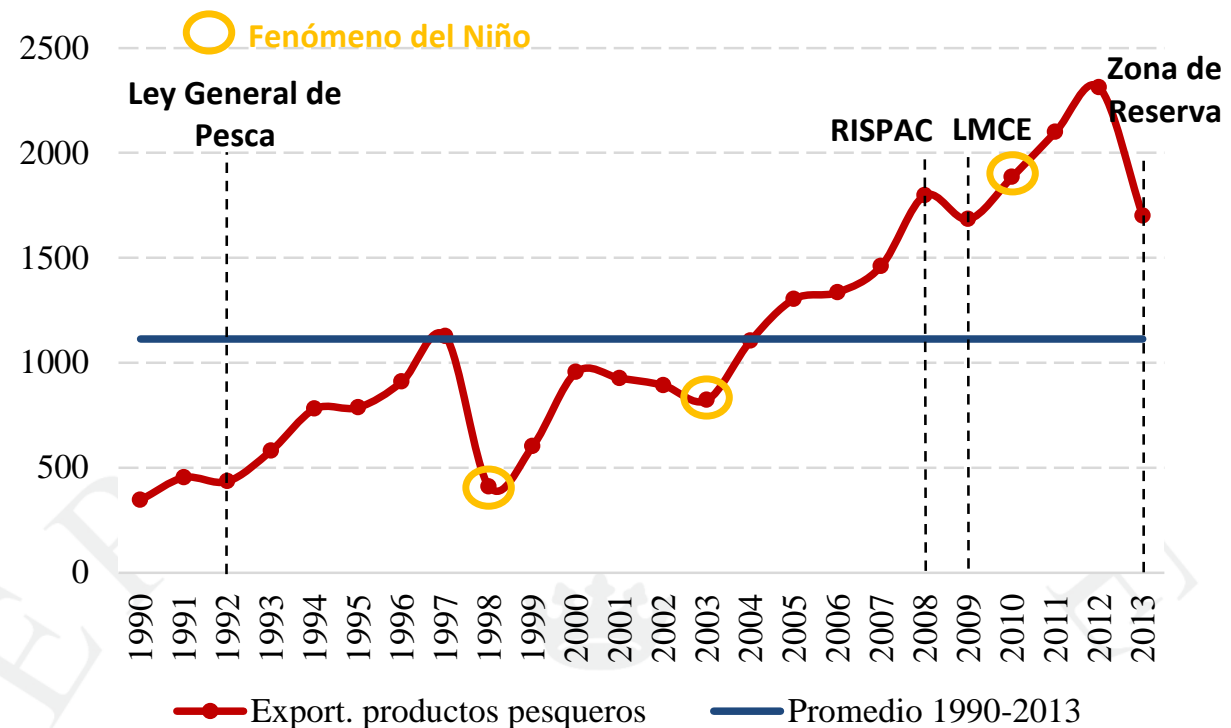

Fuente: BCRP,http://estadisticas.bcrp.gob.pe/index.asp?sFrecuencia=A, revisado 01-mayo-2014 Elaboración: Propia

Como se puede observar en esta breve descripción de la evolución del sector (gráficos 2.19 y 2.20), en la década de 1950 y especialmente en la de 1960, la pesca de la anchoveta tiene un marcado crecimiento causado por la fuerte demanda de harina de pescado a nivel internacional. Desafortunadamente, precisamente este factor generó la depredación del recurso por parte del gremio empresarial en la denominada "carrera olímpica", asociada a la falta de solidez de las instituciones pertinentes y la consecuente falta de regulación del sector.

A partir de la década de 1990, el sector presenta una recuperación. En 1992, 2007, 2008 y 2013 se promulgan una serie de leyes y un reglamento que buscan normalizar el sector en un marco de preservación de la especie, dar énfasis al CHD e implementar mecanismos de monitoreo y fiscalización de la actividad empresarial en el sector.

Es decir, el ente regulador de pesca en el Perú, a partir de 1990, genera una gestión aparentemente más sólida del recurso y el sector, basado en un marco normativo expresado en las leyes y reglamento mencionados. 
Gráfico 2.19 : Evolución de las exportaciones de productos (en millones de dólares)

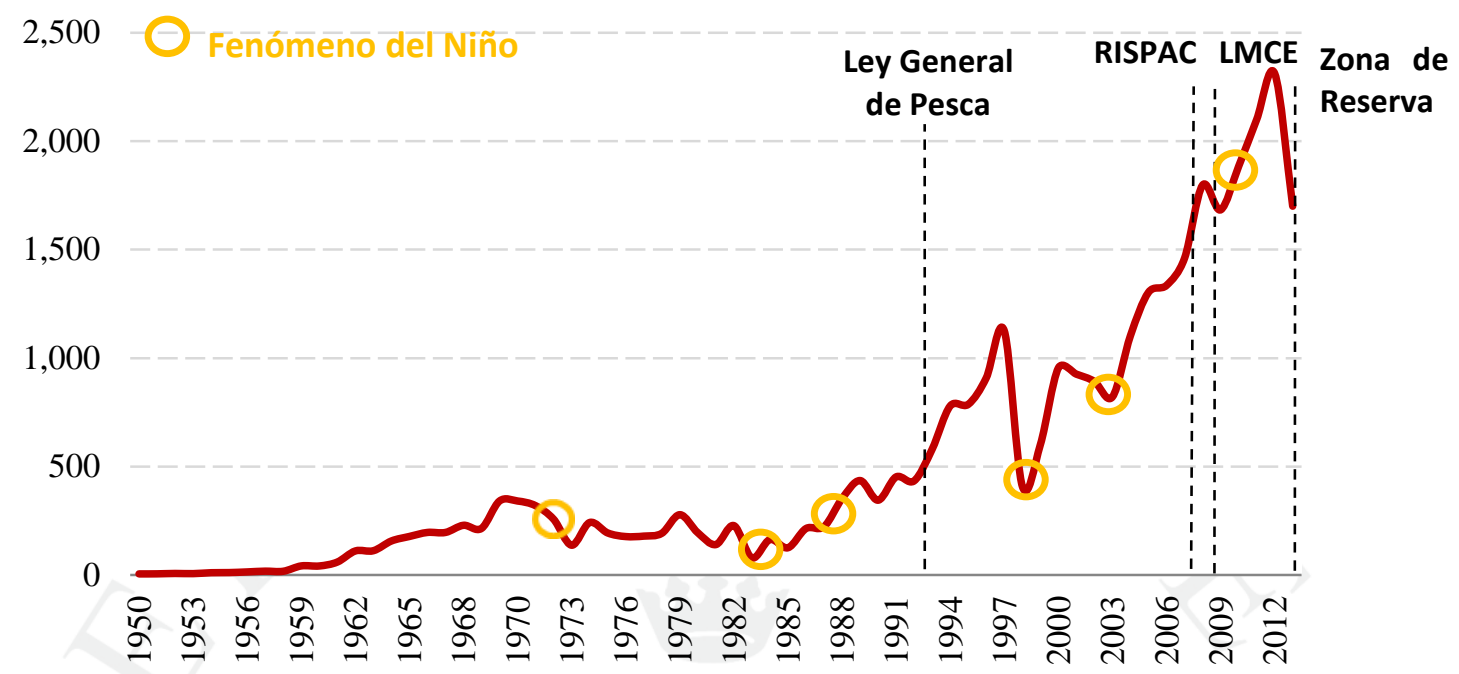

Fuente: BCRP,http://estadisticas.bcrp.gob.pe/index.asp?sFrecuencia=A, revisado 01-mayo-2014 Elaboración: Propia

Gráfico 2.20 : Desembarque de anchoveta (miles de TMB)

14,000 Fenómeno del Niño

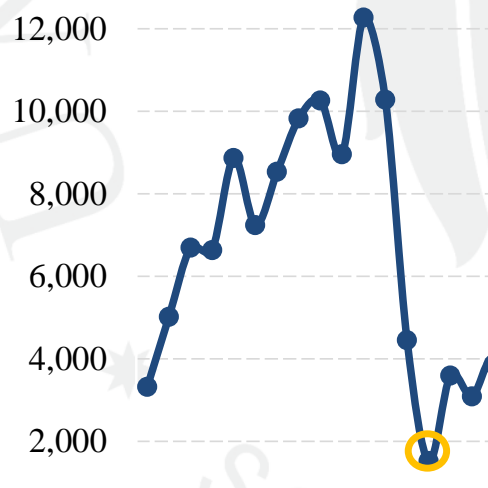

Ley General de

Pesca

RISPAC LMCE

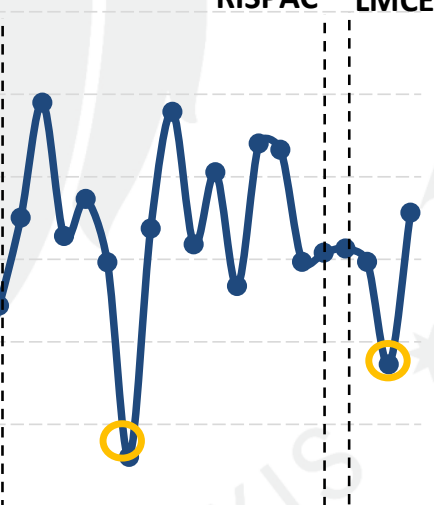

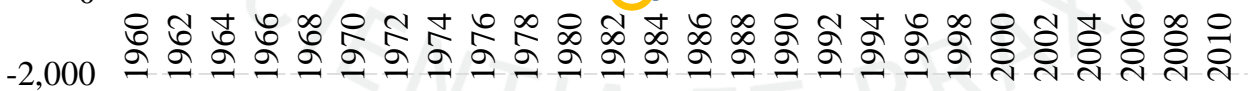

Fuente:FAO, http://www.produce.gob.pe/index.php/servicios-en-linea/embarcaciones-pesqueras\#, 10-mayo-2014 Elaboración: Propia 
En un panorama más reciente, durante las últimas décadas se observa que, si bien la producción de CHI mantiene su superioridad respecto al CHD, las tendencias del nivel de producción medido en TMB son opuestas, favoreciendo el crecimiento del CHD. Cabe resaltar que la causa del comportamiento de la producción de CHI es la evolución de los niveles de biomasa de anchoveta.

A 2013, el CHI presenta un nivel de producción $41 \%$ menor al de 1996; es decir tuvo una tasa de compuesta anual de crecimiento negativa de 3\%. Por otro lado, durante el mismo periodo, el CHD presenta una tasa compuesta anual de crecimiento de $40 \%$.

Gráfico 2.21 : Evolución de la producción por CHI y CHD (en miles de TMB)

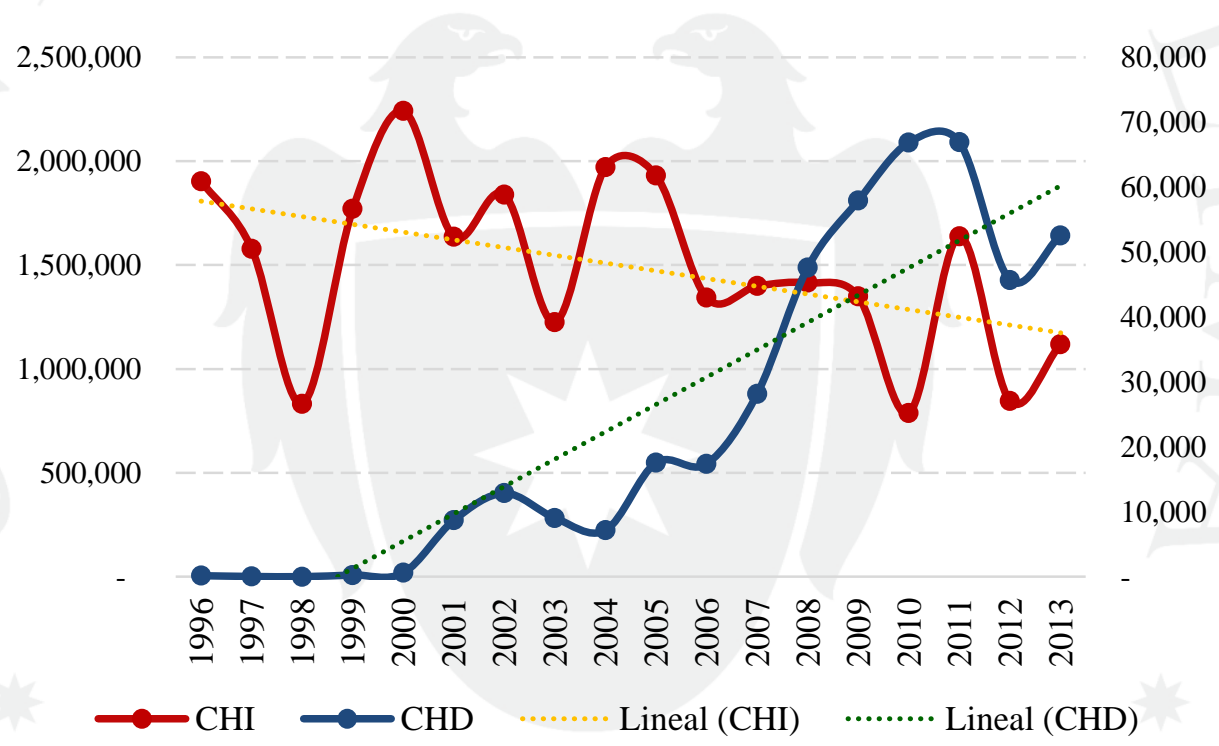

Fuente: PRODUCE, revisado 07-mayo-2014

El CHI se segmenta en el uso de anchoveta y el de otras especies. Si bien en la última década la anchoveta ha adquirido mayor preponderancia en el nivel de desembarque, de $87 \%$ para el periodo $1997-2002$ a $99.95 \%$ al periodo 2008-2012, el promedio de desembarque del CHI en estos periodos se redujo de 7,352 miles de TMB a 5,205 miles de TMB. 
Gráfico 2.22 : Composición del desembarque de CHI (en miles de TMB)

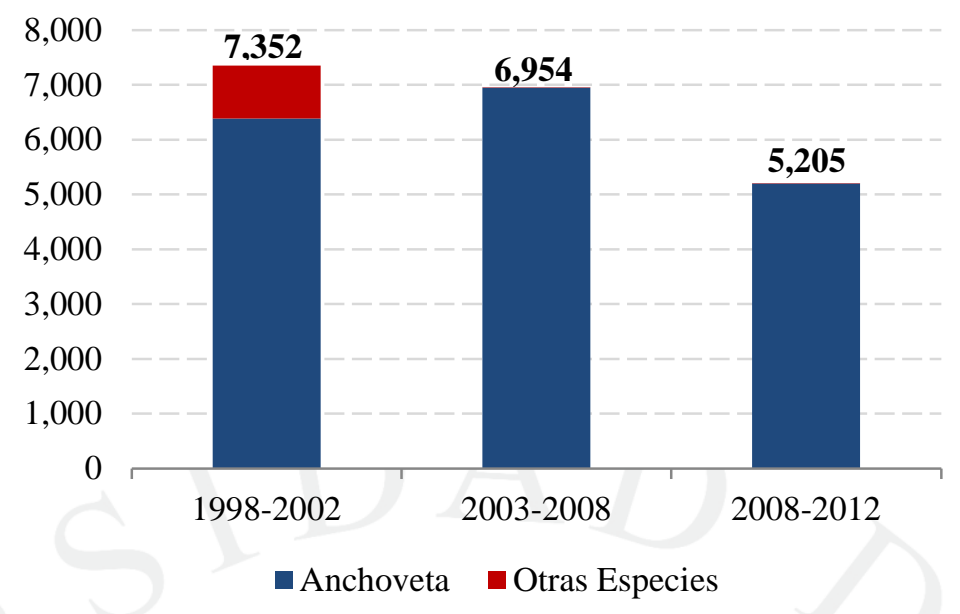

Fuente: INEI, http://www.inei.gob.pe/estadisticas/indice-tematico/economia/, revisado 07-mayo-2014

Por el lado de CHD, el recurso se divide entre productos de enlatado, congelado, curado y fresco. A lo largo del periodo señalado en el gráfico 2.23, se observa que la producción de curado y enlatado a base de anchoveta presentan una tasa compuesta de crecimiento anual de $10 \%$ y $37 \%$ respectivamente, lo cual compensa la baja del congelado y fresco.

\section{Gráfico 2.23 : Composición del desembarque de CHD}

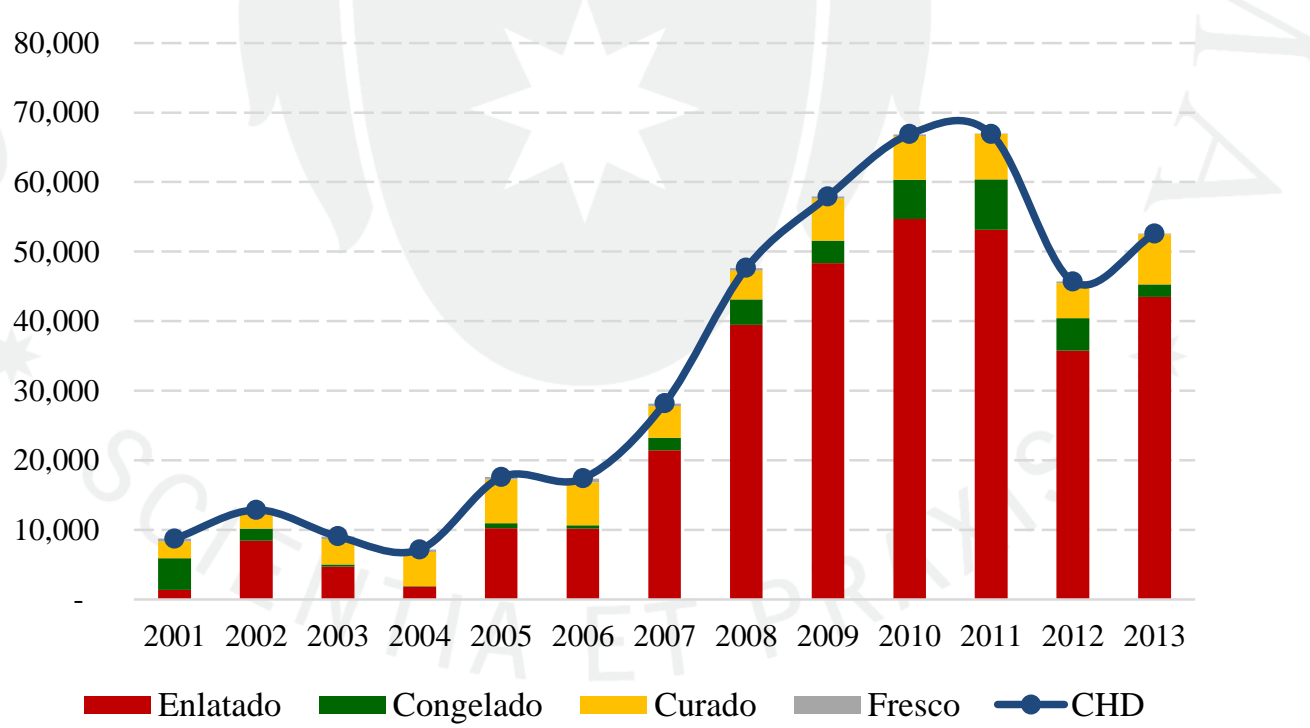

Fuente: PRODUCE, revisado 07-mayo-2014 
En cuanto a las exportaciones pesqueras, se observa una ralentización del ritmo de crecimiento, con una expansión de $26 \%$ para el periodo 20102013 respecto al 2006-2009, inferior al 52\% de dicho periodo respecto al 2002-2005. Además, el porcentaje de participación de la harina de pescado presentó una baja, ubicándose en un $81 \%$ del total de exportación pesquera 2010-2013.

\section{Gráfico 2.24 : Composición de las exportaciones pesqueras (en miles de dólares)}

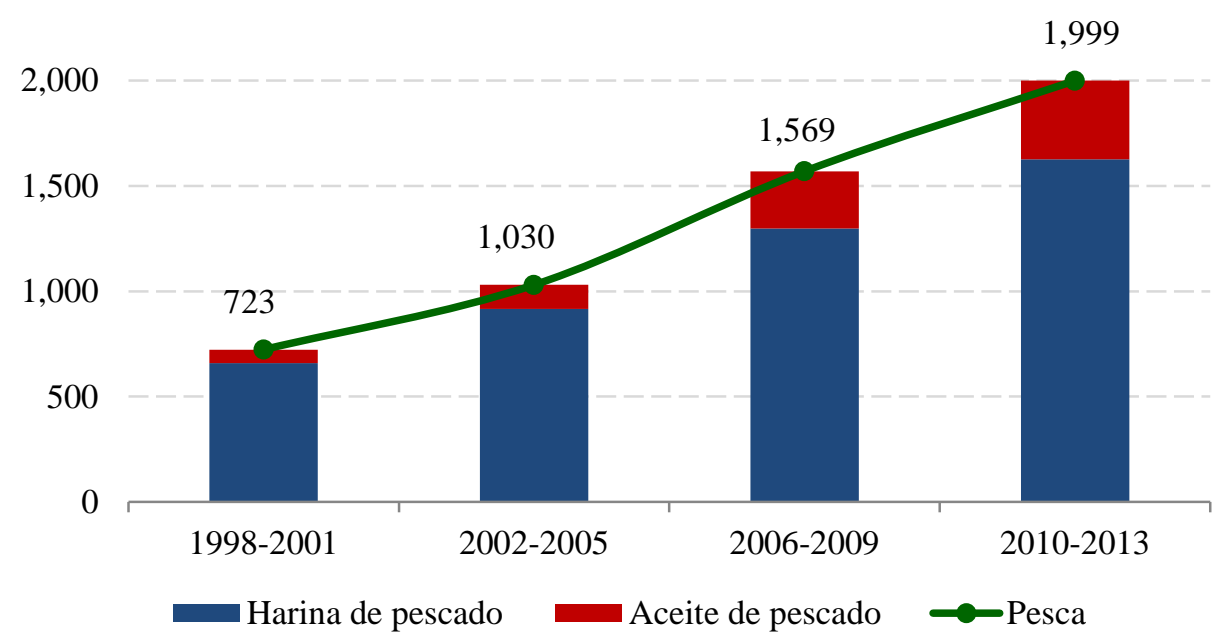

Fuente: INEI, http://www.inei.gob.pe/estadisticas/indice-tematico/economia/, revisado 07-mayo-2014

El principal driver que promueve la producción de CHI es el nivel del precio de la harina y aceite de pescado, que presenta una tendencia creciente marcada principalmente por la demanda creciente a nivel mundial, para su uso en el rubro acuícola, avícola y porcícola, y el que exista bajo nivel de sustitución del insumo anchoveta, dada la calidad biológica mencionada. Adicionalmente, el aceite de pescado destaca por nutrientes como Omega 3 que se aplican en la industria farmacéutica. Evidentemente, la cantidad ofertada también impacta en el precio, siendo determinante la oferta en Perú, marcada por eventos climatológicos (Fenómeno del Niño), y la realización de temporadas de pesca, sujeta al nivel de juveniles.

Durante el periodo 2005-2007 se generó un incremento del precio dado el incremento de la demanda por los factores mencionados; sin embargo, la crisis internacional frenó el crecimiento. Posteriormente la demanda se recuperó y la incidencia del Fenómeno del Niño que genera escasez del recurso impulso el alza del precio. 
Gráfico 2.25 : Precio Harina de Pescado (US\$ / TM)

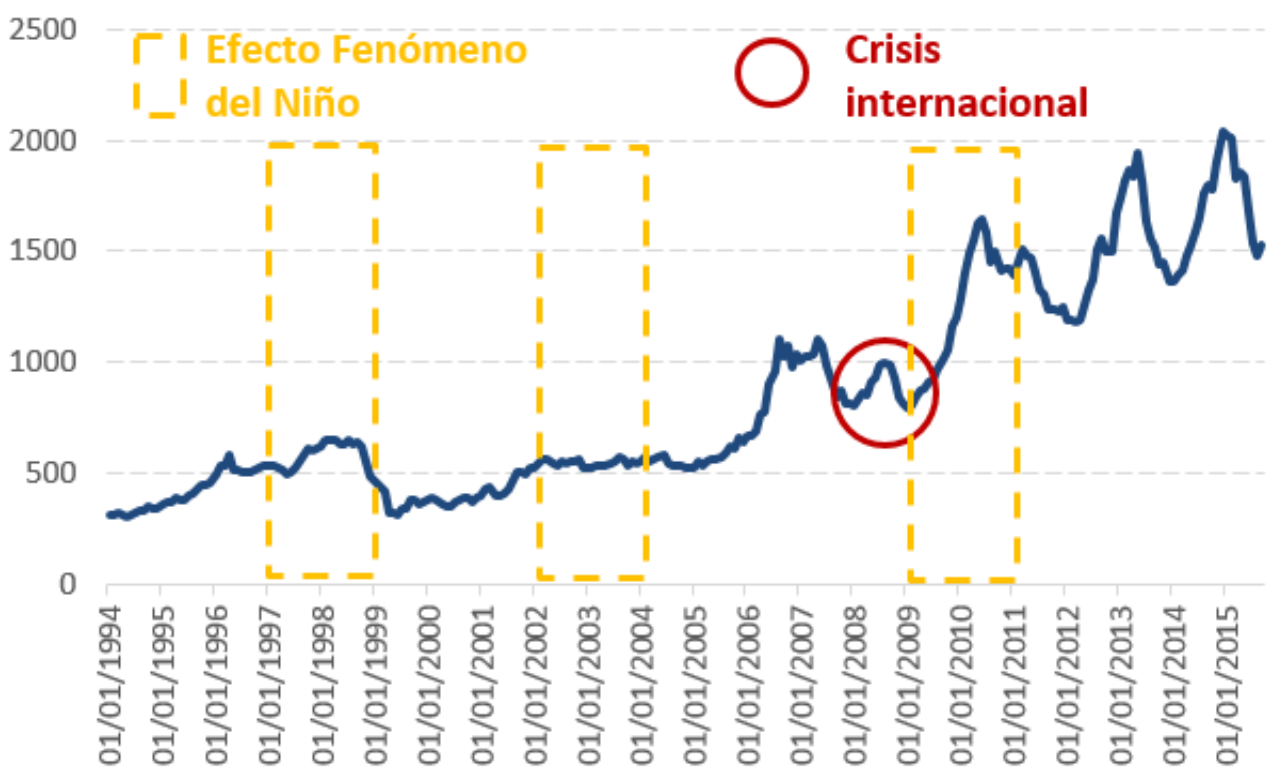

Fuente: BCRP; https://estadisticas.bcrp.gob.pe/estadisticas/series/mensuales/resultados/P00367BPM/html/ , revisado $30 / 11 / 2015$

Gráfico 2.26 : Precio Aceite de Pescado (US\$ / TM)

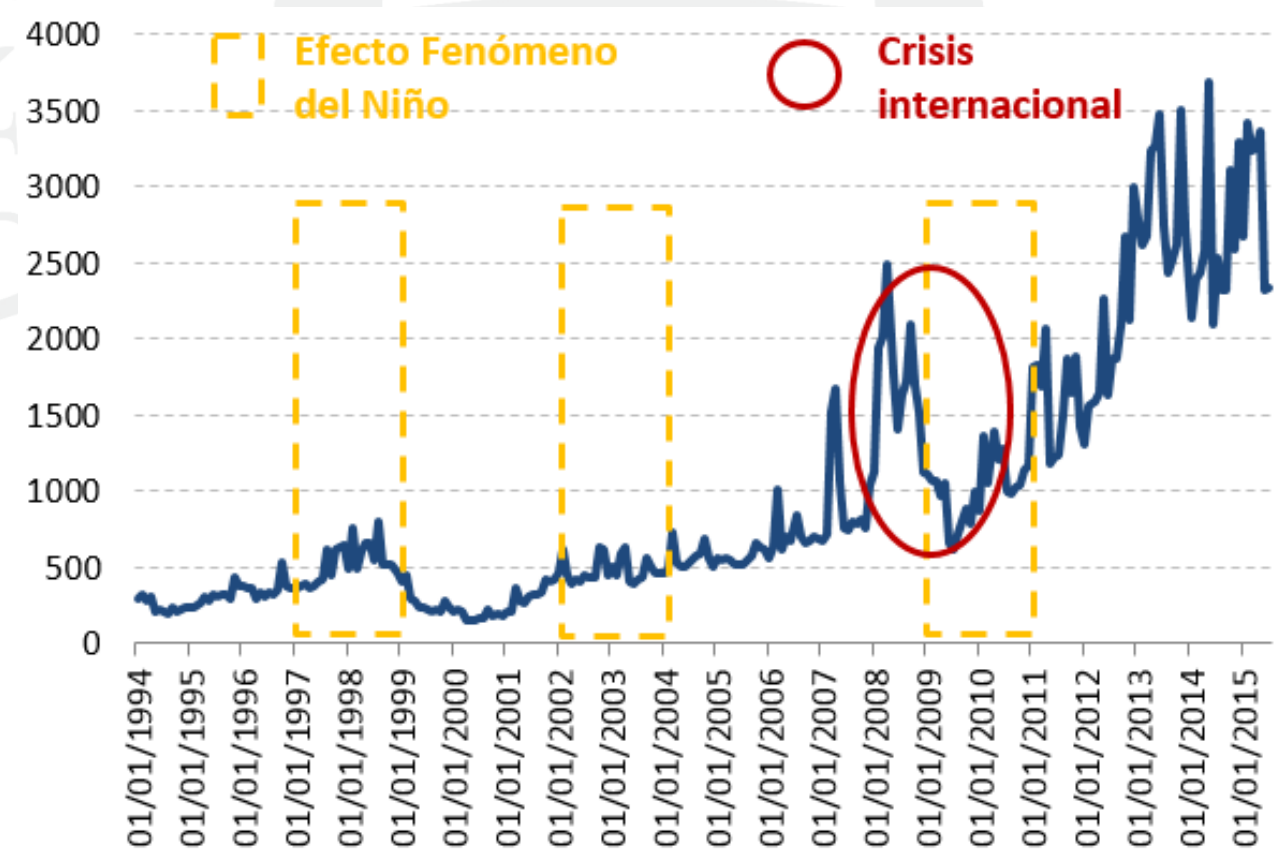

Fuente: BCRP; https://estadisticas.bcrp.gob.pe/estadisticas/series/mensuales/resultados/P00367BPM/html/ , revisado $30 / 11 / 2015$ 
En síntesis, a la fecha, en el nivel de desembarque se observa que el CHD gradualmente presenta mayor importancia en la pesca peruana, siendo la anchoveta al 2011 la tercera especie de mayor participación en el CHD con 109,010 TMB (9\%), superada por la Pota con 396,280 TMB (32\%) y el Jurel con 263,071 TMB (21\%); mientras que en el CHI, si bien la importancia de la anchoveta respecto a las otras especies se incrementa hasta un $99.99 \%$, se presenta una tendencia bajista del nivel del desembarque, explicado por el comportamiento de la biomasa. A nivel de exportaciones pesqueras, basadas principalmente en anchoveta, la actividad actualmente se rige por la tendencia alcista del precio por TM, determinada por la disponibilidad del recurso, sujeto a condiciones climatológicas, y la demanda creciente a nivel mundial, por la utilidad del producto y bajo grado de sustitución.

Es decir, en la última década se observa cambios importantes en el destino de la anchoveta. Frente a tal comportamiento, esta investigación desarrolla un análisis de la influencia de la normativa al respecto y la conveniencia de la misma en términos de eficiencia económica. 


\subsection{Organización de la industria de la anchoveta}

\subsubsection{Organización institucional}

\section{a. Viciministerio de Pesquería}

Actualmente, el Ministerio de la Producción (PRODUCE), creado por la Ley 27779 del 10 de julio de 2002 y suscrito en organización y funciones por la Ley 27789, tiene por finalidad el diseñar, establecer, ejecutar y supervisar, en armonía con la política general y planes del gobierno, políticas nacionales y sectoriales aplicables a los subsectores que tiene a cargo.

El primero se denomina MYPE e Industria, en el cual fomenta la iniciativa empresarial, la competitividad de ${ }^{o}$ la micro y pequeña empresa, la asociatividad y el cooperativismo, así como las actividades de industrialización, procesamiento y manufactura, velando por el aprovechamiento sostenible de los recursos naturales y la protección del ambiente.

El segundo es el de Pesquería, el cual comprende todos los recursos de origen hidrobiológico contenidos en las aguas marinas jurisdiccionales, ríos, lagos y otras fuentes hídricas del territorio nacional. En este, su ámbito abarca la investigación científica y tecnológica del sector pesquería; así como las condiciones ecológicas de su hábitat; los medios para su conservación y explotación, la calidad, higiene y sanidad de los productos de procedencia acuática; la infraestructura pesquera, así como los servicios adicionales y complementarios para la realización de las actividades extractivas, acuícolas y del proceso pesquero en general. Postula las políticas para la promoción del Perú como país oceánico y el uso de recursos hidrobiológicos para el consumo humano.

En tal sentido, PRODUCE cuenta con órganos de apoyo, asesoramiento y control; dos Viceministerios, que contienen órganos de primera línea; y organismos públicos descentralizados. Dentro de esta estructura, este capítulo se centra en el análisis de la 
composición institucional de la rama perteneciente al Viceministerio de Pesquería. 
Diagrama 2.3: Organigrama de produce relacionado con la gestión pesquera ${ }^{7}$

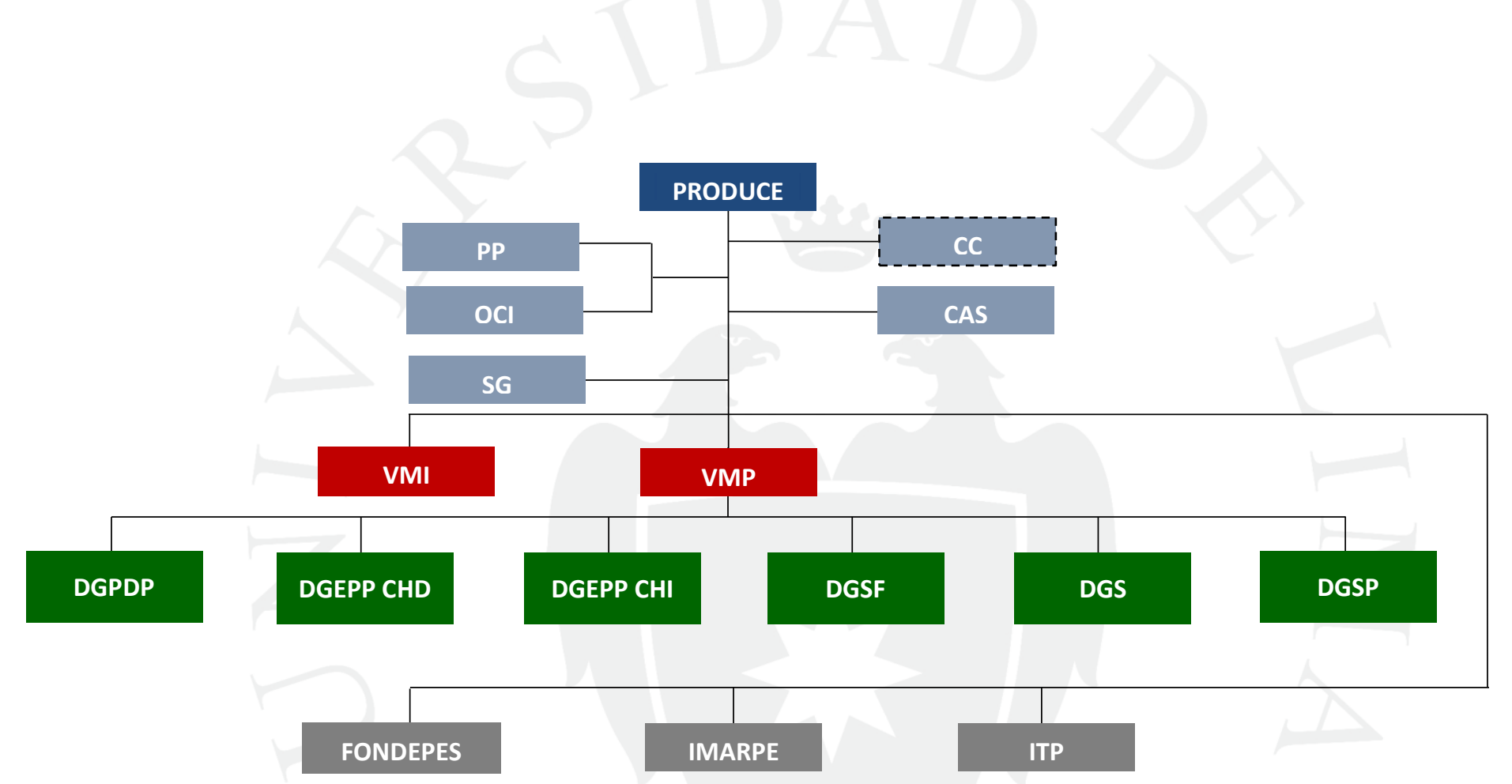

Fuente: PRODUCE-Reglamento de Organización y Funciones (ROF)

\footnotetext{
${ }^{7}$ PRODUCE: Ministerio de Producción; PP: Procuradoría Pública; OCI: Organismo de Control Institucional; CC: Comisión Consultiva; CAS: Consejo de Apelación de Sanciones; SG: Secretaría General; VMI: Viceministerio de MYPE e Industria; VP: Viceministerio de Pesquería; DGPDP: Dirección General de Políticas y Desarrollo Pesquero; DGEPPCHD: Dirección General de Extracción y Producción Pesquera para Consumo Humano Directo; DGEPPCHI: Dirección General de Extracción y Producción Pesquera para Consumo Humano Indirecto; DGSF: Dirección General de Supervisión y Fiscalización; DGS: Dirección General de Sanciones; DGSP: Dirección General de Sostenibilidad Pesquera; FONDEPES: Fondo Nacional de Desarrollo Pesquero; IMARPE: Instituto del Mar del Perú; ITP: Instituto Tecnológico de la Producción.
} 
Con la finalidad de asegurar la compatibilidad entre los intereses y acciones de los demás sectores con los objetivos de las competencias del sector producción, PRODUCE mantiene relaciones de coordinación permanentes con los diferentes sectores nacionales públicos y privados. Asimismo, coordina con los gobiernos regionales y locales todos los asuntos relativos a sus competencias.

En la Ley General de Pesca (DL N $\left.{ }^{\circ} 15997,1992\right)$ se describe la coordinación del Ministerio de Pesquería, actualmente Viceministerio, con otros organismos de la siguiente forma:

- Ministerios, Municipalidades y otros organismos competentes en materia de prevención y control de la contaminación ambiental

Coordinan los aspectos relacionados con la contaminación derivada de la actividad pesquera.

- Ministerio de Educación

Coordinan los aspectos relacionados con la política de educación al consumidor orientada a incrementar el consumo de productos pesqueros en la dieta alimentaria de la población.

\section{- Ministerio de Defensa}

A través de la autoridad marítima y de acuerdo a las normas que dicte el VMP, ejerce la función de control y protección de los recursos hidrobiológicos, además de la seguridad de la vida humana en el mar y la protección marina.

- Ministerio de Agricultura

En conjunto con el VMP, administra en los aspectos que les competen, las unidades de conservación de flora y fauna.

- Ministerio de Trabajo y Promoción Social y el Ministerio de Defensa

Dictan las normas relacionadas con el régimen laboral de los pescadores. 


\section{- Ministerio del Interior}

De acuerdo a las normas que dicte el VMP, ejerce las funciones de control y protección de los recursos pesqueros, en los lugares donde el Ministerio de Defensa no cuente con los medios para realizar dichas funciones.

\section{- Ministerio de Relaciones Exteriores}

Coordinan los acuerdos y/o convenios pesqueros a celebrarse con otros Estados, comunidades de Estados y grupos de Estados, así como con organismos y organizaciones internacionales, multinacionales y/o intergubernamentales. Las Misiones y Representaciones Diplomáticas, así como los Consulados del Perú en el exterior, apoyarán la promoción del comercio externo de productos pesqueros, estableciendo los contactos necesarios para tal fin.

\section{- Organismos regionales}

Encargados del cumplimiento de las normas emitidas por el VMP en sus respectivas regiones. Estos sólo podrán dictar dichas normas, cuando exista delegación expresa del VMP.

\section{b. Marco Normativo}

En la regulación del sector, se han emitido cuatro ítems que sobresalen respecto al conjunto de normas que comprende el marco normativo del sector. Sin embargo, debido a que ley de la Zona de Reserva para CHD (cuarto ítem) se emitió en el 2013, en base a indicadores no es posible evaluar su impacto; es decir, no se cuenta con información para determinar su efecto. En tal sentido, la "variable normativa" para términos de esta investigación se refiere a la Ley General de Pesca, el RISPAC y el LMCE. Cabe resaltar que, si bien los indicadores no cuentan con data previo a 1992 (fecha de vigencia de la ley General de Pesca), el RISPAC y el LMCE se basan en ella como mecanismos para que esta funcione en la práctica y no solo como enunciado. 
A continuación se menciona el objetivo y principales medidas de los tres grandes ítems de la regulación del sector. Para una descripción más detallada revisar el Anexo I.

\section{- Ley General de la Pesca y su Reglamento}

El 7 de diciembre de 1992 y el 14 de marzo de 2001 respectivamente, se aprobó la Ley General de Pesca (Decreto Ley $N^{\circ}$ 25977) y el Reglamento de la misma (Decreto Supremo $\mathrm{N}^{\circ}$ 012-2001-PE. Su emisión constituye el punto de partida del ordenamiento pesquero del Perú, ya que previamente, a pesar de la importancia del sector desde la década de los cincuentas, las disposiciones de regulación no habían sido significativas para una normalización del sector en términos de una economía de mercado. $\mathrm{Su}$ objetivo es promover el desarrollo sostenido del sector, como fuente de alimentación, empleo e ingresos, así como asegurar un aprovechamiento responsable de los recursos hidrobiológicos, optimizando los beneficios económicos, en armonía con la preservación del medio ambiente y la conservación de la biodiversidad.

En este se especifican los parámetros de la actividad del sector, referidas a investigación y capacitación, extracción, procesamiento, y comercialización; en base a consideraciones relacionadas a regímenes de acceso, captura total permisible, magnitud del esfuerzo de pesca, temporadas de pesca, tallas mínimas de captura, zonas prohibidas o de reserva, artes, aparejos, métodos y sistemas de pesca, así como las necesarias acciones de monitoreo, control y vigilancia, a ser respetadas según lo establecido en el punto de prohibiciones, infracciones y sanciones.

El aporte de la presente ley es normalizar y ordenar el sector pesquero en un marco general de explotación y sostenibilidad del recurso; además, se favorece el CHD mediante programas de promoción y establecimientos de zonas de reserva para uso exclusivo de este tipo de consumo. 
- Reglamento de Inspecciones y Sanciones Pesqueras y Acuícolas - RISPAC

En el 2007 se prosigue con la labor de regularizar el sector y se publica el presente Reglamento.

En este se establecen las facultades y procedimiento del fiscalizador, así como los parámetros de los decomisos de recursos hidrobiológicos destinados al CHD y CHI; se nombra a los órganos administrativos sancionadores y el procedimiento.

- Ley sobre Límites Máximos de Captura por Embarcación y su Reglamento

Un año después, entra en vigencia la Ley sobre Límites Máximos de Captura por Embarcación (Decreto Supremo $\mathrm{N}^{\circ}$ 1084) y su respectivo Reglamento (Decreto Legislativo $\mathrm{N}^{\circ}$ 1084), los cuales tienen por objetivo establecer un mecanismo de ordenamiento referido a la extracción de los recursos de anchoveta y anchoveta blanca con fines de CHI.

Para ello, se dictamina el procedimiento de fijación y asignación de cuota máxima permitida por embarcación, basado en la fijación del Límite Máximo Total de Captura Permisible del recurso anchoveta para Consumo Humano Indirecto (LMCTP), determinado en el informe científico de la biomasa del recurso publicado por el Instituto del Mar del Perú (IMARPE), y el Porcentaje Máximo de Captura por Embarcación (PMCE) asignado por el Ministerio en base a la asignación histórica.

Además, estableció el Fondo de Compensación para el Ordenamiento Pesquero, mediante el cual los trabajadores tuvieron la posibilidad de acceder al Programa de Jubilación Adelantada si contaban con cincuenta años de edad a la finalización de la campaña de difusión. De lo contrario, pudieron y pueden acogerse al Programa de Incentivos a la Reconversión Laboral hacia otras actividades pertinentes o al Programa de Desarrollo y Promoción de Mypes, por el cual se 
favorece el inicio de micro y pequeñas empresas por parte de los beneficiarios.

Antes de realizar la evaluación del impacto, desarrollado en el Capítulo 3, se especificará la composición de la organización la industria de la anchoveta, cuyos componentes son parte del análisis de indicadores del siguiente capítulo.

\subsubsection{Organización industrial}

La racionalidad para la pesca de la anchoveta se basa en la integración vertical de las empresas, siendo complementadas por agentes especializados también en el sector. Para observar esta integración vertical es necesario contar con un mapeo general de la industria y conocer la dinámica de esta.

Diagrama 2.4: Relación de los elementos que componen la organización industrial del sector pesquero

Recuso pesquero.

- INMARPE informa de los límites globales por temporadas y por zonas.

Plantas de procesamiento

- 202 harina

- 149 congelados

- 110 enlatado

- 48 curado

-99 servicios

complementarios
Embarcaciones pesqueras.

- Casco de madera

- Casco de acero

- Casco de vibra de vidrio

Compra del desembarque

- Productoras de

harina de pescado

- Productoras de

conserva de

pescado.

- Venta pescado

fresco.
Desembarque de pesca en 23 puertos:

- 16 puertos zona

norte-centro.

- 7 puertos zona sur.

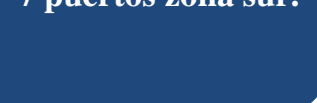

Fiscalización Produce

- Mecanismo de fiscalización en las

balanzas del puerto

(control de cuotas) y muestreo de tamaño peses (pesca de juveniles)

Fuente: PRODUCE,http://www.produce.gob.pe/index.php/servicios-en-linea/embarcaciones-pesqueras\#, revisado 17-mayo-2014 Elaboración: Propia 


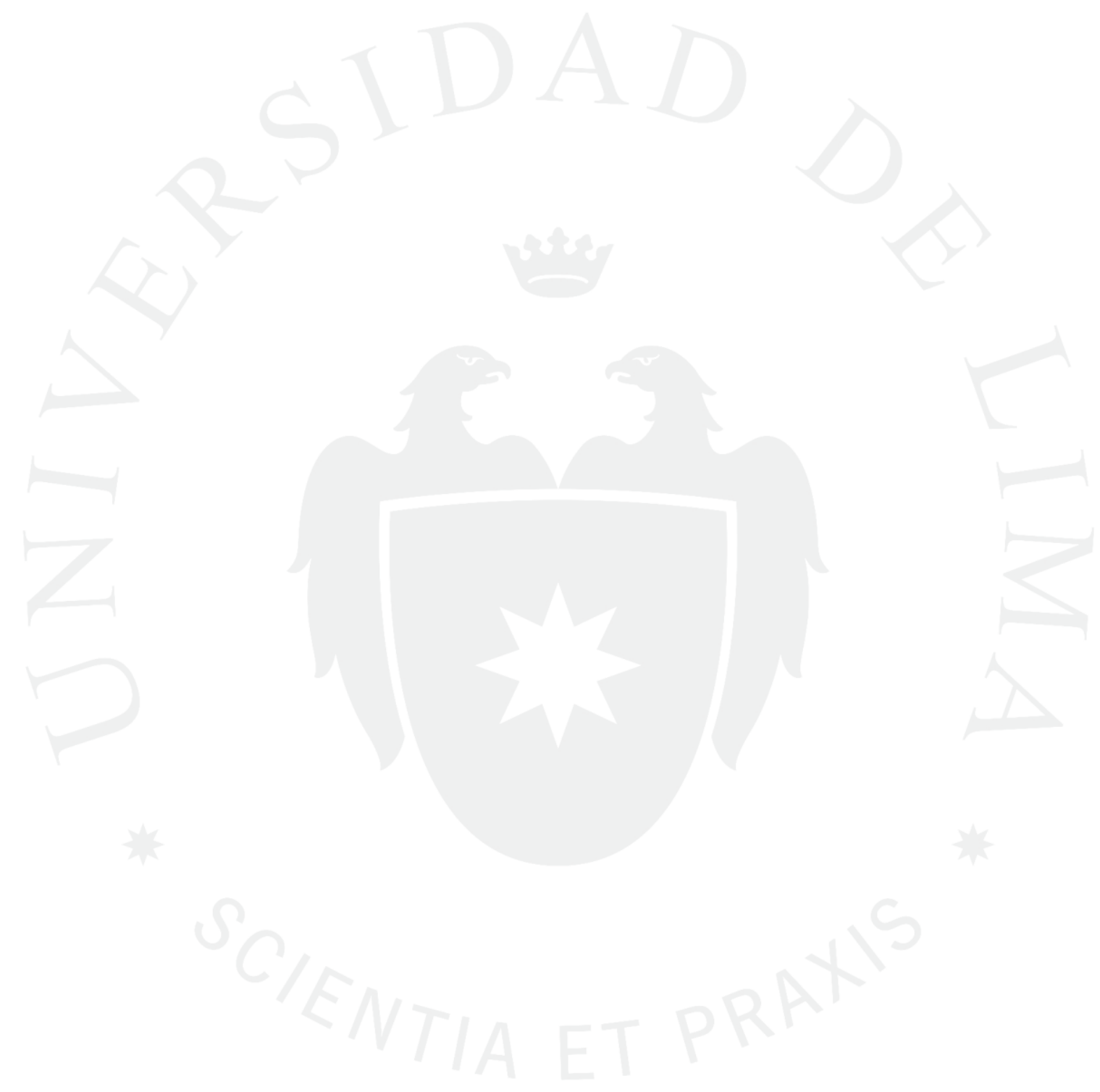




\section{a. Recurso pesquero}

La cadena productiva se inicia ante el anuncio del Produce, utilizando de insumo el informe técnico de IMARPE al inicio de la temporada de pesca, generalmente presentada en noviembre o diciembre. En este anuncio, IMARPE da a conocer la cuota global de anchoveta disponible para la pesca por parte de las embarcaciones de gran escala. En este sentido, la cuota global no significa que ese sea el total de peces en el océano, dado que siempre se intenta mantener un porcentaje de $10 \%$ en el mar peruano y otro porcentaje para la pesca de embarcaciones artesanales, pequeñas y medianas; las cuales no cuentan con cuota de pesca.

\section{b. Embarcaciones pesqueras}

Una vez presentado este anuncio por parte del IMARPE, las empresas que cuentan con embarcaciones pesqueras de mayor escala, consideradas como las embarcaciones que cuentan con una capacidad de bodega de más de $32.6 \mathrm{~m} 3$, organizan sus capacidades de pesca con el fin de ser lo más eficientes posibles.

En el mar peruano existen 984 embarcaciones con permisos de pesca, de las cuales 868 cuentan con cuotas de pesca tanto en la zona norte-centro como en la zona sur. Estas embarcaciones en promedio cuentan con una capacidad de bodega de $181 \mathrm{~m} 3$ por faena.

Tabla 2.1 : Nivel de embarcación nacional (2013)

\begin{tabular}{|c|c|c|}
\hline $\begin{array}{c}\text { Tipos de } \\
\text { embarcación }\end{array}$ & Cantidad & $\begin{array}{c}\text { Cap. de bodega } \\
\text { prom. } \\
\text { (en m3) }\end{array}$ \\
\hline Madera & 540 & 324.47 \\
\hline Acero Naval & 443 & 320.06 \\
\hline Fibra de Vidrio & 1 & 66.14 \\
\hline Total / Prom. & $\mathbf{9 8 4}$ & $\mathbf{1 8 0 . 7 2}$ \\
\hline
\end{tabular}

Fuente: PRODUCE, http://www.produce.gob.pe/index.php/servicios-en-linea/embarcaciones-pesqueras\#, revisado 17-mayo-2014 Elaboración: Propia

Aun cuando se conoce que de las 984 embarcaciones casi el $90 \%$ cuentan permiso para pescar en ambas zonas, es conveniente hacer el análisis de cada una de estas zonas, dado que 
es relevante conocer el estrés y las condiciones de pesca de cada una de estas zonas.

\section{- Embarcaciones Zona Norte-Centro}

Actualmente se cuenta con 968 embarcaciones de gran escala, distribuidas en 539 de casco de madera, 428 de casco de acero naval y 1 de casco de fibra de vidrio. Como se pude ver en el siguiente cuadro, las embarcaciones de acero naval cuentan en promedio con una mayor capacidad de bodega, siendo casi 5 veces más grandes que las de casco de madera.

Tabla 2.2 : Nivel De embarcación en la Zona Norte-Centro (2013)

\begin{tabular}{|c|c|c|}
\hline $\begin{array}{c}\text { Tipo de } \\
\text { embarcaciones }\end{array}$ & Cantidad & $\begin{array}{c}\text { Cap. de bodega } \\
\text { prom. } \\
\text { (en m3) }\end{array}$ \\
\hline Madera & 539 & 66.1 \\
\hline Acero Naval & 428 & 321.3 \\
\hline Fibra de Vidrio & 1 & 324.5 \\
\hline Total / Prom. & $\mathbf{9 6 8}$ & $\mathbf{2 3 7 . 3}$ \\
\hline
\end{tabular}

Fuente: PRODUCE, http://www.produce.gob.pe/index.php/servicios-en-linea/embarcaciones-pesqueras\#, revisado 17-mayo-2014 Elaboración: Propia

Adicionalmente, hay que considerar los mecanismos para preservar la captura en una faena diaria. Se observa que las embarcaciones de acero naval son las que poseen la mejor tecnología para preservar la anchoveta durante la faena con el sistema de preservación (Refrigerated Sea Water-RSW). Sin embargo, se observa también que, de manera global, la embarcación fibra de vidrio, que posee la mayor capacidad de pesca instalada en la industria, no cuenta con un sistema de preservación para la pesca de anchoveta.

Tabla 2.3 : Nivel de embarcaciones por sistema de preservación en la Zona Norte-Centro (2013)

\begin{tabular}{|c|c|c|c|c|c|}
\hline Sistema de preservación & RSW (1) & $\begin{array}{c}\text { CAJ/HIE } \\
\text { (2) }\end{array}$ & CSW (3) & N/P (4) & Total \\
\hline Acero Naval & 49,500 & 336 & 205 & 87,489 & $\mathbf{1 3 7 , 5 3 1}$ \\
\hline Fibra de Vidrio & & & & 324 & $\mathbf{3 2 4}$ \\
\hline Madera & & 22,306 & 66 & 13,256 & $\mathbf{3 5 , 6 2 8}$ \\
\hline Total & $\mathbf{4 9 , 5 0 0}$ & $\mathbf{2 2 , 6 4 3}$ & $\mathbf{2 7 1}$ & $\mathbf{1 0 1 , 0 7 0}$ & $\mathbf{1 7 3 , 4 8 3}$ \\
\hline
\end{tabular}

1: Sistema de refrigeración de agua de mar RSW.

2: Sistema de preservación Caja/Hielo.

3: Agua refrigerada.

4: No poseen.

Fuente: PRODUCE, http://www.produce.gob.pe/index.php/servicios-en-linea/embarcaciones-pesqueras\#, revisado 17-mayo-2014 
Elaboración: Propia

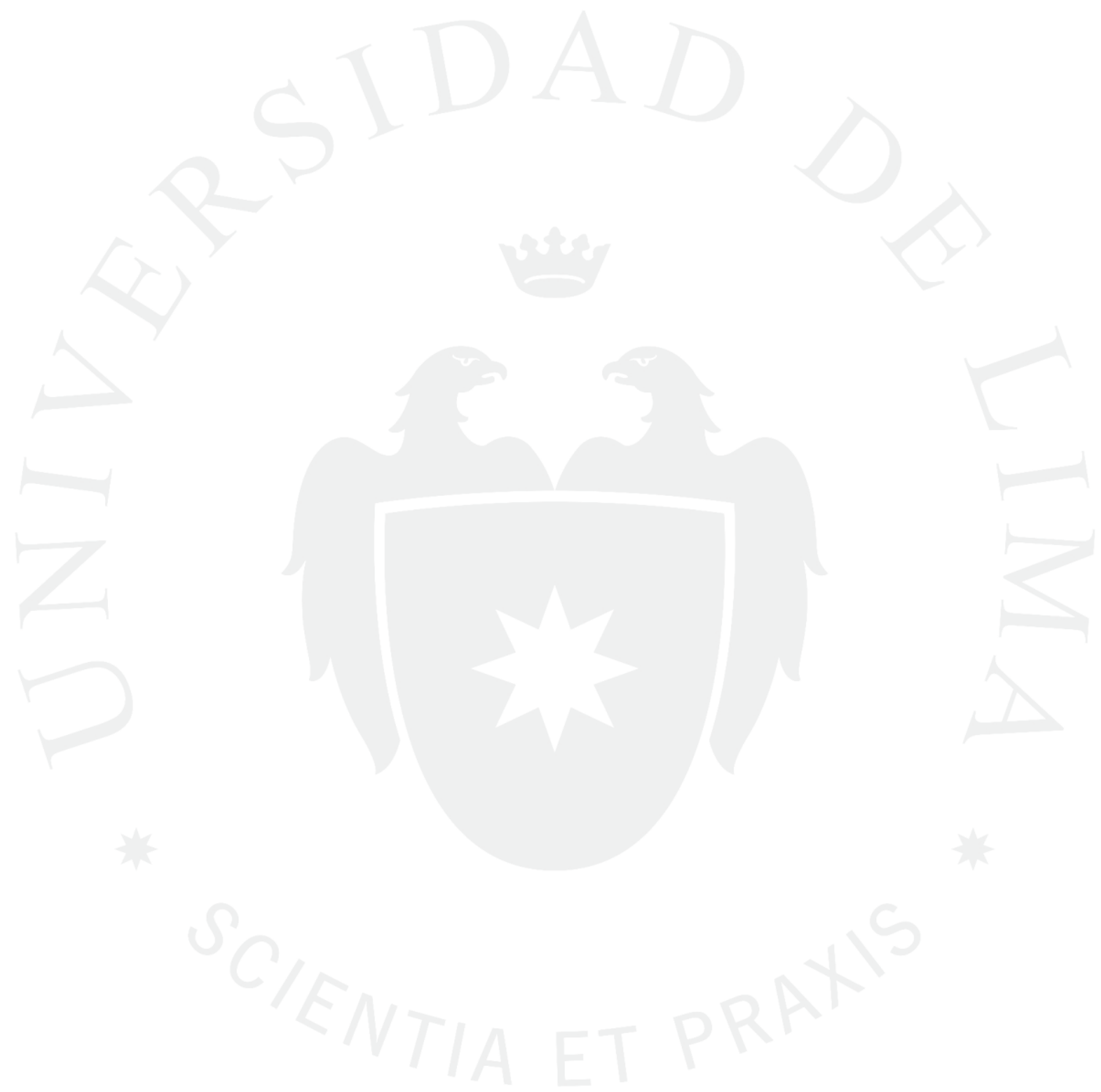


- Embarcaciones Zona Sur

En la zona sur se cuenta con 501 embarcaciones, de las cuales 378 son de acero naval, 122 de madera y 1 de fibra de vidrio. En total se cuenta con una capacidad de bodega total de $129,811 \mathrm{~m} 3$ y en promedio cada embarcación cuenta con 259 m3 de capacidad

Tabla 2.4 : Nivel de embarcaciones en la Zona Sur (2013)

\begin{tabular}{|l|c|c|}
\hline $\begin{array}{c}\text { Tipo de } \\
\text { embarcación }\end{array}$ & Cantidad & $\begin{array}{c}\text { Cap. de bodega } \\
\text { prom. } \\
\text { (en m3) }\end{array}$ \\
\hline Madera & 122 & 88.4 \\
\hline Acero Naval & 378 & 314 \\
\hline Fibra de Vidrio & 1 & 324 \\
\hline Total / Prom. & $\mathbf{5 0 1}$ & $\mathbf{2 5 9}$ \\
\hline
\end{tabular}

Fuente: PRODUCE, http://www.produce.gob.pe/index.php/servicios-en-linea/embarcaciones-pesqueras\#, revisado 17-mayo-2014 Elaboración: Propia

De estas embarcaciones, las de acero naval son las únicas que cuentan con un sistema de preservación RSW, mientras que las de madera cuentan con un gran porcentaje con sistema de preservación de cajas con hielo. Así como con las embarcaciones de permiso de la zona norte-centro, más del $50 \%$ de la capacidad de bodega instalada no cuenta con un sistema de preservación en la embarcación.

Tabla 2.5 : Nivel de embarcaciones por sistema de preservación en la Zona Sur (2013)

\begin{tabular}{|c|c|c|c|c|c|}
\hline Sistema de preservación & RSW (1) & $\begin{array}{c}\mathrm{CAJ} / \mathrm{HIE} \\
\text { (2) }\end{array}$ & CSW (3) & $\mathbf{N} / \mathbf{P}(4)$ & Total \\
\hline Acero Naval & 39,543 & 336 & 570 & 78,247 & 118,696 \\
\hline Fibra de Vidrio & & & & 324 & 324 \\
\hline Madera & & 6,929 & 66 & 3,795 & 10,790 \\
\hline Total & 39,543 & 7,266 & 636 & 82,367 & $\mathbf{1 2 9 , 8 1 1}$ \\
\hline $\begin{array}{l}\text { 1: Sistema de refrigeración de agua } \\
\text { 2: Sistema de preservación Caja/Hi } \\
\text { 3: Agua refrigerada. } \\
\text { 4: No poseen. }\end{array}$ & mar RSW. & & & & \\
\hline
\end{tabular}




\section{c. Desembarque de pesca en puertos}

En la zona norte-centro se encuentran 16 puertos pesqueros que reciben a las 968 embarcaciones que cuentan con permisos de pesca en dicha zona. Mientras siete puertos están ubicados en la zona sur, y reciben a las 501 embarcaciones con permisos de pesca para dicha zona.

Se debe tener en consideración que la importancia de estos puertos es la capacidad de recibir los desembarques de las embarcaciones y evitar la comercialización de juveniles, evitar la venta de pesca destinada de CHD a CHI; todo esto dentro de un rango geográfico de acción que permita un sistema de transporte eficiente y que disminuya la merma de peces desde el puerto a la planta de procesamiento.

En este sentido, los cuadros anteriores demuestran la poca capacidad de las embarcaciones de conservar en buen estado los peces capturados, por lo que se debe tener en cuenta que toda la labor de conserva se da desde el puerto hacia las plantas de procesamiento, siendo ello un posible sobre costo para las empresas procesadoras.

En el Perú se encuentra muy marcado el desarrollo pesquero por zonas geográficas, siendo justamente la zona norte centro la más importante. Esta representa el $90 \%$ de los desembarques de anchoveta para harina de pescado, mientras que solo 105 se encuentra en la zona sur. En este sentido, se deriva que los 16 puertos de dicha zona soportan el 3,2 millones de toneladas en la 1ra temporada en promedio mientras que siete puertos de la zona sur soportan 400 mil toneladas. Se puede observar en el siguiente gráfico cómo es que dentro de la zona norte-centro los puertos más importantes son Chicama y Chimbote, ambos con casi $16 \%$ de participación en los desembarques. Así mismo, se observa la importancia de Casma y el Callao, los cuales se pueden entender que sean importantes dado la cercanía a la capital. Por último, se observa que el puerto de Pisco se encuentra entre los más 
importantes, lo cual puede suponer que sea el nexo entre la zona sur con la zona centro.

Gráfico 2.27 : Desembarques de anchoveta por puerto al 2013 (en TM y porcentajes)

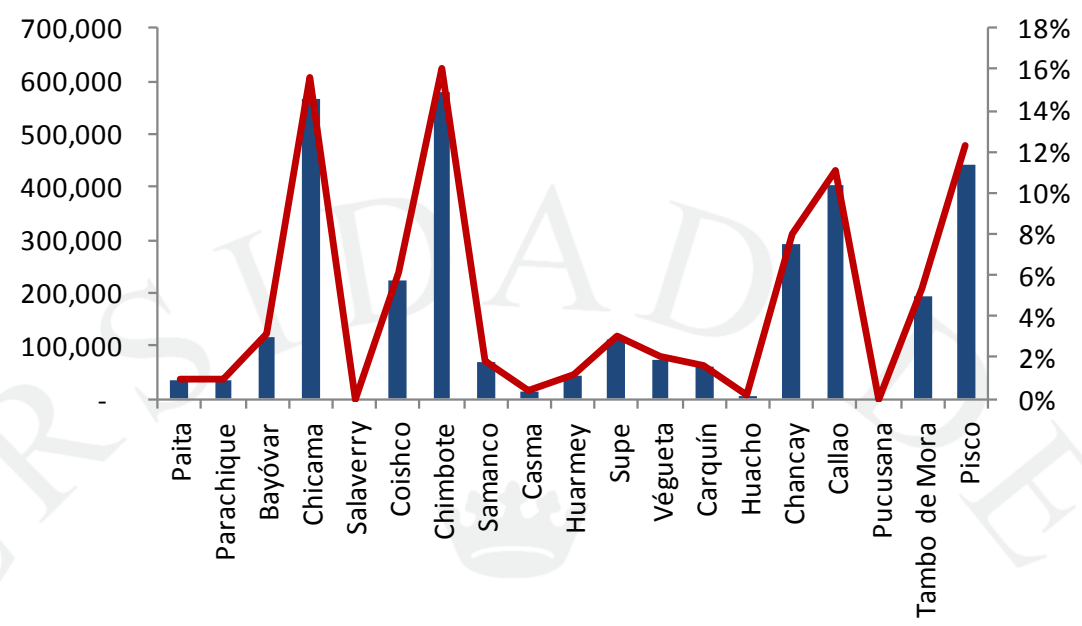

Fuente: PRODUCE, http://www.produce.gob.pe/index.php/servicios-en-linea/embarcaciones-pesqueras\#, revisado 17-mayo-2014 Elaboración: Propia

En la zona sur, la dinámica es muy marcada, siendo el puerto de Ilo el más importante con una participación del $4 \%$ del desembarque nacional. En menor medida destacan Atico y La Planchada, lo cual debe estar asociado a la presencia de plantas industriales en la zona.

Gráfico 2.28 : Desembarques de anchoveta por puerto al 2013 (en TM)

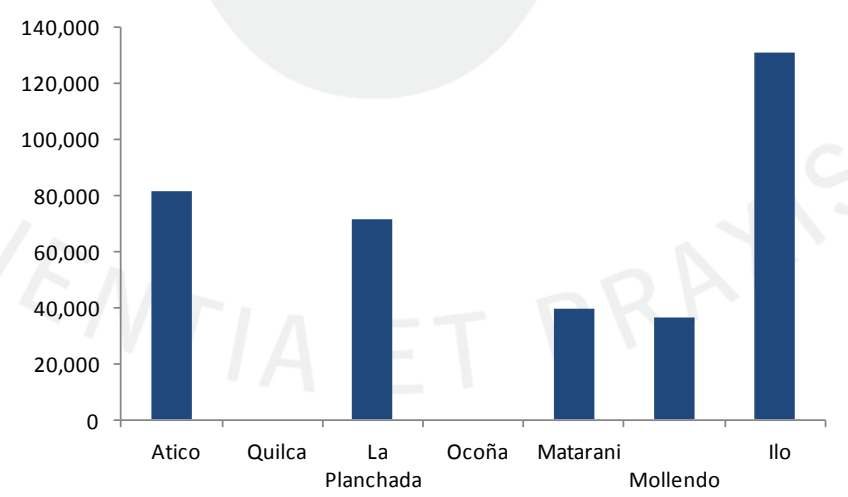

Fuente: PRODUCE, http://www.produce.gob.pe/index.php/servicios-en-linea/embarcaciones-pesqueras\#, revisado 17-mayo-2014 Elaboración: Propia 


\section{d. Plantas de procesamiento}

La compra del desembarque realizado en los diferentes puertos pesqueros, se realiza en gran medida por las empresas que cuentan con plantas de procesamiento de la anchoveta. Estas plantas se distribuyen en:

1. Harineras

2. Productos congelados

3. Productos curados

4. Productos congelados

5. Servicios complementarios

Con información de PRODUCE a mayo 2014, existen 638 plantas de procesamiento de pescados, básicamente anchoveta. De estas, 78 plantas realizan el servicio de curado, 99 brindan servicios complementarios de lavado de peses y cortado, 110 servicio de enlatado, 149 servicio de congelado, y 202 plantas son harineras.

Del total de plantas instaladas se observa una gran predominancia en Piura, Anchas e Ica. Esto va acorde con lo expresado con los niveles de desembarque por puerto, siendo razonable entender que la utilización de un puerto u otro depende de la ubicación de las plantas de procesamiento.

Gráfico 2.29 : Número de plantas de procesamiento por departamento y por tipo de producto

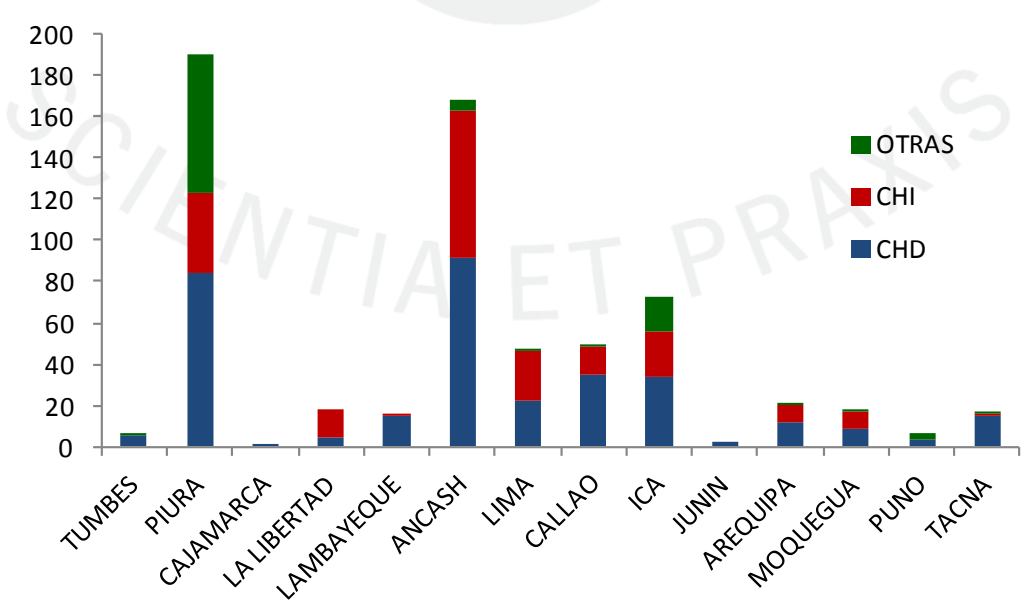

Fuente: PRODUCE, http://www.produce.gob.pe/index.php/servicios-en-linea/embarcaciones-pesqueras\#, revisado 17-mayo-2014 Elaboración: Propia 


\section{e. Armadores}

Para concluir el contexto de la organización industrial, que hasta el momento se ha detallado al corte de 2013, en el gráfico 2.30 y 2.31 se aprecia la evolución de los armadores (independientes y por empresas) que son quienes dan la dinámica a este sector.

En estos gráficos se muestra que el número de armadores presenta una fuerte tendencia a la baja a partir de 2008, que se estabiliza alrededor de 2012. Dentro de los principales grupos (en términos de número de embarcaciones) a inicios del periodo el Grupo de Sindicato Pesquero contaba con la mayor participación, lo cual se revirtió de forma tal que al cierre de 2013 no forman parte del conjunto de armadores. Es decir, la organización industrial ha presenciado una reestructuración en su composición a partir de 2008, coincidente con la promulgación del LMCE, soportado por el RISPAC y basado en los lineamientos de la Ley General de Pesca.

Gráfico 2.30 : Evolución del número de armadores

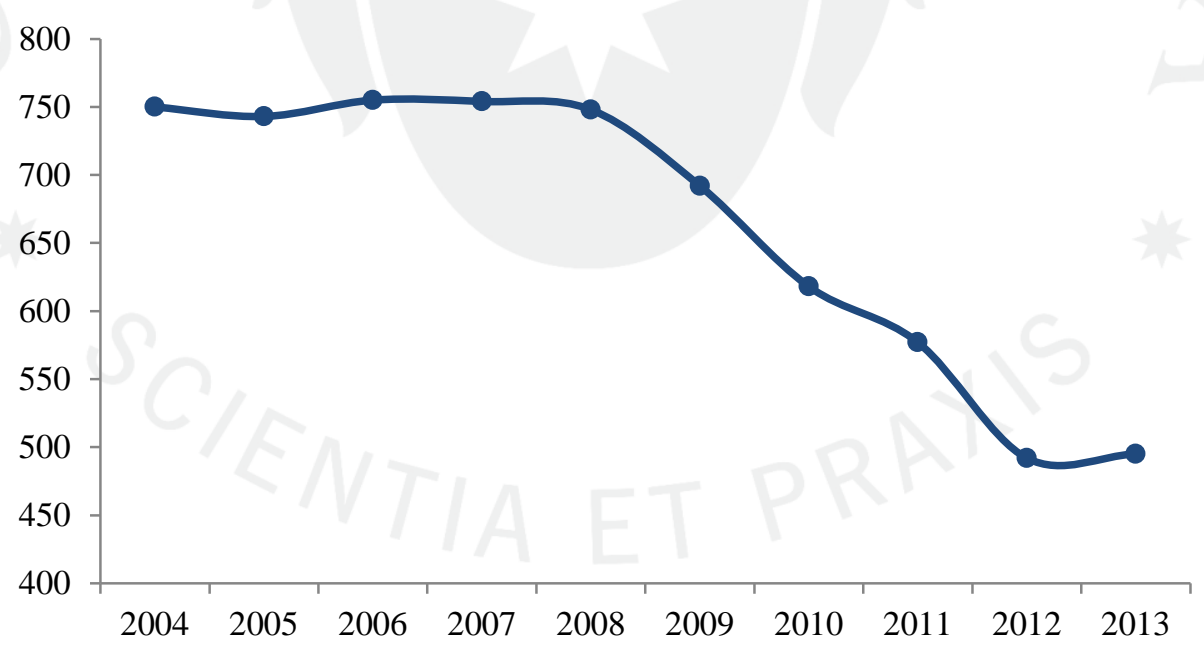

Fuente: PRODUCE, http://www.produce.gob.pe/index.php/servicios-en-linea/embarcaciones-pesqueras\#, revisado 17-mayo-2014 
Gráfico 2.31 : Evolución del número de embarcaciones por armador

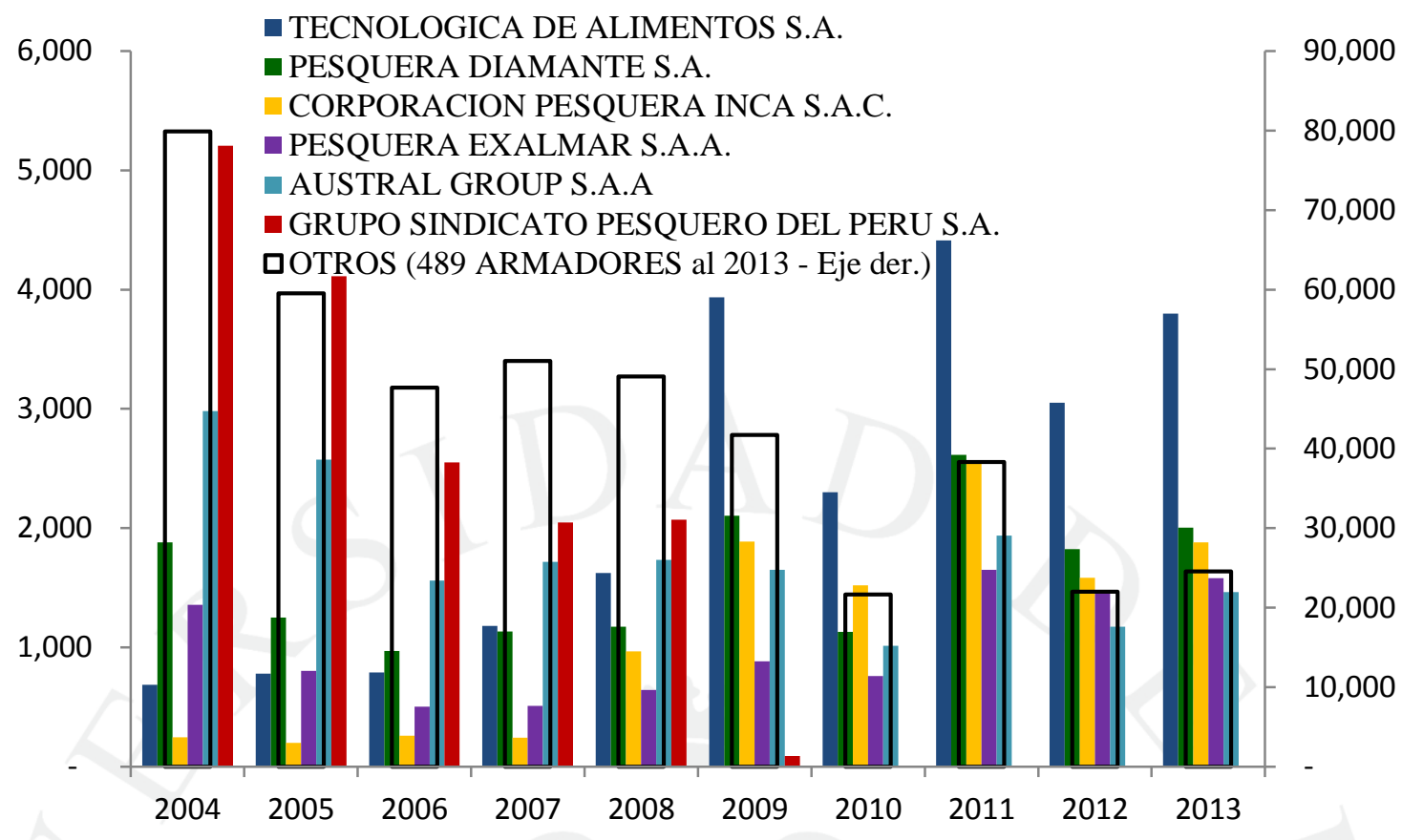

Fuente: PRODUCE, http://www.produce.gob.pe/index.php/servicios-en-linea/embarcaciones-pesqueras\#, revisado 17-mayo-2014

Debido a que la normativa detallada dentro de la organización institucional impacta en la dinámica de la organización industrial, puesto que afecta las decisiones de los productores, en el capítulo siguiente se evalúa dicho impacto en términos de eficiencia económica en base al marco conceptual y teórico detallado en el capítulo 1; es decir, según su impacto en el esfuerzo pesquero, distribución y sostenibilidad del recurso. 


\section{CAPÍTULO III: EVALUACIÓN DE EFICIENCIA EN LA DINÁMICA PESQUERA DE LA ANCHOVETA}

Para determinar el impacto de la normativa en la eficiencia económica, el análisis se descompone en la evaluación del impacto sobre sus sub-variables (esfuerzo pesquero, distribución y sostenibilidad).

En el análisis del esfuerzo pesquero y sostenibilidad se emplea la evolución de un conjunto de indicadores, mientras que en el caso de distribución se emplea la metodología de Valor Agregado (VA).

\subsection{Esfuerzo Pesquero}

El esfuerzo pesquero hace referencia al nivel de los factores de producción empleados en el sector. Para determinar si el impacto de la normativa sobre sobre dichos factores fue positivo, no basta con que los niveles asociados se reduzcan, sino que tiene que estar relacionado a la evolución de la pesca del recurso. Es decir, el impacto será positivo si los niveles de factores de producción se reducen mientras la cantidad pescada del recurso se incrementa o se mantiene en el tiempo; y, análogamente, si el esfuerzo pesquero se mantiene en el tiempo y el la cantidad pescada incrementa, esto último sujeto a la disponibilidad del recurso (biomasa).

Los principales factores de producción del sector están constituidos por el tiempo destinado a la actividad, las plantas de procesamiento, las embarcaciones y los trabajadores. En tal sentido, se ha asignado un sistema de indicadores en función a la relación del nivel de estos factores de producción y su productividad. 
En el caso de las plantas de procesamiento, la data asociada al recurso es el de la capacidad, entendida como el nivel máximo de procesamiento. En el caso de las embarcaciones y el tiempo empleado, la productividad es el desembarque de la anchoveta. En términos del nivel de empleados, se analiza la efectividad del programa del FONCOPES.

Tabla 3.1 : Relación de factores de producción e indicadores

\begin{tabular}{|l|l|}
\hline \multicolumn{1}{|c|}{ Factor } & \multicolumn{1}{c|}{ Indicadores } \\
\hline Tiempo & Desembarque por día de pesca \\
\hline Planta & Promedio de capacidad por planta según tipo de producto \\
\hline Embarcación & $\begin{array}{l}\text { Capacidad promedio disponible de pesca por embarcación vs número de } \\
\text { embarcaciones. }\end{array}$ \\
\hline Empleo & Nivel de efectividad del programa FONCOPES \\
\hline \multicolumn{2}{|l}{ Elaboración: Propia }
\end{tabular}

\subsubsection{Desembarque por día de pesca}

La relación del desembarque anual de anchoveta y los días de pesca anual representa la productividad promedio anual por día de pesca en términos de desembarque de anchoveta.

Este indicador resulta útil para evaluar la evolución de la llamada carrera olímpica experimentada en el sector, puesto que esta se expresa como la saturación del desembarque de anchoveta en un número reducido de días de pesca.

Este escenario resulta sub-óptimo porque implicaría el sobredimensionamiento o sobreutilización de la flota de embarcaciones $\mathrm{y}$, consecuentemente, el desatender las inversiones necesarias en el aspecto de procesamiento, tal cual se expresó en la carrera olímpica (década de 1970).

Como se puede apreciar en el gráfico 3.1, el nivel del desembarque a lo largo del periodo de estudio responde al comportamiento de la biomasa del recurso, con un coeficiente de correlación de $99.98 \%$. Por otro lado, los días de pesca anuales presentan un comportamiento diferenciado, creciendo durante el periodo 2009-2013 a una tasa compuesta anual de $11 \%$. Esto se evidencia notablemente en el indicador, el cual muestra volatilidad previo al 2008 y en adelante una fuerte reducción tras la cual se observa un nivel estacionario. 
Tomando en cuenta que el RISPAC y el LMCE entran en vigencia en el año 2007 y 2008 respectivamente, los resultados sugieren que el limitar de forma efectiva la captura por embarcación redujo significativamente los incentivos que generan la carrera olímpica y así el esfuerzo de pesquero se distribuyó de forma más eficiente en las temporadas de pesca.

Gráfico 3.1 : Evolución de la Biomasa y Desembarque de anchoveta (en millones de toneladas)

12000

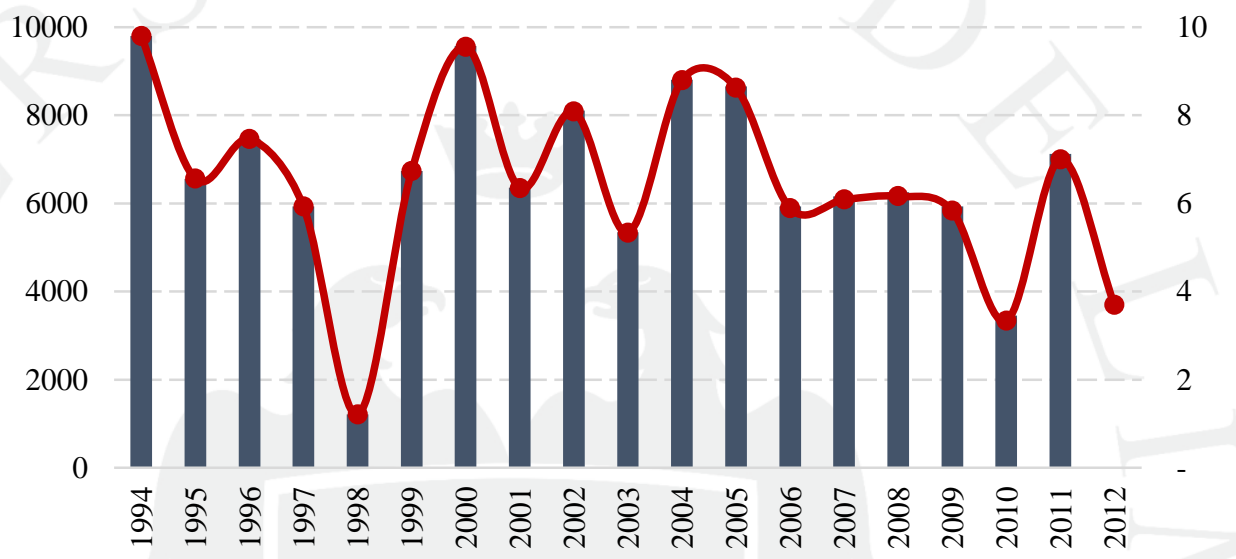

Biomasa $\longrightarrow$ Desembarque (eje derecho)

Fuente: FAO, http://www.produce.gob.pe/index.php/servicios-en-linea/embarcaciones-pesqueras\#, revisado 03-mayo-2014 y PRODUCE, revisado 03-junio-2014

Gráfico 3.2 : Evolución del desembarque de anchoveta y los días de pesca

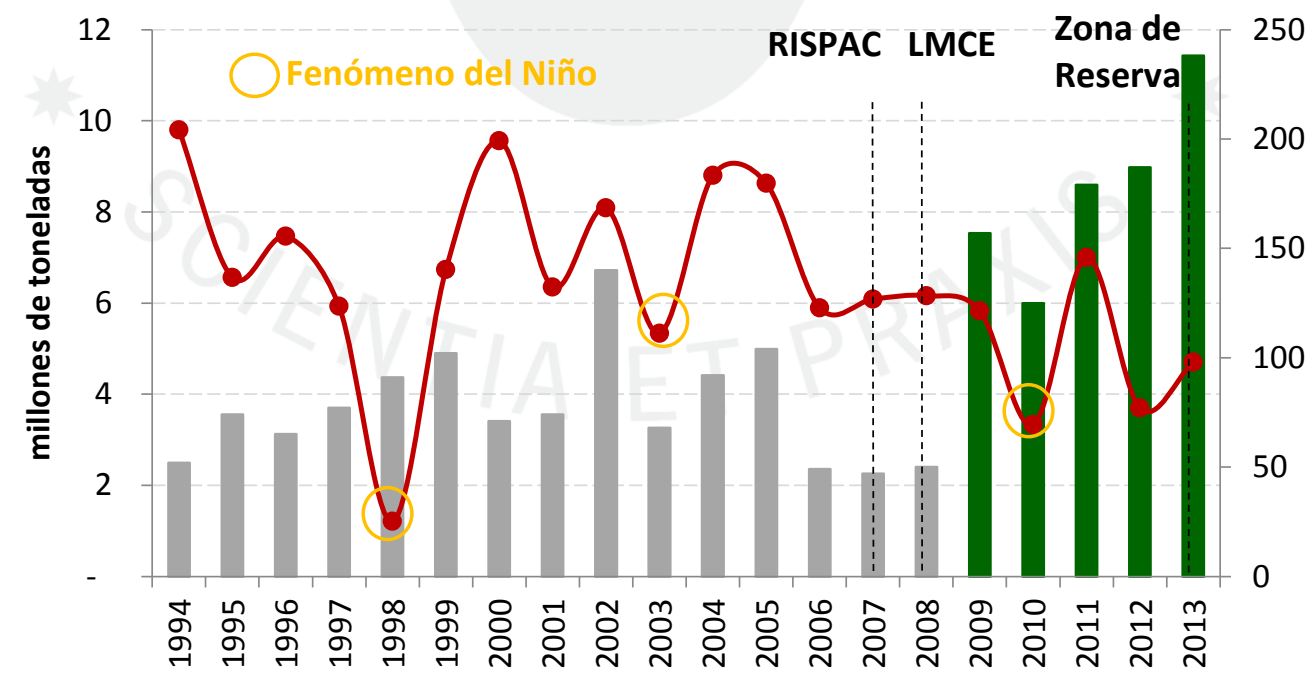

Días de pesca previo al RISPAC y LMCE (eje derecho) $\longrightarrow$ Desembarque 
Gráfico 3.3 : Evolución del desembarque por día de pesca

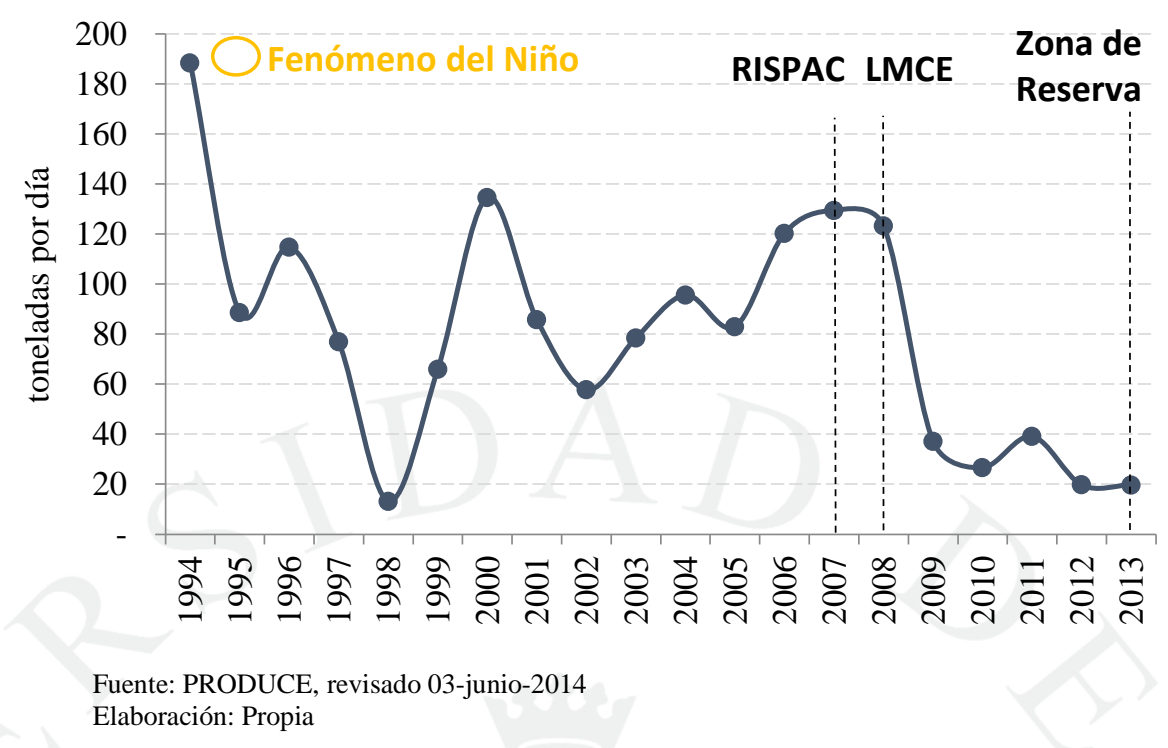

\subsubsection{Planta: Promedio de capacidad por planta según tipo de producto}

Las plantas de procesamiento de anchoveta se distinguen según el producto final al cual se destinan. Debido a las diferencias en su procesamiento, la capacidad de planta se mide en escalas distintas. Es así que el análisis de este indicador se segmentará en la capacidad de la planta de enlatado, medida en turno por ocho horas; de congelado, medida en toneladas por día; de curado, medida en tonelada por mes; y de harina de pescado, medida en tonelada por hora.

\section{a. Enlatado}

El indicador presenta una tendencia creciente a los largo del periodo, basado en el crecimiento nulo de la capacidad de planta y una tasa anual compuesta de $-3 \%$ en el caso del número de plantas. Debido al alto crecimiento del nivel de biomasa en el periodo 1991-1994, a 1994 el nivel de capacidad de planta presenta un crecimiento de $42 \%$ respecto a 1993 , más que proporcional al crecimiento de del número de plantas ubicado en $24 \%$.

Análogamente, en el periodo 1995-2000 se observa una tasa compuesta de crecimiento anual de $8 \%$ para capacidad de planta y de $-3 \%$ del número de plantas; con lo que la base de la capacidad asociado a tecnología o expansión de plantas se incrementa. 
En los siguientes siete años, ambas variables presentan una tendencia descendente, siendo la del número de plantas de mayor nivel; es decir, el impacto de la reducción de plantas sobre la capacidad de planta fue menos que proporcional a su evolución.

Durante el periodo 2009-2012, ambas variables perciben un crecimiento anual compuesto de $2 \%$, por lo que el indicador se estabiliza. En este caso, no se percibe un impacto notorio de la normativa pesquera.

Gráfico 3.4 : Evolución del promedio de capacidad por planta de enlatado (turno por 8 horas por planta)

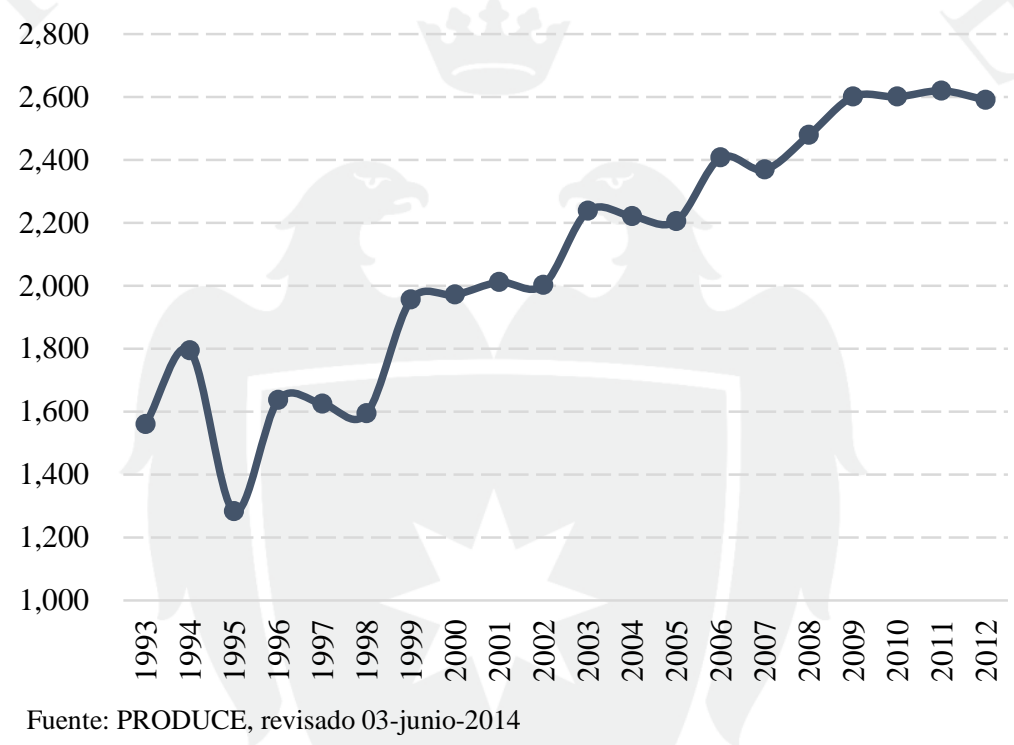

Gráfico 3.5 : Evolución de la capacidad de planta y número de plantas de enlatado

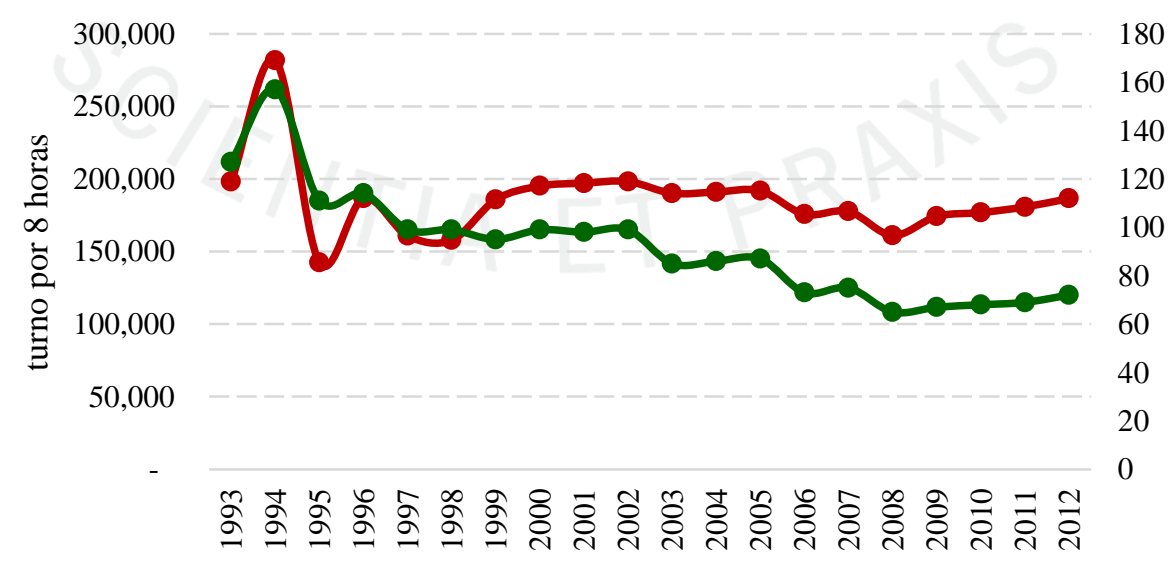

$\longrightarrow$ Capacidad de planta $\quad \longrightarrow$ Número de plantas (eje derecho)

Fuente: PRODUCE, revisado 03-junio-2014 


\section{b. Congelado}

El indicador presenta una tendencia alcista, puesto que el crecimiento de la capacidad de planta es más que proporcional al crecimiento del número de plantas a partir de 1995, tras presentar un crecimiento semejante en 1994.

El indicador no muestra un impacto notorio de la normativa pesquera.

Gráfico 3.6 : Evolución del promedio de capacidad por planta de congelado (tonelada por día por planta)

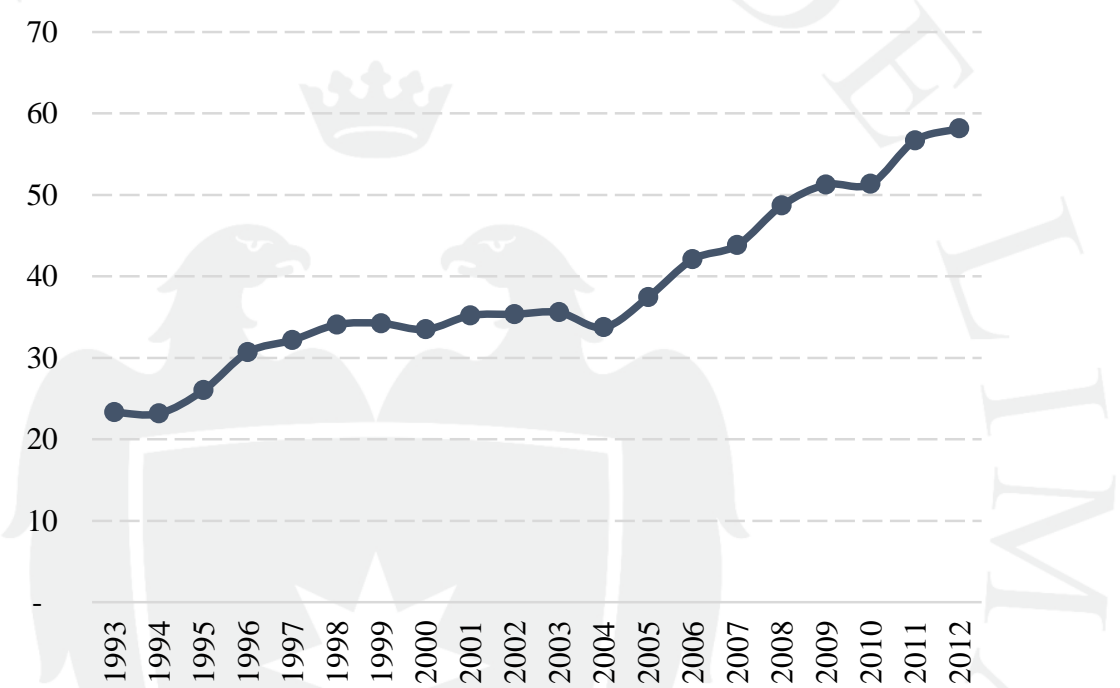

Fuente: PRODUCE, revisado 03-junio-2014

Gráfico 3.7 : Evolución de la capacidad de planta y número de plantas de congelado

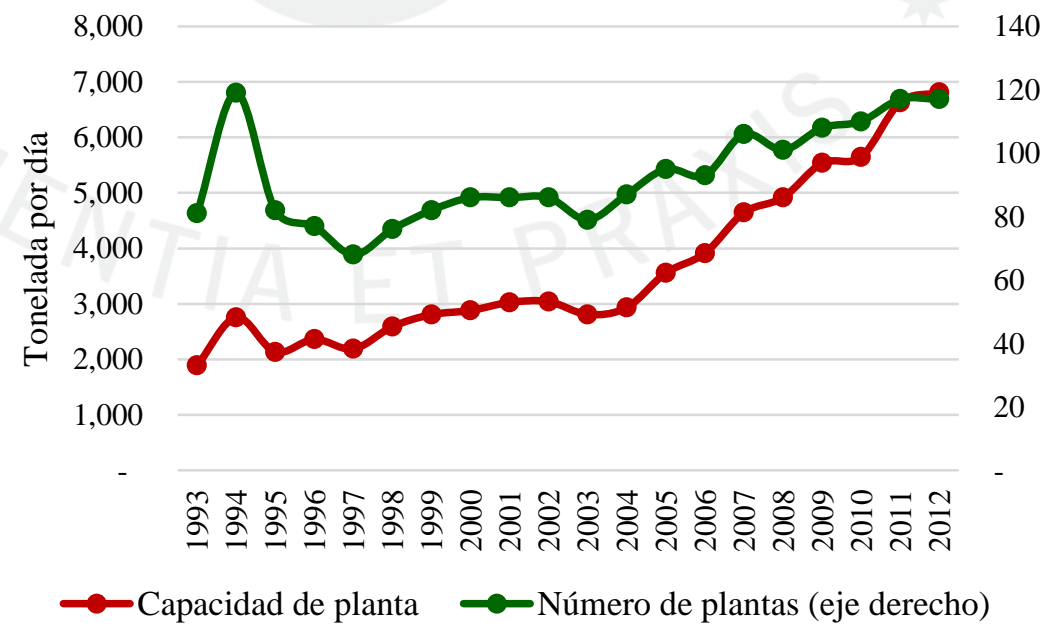

Fuente: PRODUCE, revisado 03-junio-2014 


\section{c. Curado}

El indicador presenta una tendencia ascendente, basada en el crecimiento de la capacidad de planta a una tasa anual compuesta de 10\%; mientras que el número de plantas presenta un $-1 \%$. Incluso en los periodos crecientes del número de plantas (1994 y 2006-2012), el crecimiento de la capacidad fue mayor.

Gráfico 3.8 : Evolución del promedio de capacidad por planta de curado (tonelada por mes por planta)

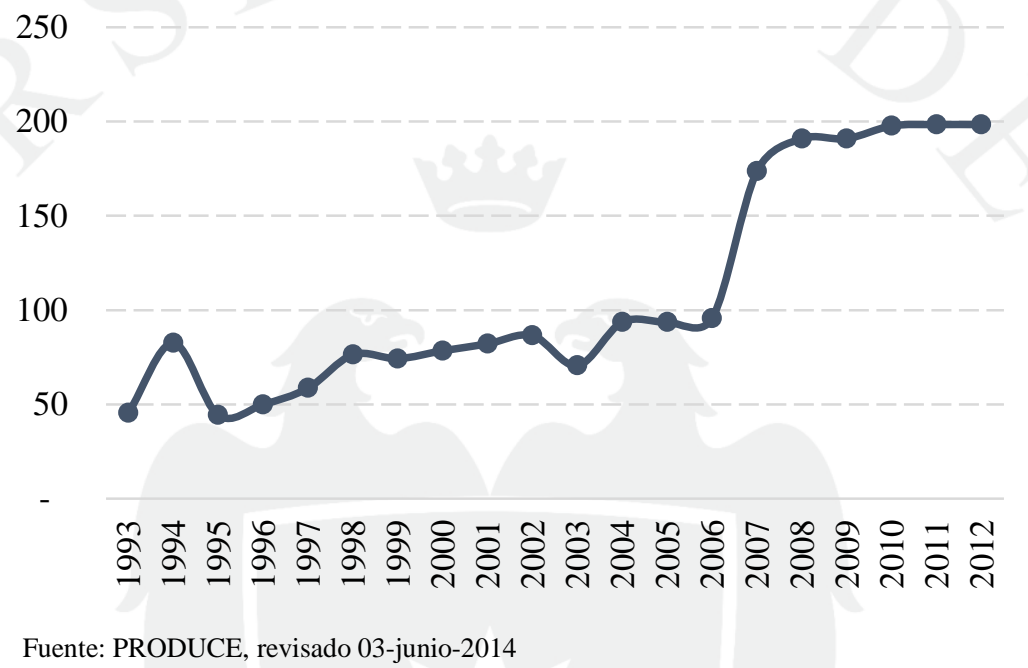

Gráfico 3.9 : Evolución de la capacidad de planta y número de plantas de curado

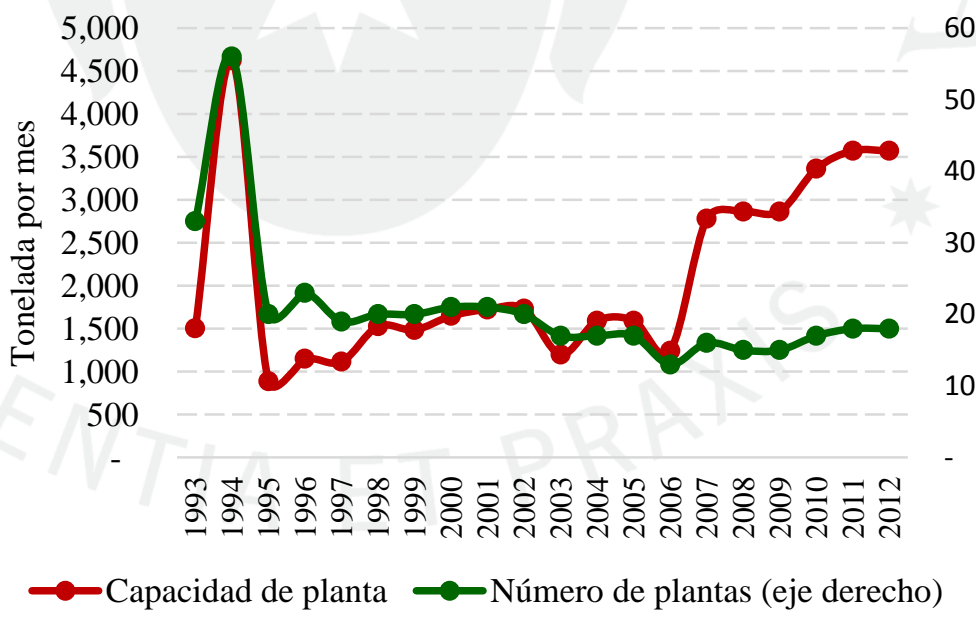

Fuente: PRODUCE, revisado 03-junio-2014 


\section{d. Harina de Pescado}

El indicador presenta una tendencia creciente hasta 1996, puesto que el crecimiento de la capacidad de planta es más que proporcional al crecimiento del número de plantas. En adelante, el número de plantas presenta una tasa de crecimiento anual compuesta de $2 \%$; mientras que la capacidad de planta presenta $0 \%$, por lo que el indicador presenta una ligera tendencia a la baja. Esta evolución estable sugiere que la estructura de las plantas de procesamiento harineras ha alcanzado un estado de equilibrio.

Gráfico 3.10 : Evolución del promedio de capacidad por planta de harina de pescado (tonelada por hora por planta)

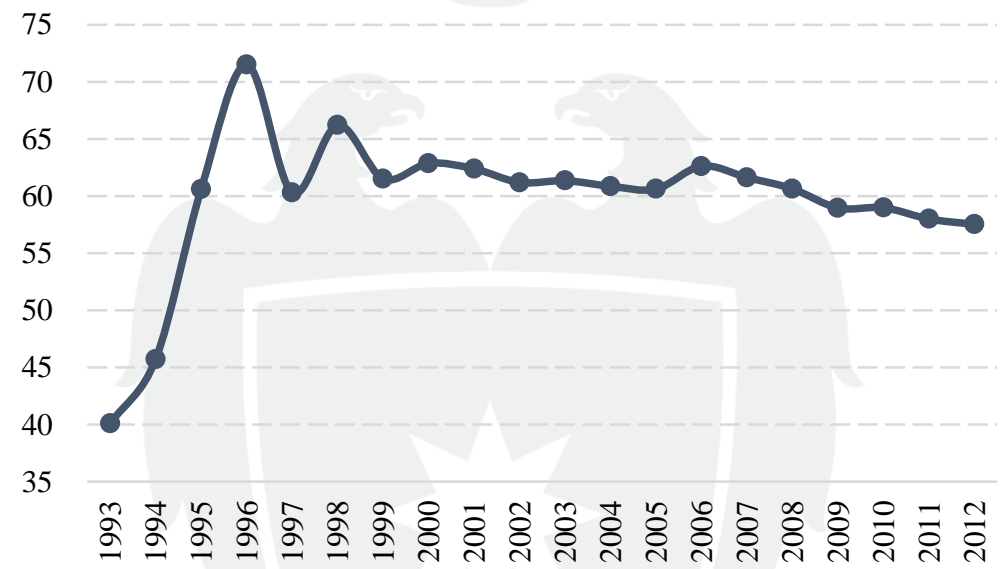

Fuente: PRODUCE, revisado 03-junio-2014

Gráfico 3.11 : Evolución de la capacidad de planta y número de plantas de harina de pescado

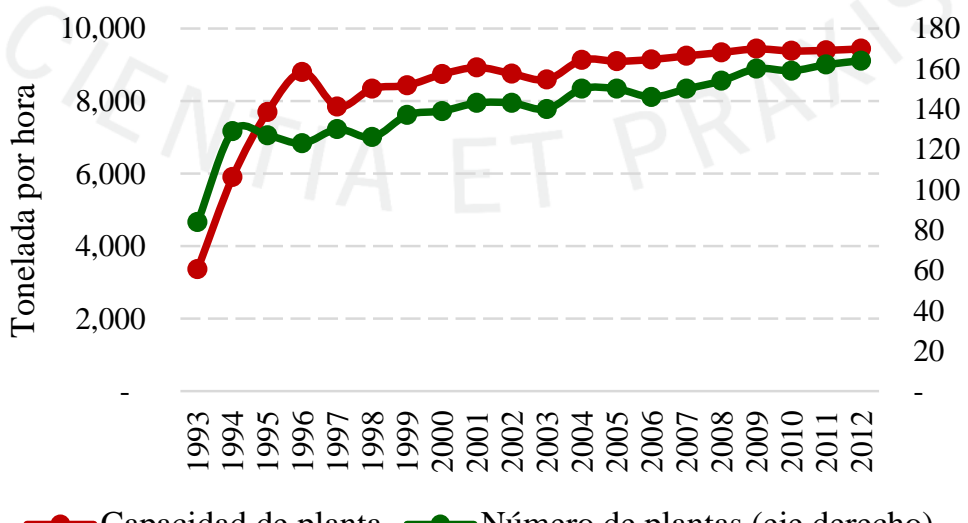

Fuente: PRODUCE, revisado 03-junio-2014 


\section{e. Análisis conjunto}

Para el periodo 1993-2012, la tasa compuesta de crecimiento anual de la capacidad de planta de cada tipo de producto es superior a la del número de plantas, generando el crecimiento de la capacidad por planta.

Este comportamiento sugiere que hay una mejora tecnológica en estos rubros y/o ampliaciones de las plantas existentes.

Tabla 3.2 : Tasa compuesta de crecimiento anual del promedio de capacidad por planta y sus componentes según producto (1993-2013)

\begin{tabular}{|c|c|c|c|}
\cline { 2 - 4 } & $\begin{array}{c}\text { Prom. Capacidad } \\
\text { por planta }\end{array}$ & $\begin{array}{c}\text { Capacidad de } \\
\text { planta }\end{array}$ & $\begin{array}{c}\text { Número de } \\
\text { plantas }\end{array}$ \\
\hline Enlatado & $3 \%$ & $0 \%$ & $-3 \%$ \\
\hline Congelado & $5 \%$ & $7 \%$ & $2 \%$ \\
\hline Curado & $8 \%$ & $5 \%$ & $-3 \%$ \\
\hline Harina de Pescado & $2 \%$ & $6 \%$ & $4 \%$ \\
\hline
\end{tabular}

Fuente: PRODUCE, revisado 03-junio-2014

Gráfico 3.12 : Evolución del promedio de capacidad por planta según producto

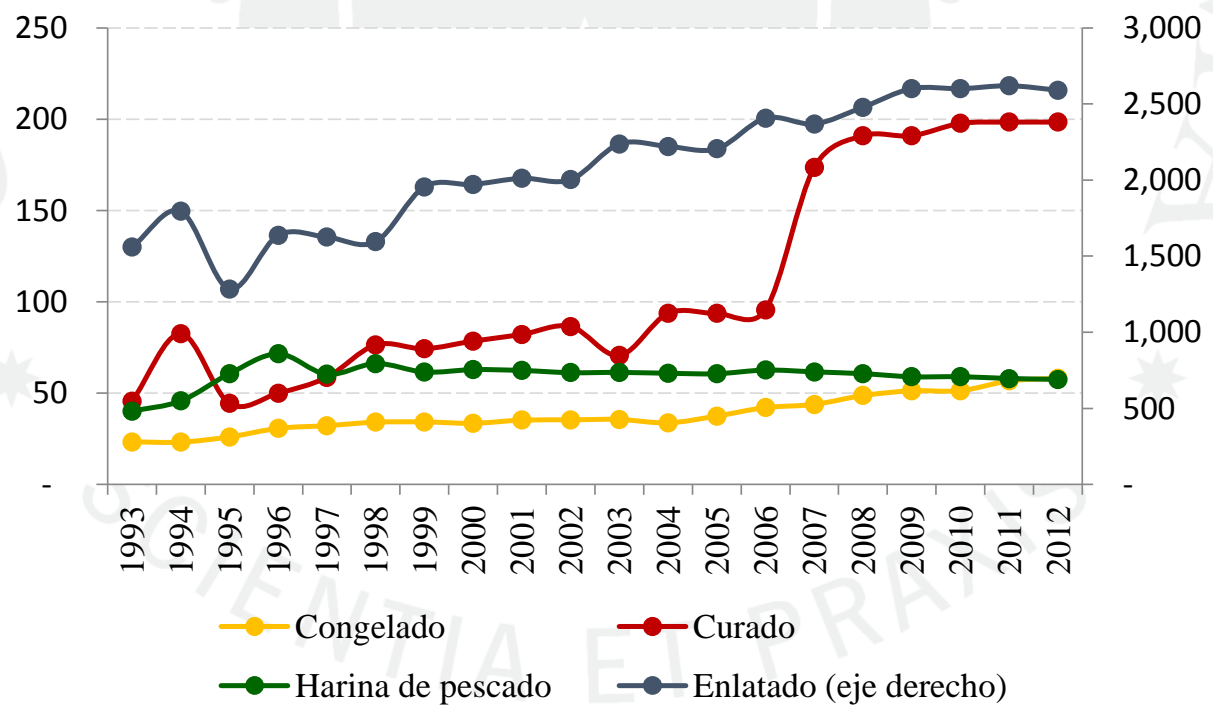

Fuente: PRODUCE, revisado 03-junio-2014 


\subsubsection{Embarcaciones: Capacidad promedio disponible de pesca por embarcación}

La relación del número de embarcaciones nominadas que zarpan anualmente de por sí es un indicador potente para poder observar el impacto de las normativas en el sector. Independientemente de ello, se evalúa la relación entre el número de embarcaciones nominadas y la disponibilidad de carga de estas embarcaciones en promedio.

Gráfico 3.13 : Capacidad promedio disponible de pesca por embarcación vs número de embarcaciones

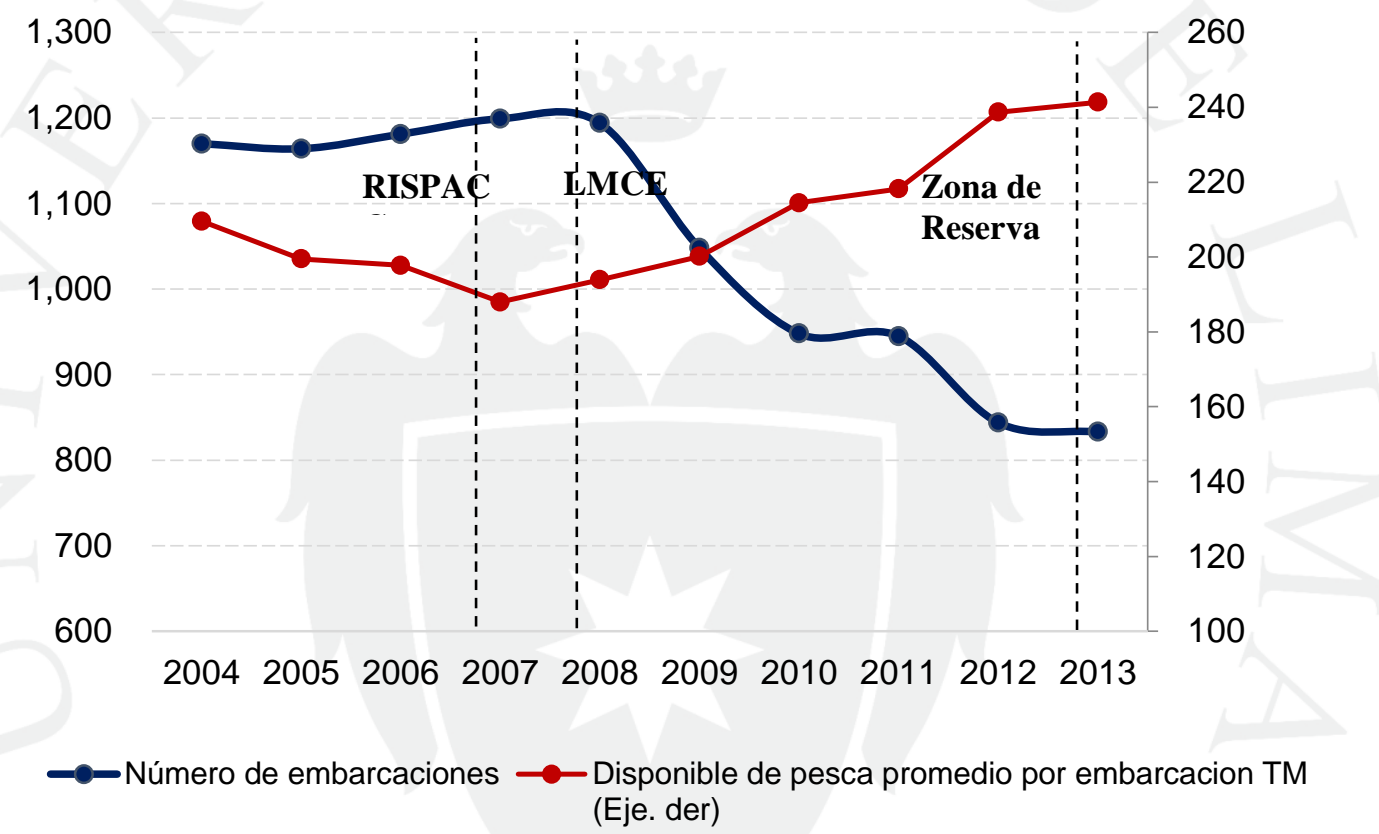

Fuente: PRODUCE, revisado 03-junio-2014

Queda claro que existe un impacto importante en el número de embarcaciones nominadas. Esto no solo es reflejo de la caída de embarcaciones entre el año 2008 al año 2009, sino que se observa que había un incremento de embarcaciones entre el año 2004 al 2008, mientras que desde el 2008 al 2013 cada año se reduce el número de embarcaciones. 
Por otro lado, se observa una reducción sostenida de la disponibilidad promedio de pesca por embarcación desde el 2004 al año 2007 y a partir de ese año empieza a incrementarse anualmente hasta el 2013. Esto último, si bien no se encontraba como parte de objetivo de la normativa, se desprende que fue un efecto de ella, dado que para mantener niveles de pesca en función a la biomasa disponible es más eficiente contar con menores embarcaciones con capacidades más holgadas, disminuyendo así la posible merma en el almacenaje de la anchoveta. Esta relación cuenta con mucho sentido en la posible decisión del armador.

Es decir, la asignación de cuotas por embarcación, contemplada en el LMCE y reforzada por el RISPAC, al desincentivar la "carrera olímpica", modalidad de pesca utilizada en la década de 1970 mediante la cual se saturaba del desembarque de anchoveta en un número reducido de días, ha reducido el sobredimensionamiento de la flota de embarcaciones.

\subsubsection{Nivel de efectividad del programa FONCOPES}

El Decreto Legislativo $\mathrm{N}^{\mathrm{o}} 1084$ introdujo una serie de incentivos para motivar la salida voluntaria de los trabajadores corrigiendo los excesos de capacidad instalada, tal como se vio en la cantidad de embarcaciones. En este sentido, se introdujo la creación del Fondo de Compensación para el Ordenamiento Pesquero (FONCOPES) como estrategia para canalizar los beneficios de estos incentivos.

El objetivo de FONCOPES es financiar los Programas de Beneficios creados mediante el Decreto Legislativo $N^{\circ} 1084$, dirigidos exclusivamente a trabajadores cuya embarcación cuente con permiso de pesca vigente.

El impacto de FONCOPES debería evaluarse respecto a indicadores agregados de bienestar social como empleo o ingresos. Por la falta de información relevante así como el poco tiempo transcurrido (ya que los efectos deben madurar) no es posible realizar una evaluación como esta. De este modo, este indicador se limita a reportar y analizar algunos resultados operativos identificados e intuir la dirección de algunos otros efectos. 
Respecto a los impactos a nivel operativo del programa, destaca que de 2,049 trabajadores renunciantes, 1,743 son atendidos por Foncopes, de los cuales 1,089 reciben asesoría, 1,066 se acogen a itinerarios formativos y 865 son matriculados en talleres educativos (FONCOPES).

El proceso de baja de las embarcaciones determina una serie de opciones para los trabajadores asociados a estas. La primera decisión que adoptan los trabajadores de una embarcación dada de baja es o bien renunciar voluntariamente y optar por los esquemas de beneficios o integrarse a las embarcaciones que continúan en operación bajo un sistema de rotación laboral. Los incentivos están alineados para que la decisión sea el retiro voluntario a partir de la definición de un esquema de beneficios bastante ventajoso.

Así, primero se cuenta con un incentivo al retiro de 2.25 remuneraciones por año trabajado con un tope máximo de 18 sueldos. Luego, un paquete de beneficios a la reconversión o reincorporación laboral o esquemas de jubilación anticipada. Finalmente, una subvención económica con duración máxima de dos años, que asciende a $20 \%$ del salario del pescador con un tope de 1.5 veces la remuneración mínima vital.

Cabe resaltar que para desarrollar este indicador se ha utilizado información de la Encuesta Nacional de Hogares del periodo 20072010; es decir, una muestra. Considerando que no se cuenta con datos de panel en este sector, buscar una serie de datos sería distorsionado.

De acuerdo con la Encuesta Nacional de Hogares (ENAHO), ejecutada por el Instituto Nacional de Estadística e Informática (INEI), se estima que entre los años 2007-2008 la fuerza laboral del sector pesquero estuvo representada en promedio por 86,718 trabajadores que se dedican a la actividad pesquera donde alrededor de $85 \%$ representa a la mano de obra no calificada dentro del sector. 
En el segundo periodo de evaluación, entre los años 20092010, el número de trabajadores promedio del sector pesquero se estimó en 86,868 trabajadores de los cuales se aproxima que $88 \%$ representa la mano de obra no calificada. En el cuadro 3.3 se presenta información sobre la distribución geográfica de los trabajadores pesqueros.

Tabla 3.3 : Fuerza laboral del sector pesquero

\begin{tabular}{lrrrr}
\hline & $2007-2008$ & \multicolumn{3}{c}{$\mathbf{2 0 0 9 - 2 0 1 0}$} \\
\hline Pescadores (Nacional) & 86,717 & 86,872 \\
\hline Por región natural & & & \\
Costa & 65,915 & $76.0 \%$ & 64,989 & $74.8 \%$ \\
Sierra & 2,275 & $2.6 \%$ & 2,859 & $3.3 \%$ \\
Selva & 18,527 & $21.4 \%$ & 19,024 & $21.9 \%$ \\
\hline Por zona costera & & & 31,109 & $35.8 \%$ \\
Norte & 34,019 & $39.2 \%$ & 21,120 & $24.3 \%$ \\
Centro & 17,504 & $20.2 \%$ & 8,234 & $9.5 \%$ \\
Sur & 8,549 & $9.9 \%$ & 4,526 & $5.2 \%$ \\
Lima metropolitana & 5,843 & $6.7 \%$ & 64,989 & $74.8 \%$ \\
\hline Selección & 65,915 & $76.0 \%$ & &
\end{tabular}

En lo que respecta al ámbito laboral, el cuadro 3.4 muestra la relación que estos trabajadores mantienen con sus empresas. Así, se observa que en el periodo 2007 - 2008, el $57 \%$ de la fuerza laboral es dependiente, proporción que aumenta hasta el $64 \%$ para el periodo 2009 - 2010. Del total de estos trabajadores, solo el 23\% han suscrito un contrato de trabajo. De este modo, considerando a los trabajadores independientes y a los dependientes sin contrato, se puede inferir un nivel de informalidad del sector casi del $86 \%$ en el primer periodo y alrededor del $81 \%$, en el segundo. Este cambio de composición posiblemente haya estado relacionado con los cambios en el sistema de captura.

Asimismo, por tamaño de empresa, se observa que en el periodo 2007 - 2008, 83\% de la fuerza laboral se concentra en empresas de menor tamaño (hasta 20 trabajadores); mientras que para el segundo periodo de 2009 - 2010, la proporción disminuyó en 5 puntos porcentuales manteniéndose por encima de $75 \%$ de la fuerza laboral costera, en línea con el proceso de formalización y ganancia de eficiencia media. Por otro lado, es interesante verificar que, 
paralelamente al proceso de formalización, también se registra un aumento en la tasa de sindicalización del sector. Así, en el periodo 2007 - 2008 se registra que alrededor del $11 \%$ de los trabajadores se encuentran sindicalizados, llegando a superar el $16 \%$ en el periodo 2009 - 2010. Estas cifras si bien parecen bajas en el agregado, si se considera únicamente los trabajadores dependientes con contrato significan que en promedio $89 \%$ de los trabajadores pertenecen a un sindicato.

Finalmente, en lo que respecta a las remuneraciones del sector, se calcula un ingreso laboral promedio mensual de S/. 590 para el periodo 2007 - 2008, cifra que aumenta en $17 \%$ para el periodo 2009 2010 ubicándose en casi S/. 700 (INEI).

Tabla 3.4 : Características laborales de los trabajadores pesqueros

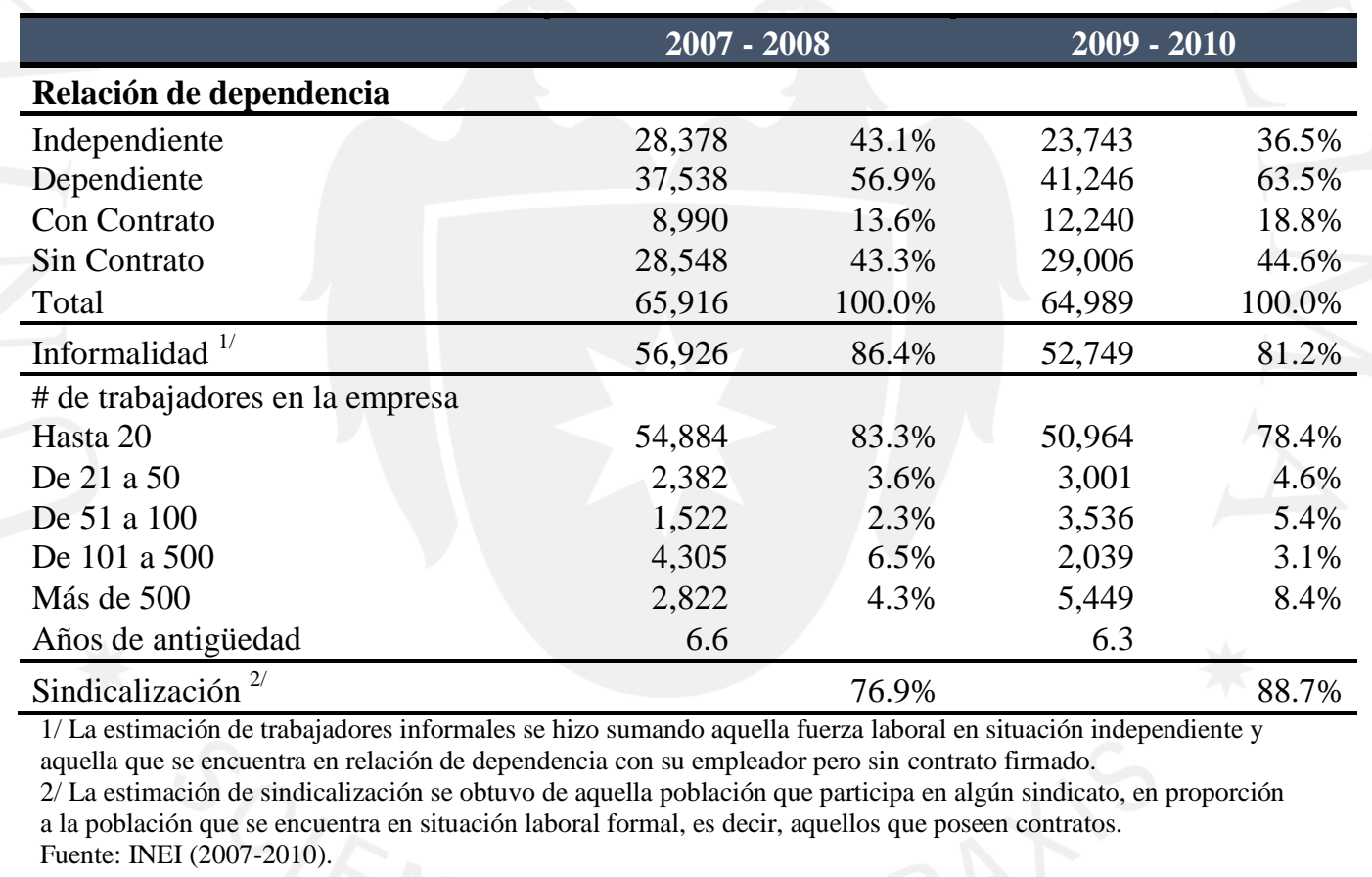


En el cuadro 3.5, se recoge el número de trabajadores que fueron acogidos el programa FONCOPES por modalidad y según las empresas que declararon al respecto. Este indicador muestra que el $80 \%$ opta por la modalidad que le genera oportunidades de desarrollo ya sea en otra labor o propio.

Tabla 3.5 : Trabajadores acogidos a programas de beneficios según empresas

\begin{tabular}{lcccc}
\multicolumn{1}{c}{ Armador } & $\begin{array}{c}\text { Desarrollo y } \\
\text { Promoción de } \\
\text { MYPES }\end{array}$ & $\begin{array}{c}\text { Incentivo a la } \\
\text { Reconversión } \\
\text { Laboral }\end{array}$ & Sin Programa & Total \\
\hline Austral Group S.A.A. & 116 & 156 & 0 & 272 \\
\hline CFG Investment S.A.C. & 21 & 36 & 51 & 108 \\
\hline $\begin{array}{l}\text { Corporación Pesquera Inca } \\
\text { S.A.C }\end{array}$ & 170 & 347 & 8 & 525 \\
\hline $\begin{array}{l}\text { P.E.E:A. Costa del Sur } \\
\text { S.R:L. }\end{array}$ & 1 & 0 & 0 & 1 \\
\hline Pesquera Asturias S.A. & 16 & 7 & 0 & 23 \\
\hline Pesquera Centinela S.A.C. & 2 & 3 & 0 & 5 \\
\hline Pesquera Diamante S.A. & 25 & 80 & 246 & 328 \\
\hline Pesquera Exalmar S.A. & 23 & 59 & 29 & 76 \\
\hline Pesquera Hayduk S.A. & 12 & 35 & 1 & 1 \\
\hline Pesquera Mistral S.A. & 0 & 0 & 72 & 588 \\
\hline Tecnológica de Alimentos & 215 & 301 & 409 & 2034 \\
\hline S.A. (Tasa) & 601 & 1024 & $20 \%$ & $100 \%$ \\
\hline Total General & $30 \%$ & $50 \%$ & & 2 \\
\hline
\end{tabular}

Si bien no se cuenta con el porcentaje del total de trabajadores que representa en el mercado, el hecho de que 2,034 de los empleados pertenecientes a las empresas que declararon al respecto se acojan al programa refleja el incremento del nivel de rotación de empleados en el sector. 


\subsection{Distribución de la dotación inicial de anchoveta}

Según la base de la economía de mercado, las decisiones de consumo y producción se generan en base a los precios relativos. Queda claro que para el caso de los consumidores, la relación entre dos productos se basará en las preferencias por cada uno de estos, expresado en el beneficio dentro de la función de utilidad del agente, el cual mostrará la valorización (precios) relativa entre cada producto.

De esta misma manera, las empresas basarán sus preferencias entre aquellos productos a ser elaborados en función a la tecnología productiva. Esta mostrará si, relativamente, es caro o barato producirlo; determinando a la vez la escasez o abundancia de los recursos necesarios para su producción.

Considerando ambos puntos, en equilibrio de entre oferta y demanda, las preferencias de los consumidores y la tecnología de las empresas definen los precios relativos y los niveles de producción óptimas de cada bien.

Las preferencias de los consumidores se reflejan en funciones de utilidad conjuntas de la sociedad. Asimismo, para un mismo nivel de insumos (capital, trabajo, dotaciones de recursos naturales, entre otros) existirá un grado de trade off entre la producción de distintos bienes (para aumentar la producción de uno se deberá reducir la producción de otro). Aquellas combinaciones posibles de producción que maximizan la utilización de recursos se denomina "frontera de producción".

El nivel de producción que maximiza la utilidad de los consumidores y los beneficios de la empresa será aquella combinación donde los hogares registran el mayor nivel de utilidad que puede alcanzar, y que es alcanzable con los recursos disponibles de la economía (se encuentra dentro de la frontera de producción).

La teoría microeconómica señala que donde la demanda sea baja o casi inexistente y los precios relativos bajos, los empresarios no se sienten atraídos para la inversión y desarrollo en dicho sector por lo que redirigen sus recursos hacia el sector con mayor rendimiento. Para la economía, este 
fenómeno conduce a un escenario óptimo donde se utilizan los recursos eficientemente y se alcanza el mayor bienestar para la sociedad.

\subsubsection{Racionalidad en la elección de un recurso escaso}

El sector pesquero demandará insumos (capital, trabajo, recursos naturales) para producir bienes finales, ya sea sector de $\mathrm{CHI}$ o CHD. Tal como se determinó anteriormente, la demanda de los insumos para producción se determina simultáneamente con la elección óptima de los consumidores por cada uno de estos productos finales, en función a sus preferencias reveladas.

Es decir, cada elección óptima de bienes en equilibrio general le corresponde una producción óptima de las empresas que determinará la demanda óptima de insumos necesarios para su producción. Se debe tener en cuenta que la estructura de producción puede ser muy distinta a la estructura de uso de los recursos.

\section{Gráfico 3.14 : Participación de Insumos para CHI (en \%)}

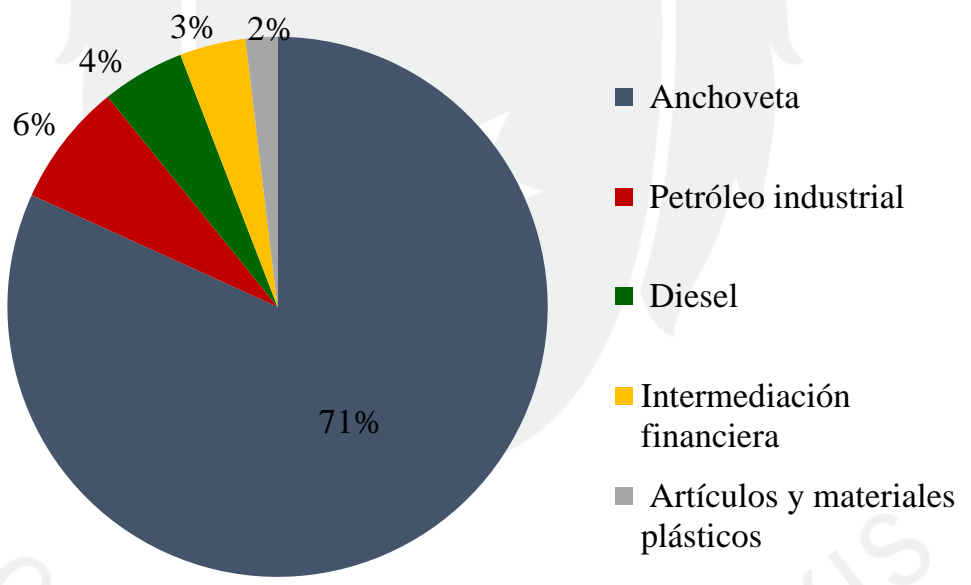

Fuente: TIP, 2007 (INEI) revisado 03-junio-2014

Tal como se mencionó, las decisiones de producción dependerán de cada uno de los factores de producción necesarios para el bien final. Se observa que la producción de CHI cuenta con una utilización de $70 \%$ de anchoveta, y le sigue de los combustibles necesarios para la puesta en marcha de las plantas harineras. Otro aspecto que es importante resaltar es la necesidad de financiamiento dentro de su factor de producción. 
Gráfico 3.15 : Participación de Insumos para CHD (en porcentajes)

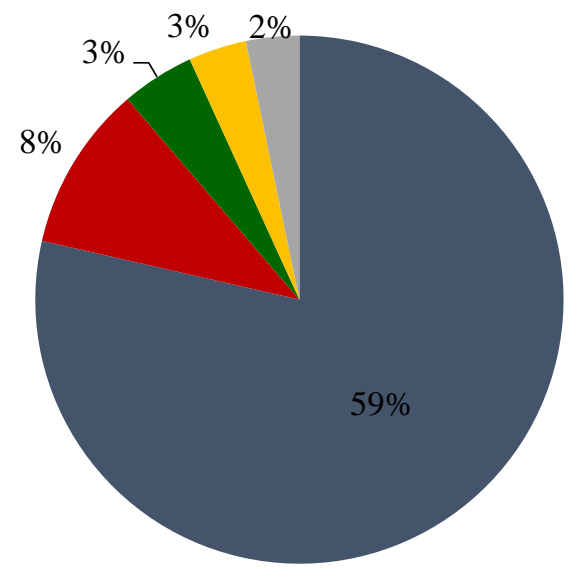

- Anchoveta

- Servicios de transporte terrestre

- Artículos y materiales plásticos

Diesel

Intermediación financiera

Fuente: TIP, 2007 (INEI) revisado 03-junio-2014

Por otro lado, en lo referente al CHD, resalta que si bien la necesidad de anchoveta es similar que en el de CHI; la necesidad de transporte terrestre y mayor participación en los recursos plásticos refleja el efecto de ser un producto altamente perecible en el tiempo.

Las características de los factores de producción y la interacción de la demanda por los productos finales, genera un equilibrio en el que se llega a producir un estado natural de producción. El cambio de la distribución del recurso entre CHD y CHI se observa en los siguientes gráficos.

En el gráfico 3.16 se observa que la producción de CHD a partir del 2000 tiene una tendencia creciente, siendo más enfática a partir del 2006; mientras que el CHI presenta altas y bajas. Sin embargo, hay que tener en cuenta que es en forma similar al movimiento de la biomasa de anchoveta. Con el gráfico 3.17 queda claro que, si bien el nivel de producción de CHD va en aumento, aún casi la totalidad del insumo (desembarque de anchoveta) es destinado a CHI. 
Gráfico 3.16 : Niveles de producción de CHI y CHD por tipo (en TM)

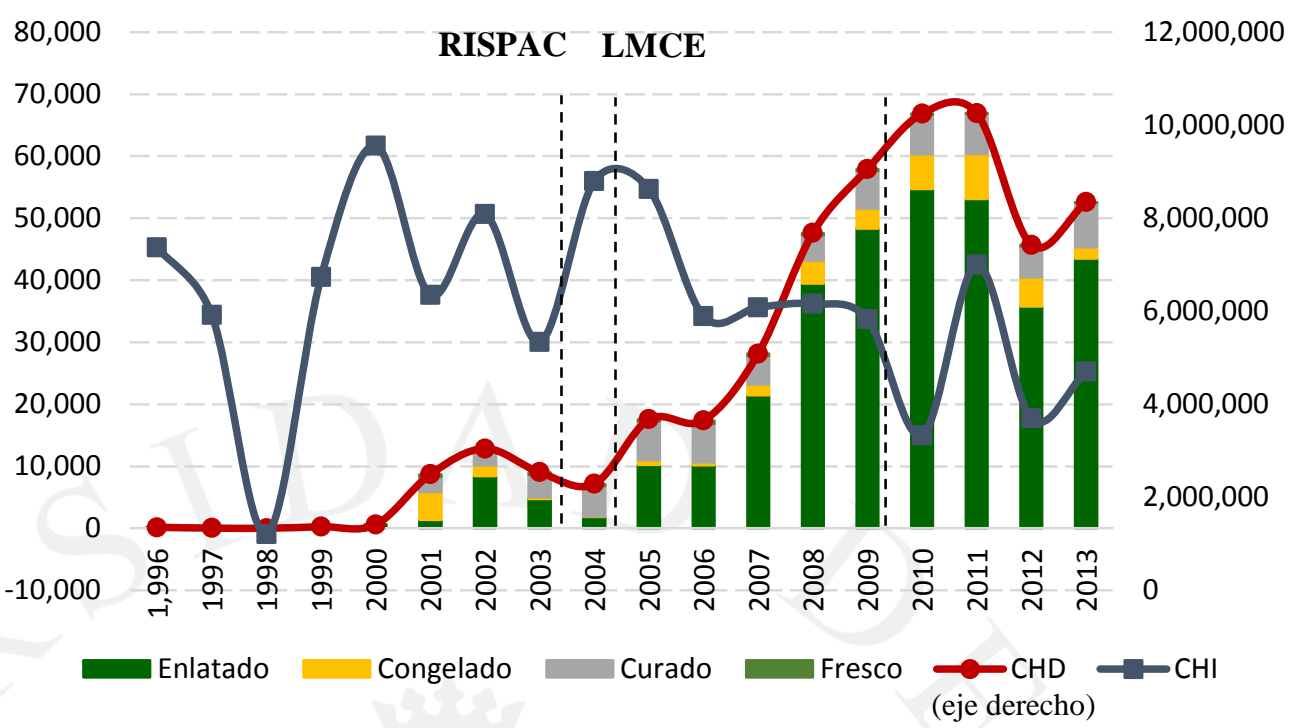

Fuente: PRODUCE, revisado 03-junio-2014

Gráfico 3.17 : Participación de desembarque de anchoveta por destino (en porcentaje)

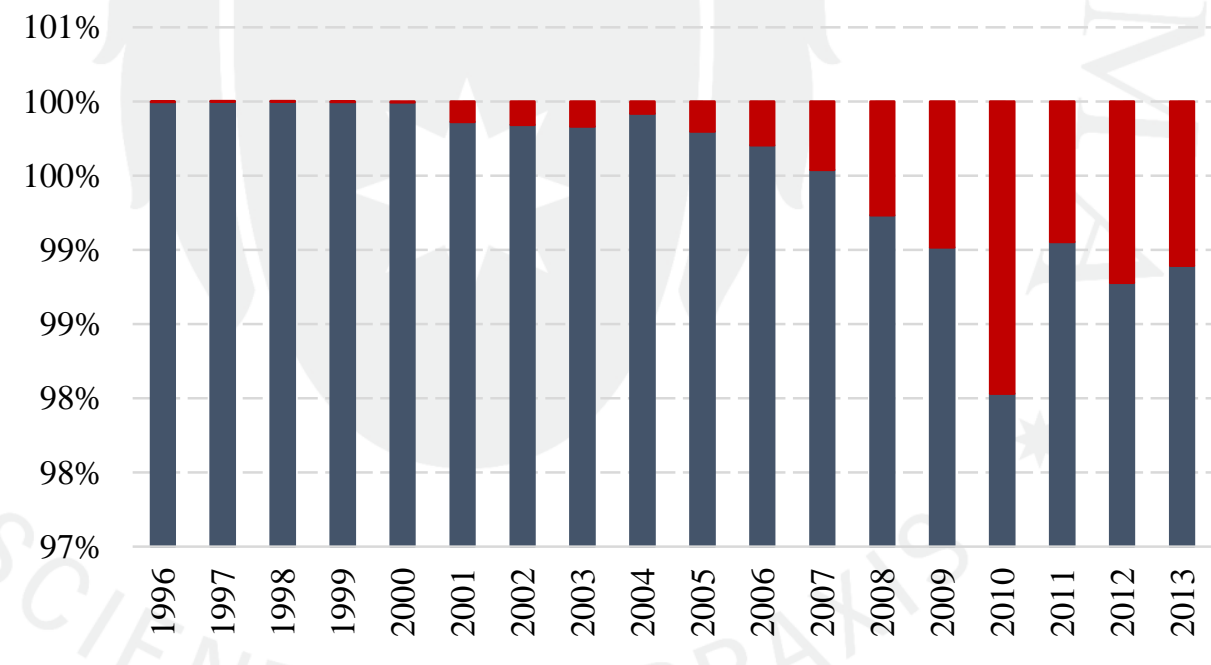

Fuente: PRODUCE, revisado 03-junio-2014 


\subsubsection{Valor Agregado Bruto (VAB) y la relación con Empleo Generado}

Tanto teórica como analíticamente se ha observado que existen sectores económicos que son intensivos en capital y otros que son intensivos en mano de obra. Se conoce que dentro de los sectores que son intensivos en capital se encuentra la minería e hidrocarburos; sectores que particularmente cuentan con una participación muy elevada dentro del PBI Nacional (12\% a 2007), pero no generan altos niveles de empleo. En el otro extremo, se encuentra sectores como el agropecuario y pesquero que cuentan con una participación de $5.8 \%$ del PBI a 2007, pero que demandan un alto nivel de empleo.

El análisis que se realiza a continuación de Valor Agregado se basa en la relación del aporte al valor agregado bruto que genera el sector en la economía, dentro de lo cual está comprendido el aporte a la generación de empleo. Esto se debe al esfuerzo de las políticas públicas y normativas en promover la inversión. El Estado promueve la generación de riqueza expresado en términos económicos como Valor Agregado que se distribuirá en utilidades, salarios e impuestos; sin considerar a priori la cantidad de empleos que se generarán.

Estos aspectos se encuentran en la Tabla Insumo Producto (TIP) de 2007, estimada por el Instituto Nacional de Estadística e Informática (INEI), la cual presenta las relaciones económicas entre cada producto, determinando la estructura de bienes intermedios y bienes finales (metodología del cálculo en el Anexo 1). Al respecto cabe precisar que la data se obtiene a través de una Encuesta Nacional realizada a las empresas que forman parte de las actividades involucradas, siendo cada matriz expresada en millones de nuevos soles. En tal sentido, el resultado del VA a través de las encuestas incorpora las variables cantidad y precio sin mostrar el impacto de cada una.

La estructura de la demanda del sector Pesca y Acuicultura determinado por el INEI es de: $21 \%$, compras de los hogares (que consumen productos frescos); $21 \%$, compras del sector elaboración y preservación de pescado; 54\%, compras del sector Harina y Aceite de Pescado; 3\%, las compras de restaurantes y hoteles; y $1 \%$, otros. 
Mientras que la estructura de la demanda del sector Elaboración y Presentación de Pescado está compuesta por: 48\%, compras de conservas los hogares; $46 \%$, por exportaciones; $4 \%$ por compras de hoteles y restaurantes; y, $2 \%$ otros.

En el gráfico 3.18 se observa una tendencia positiva tanto del valor agregado de harina de pescado como de la elaboración y preservación de anchoveta, basado en la proporción a 2007, según las TIP, de valor agregado por tipo de consumo en la actividad pesquera y consecuentemente la actividad nacional, siendo el primero de mayor monto que el segundo.

Gráfico 3.18 : VAB de CHI y CHD (en Millones de soles constantes del 2007)

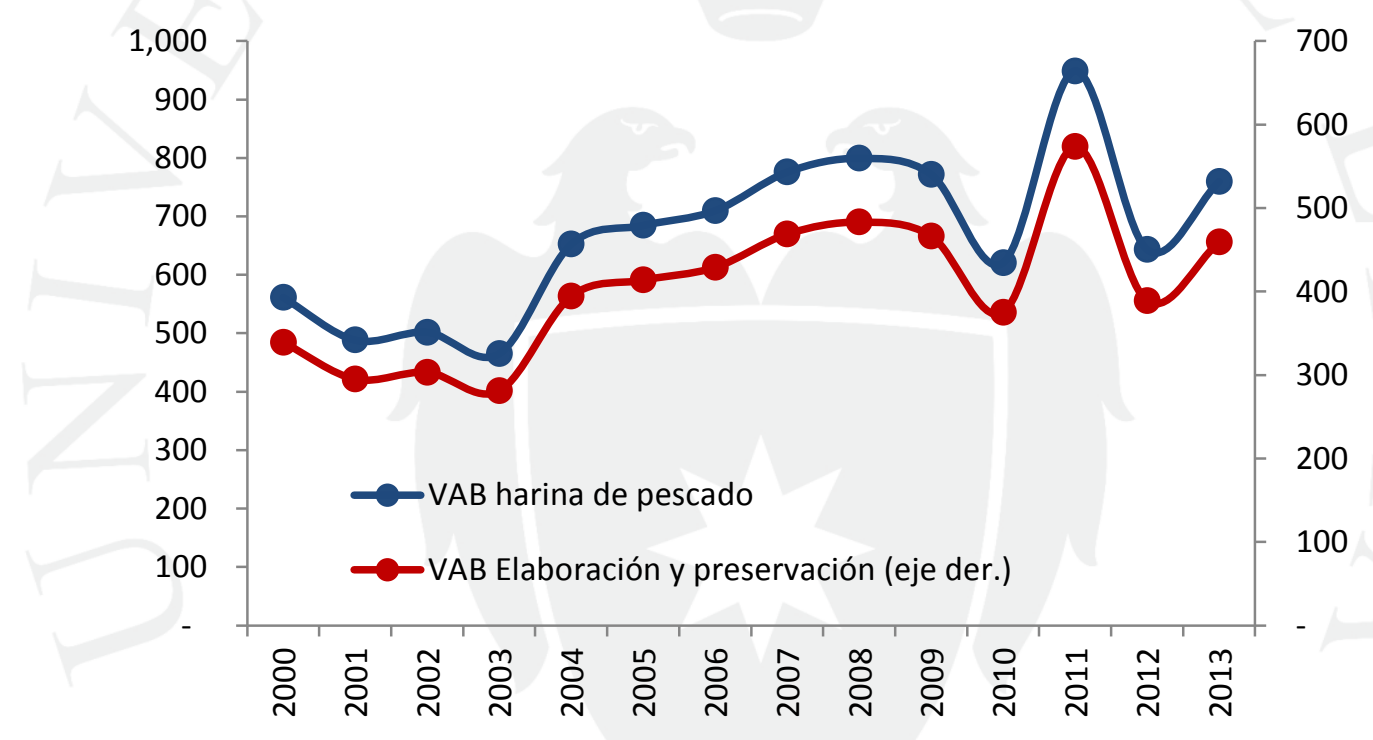

Fuente: TIP, 2007 (INEI), revisado 03-junio-2014

En la pesca, cada sector determina la demanda de recursos que maximice los beneficios de las empresas; así, se observa que el sector de pesca y acuicultura (desembarque o capturas) que representa $47 \%$ del VAB del sector, demanda 73\% del empleo de la pesca; los sectores Harina y Aceite de Pescado y Elaboración y Preservación de Pescado son menos intensivos en trabajo, siendo el primero más intensivo. 
Gráfico 3.19 : Estructura del VAB y generación del empleo en el Sector Pesquero 2007 (\% del total)

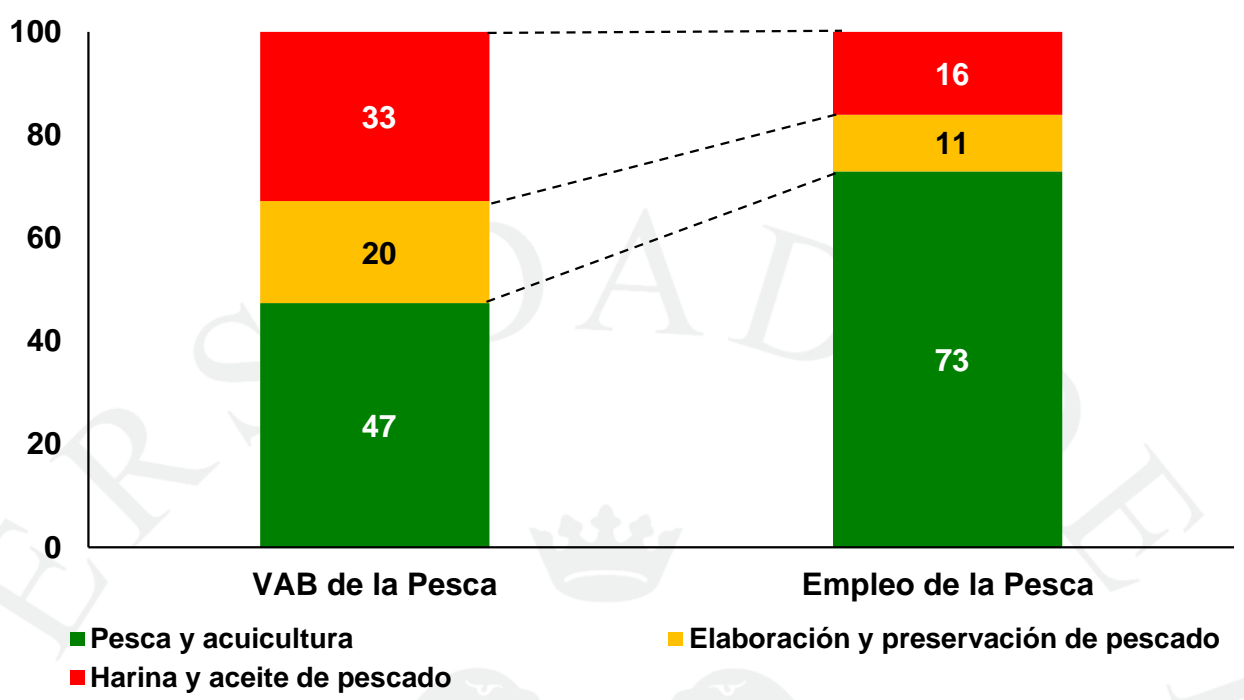

Fuente: TIP, 2007 (INEI) , revisado 03-junio-2014

La opción preferible para la sociedad será aquella que maximice el bienestar de la sociedad o el valor agregado que se genere. Asimismo, la mayor generación de valor agregado estará asociada a la eficiencia o productividad de los ecosistemas y la acuicultura, y cómo la sociedad valora cada producción.

Las políticas públicas deben promover por igual todos los sectores económicos para generar mayor valor agregado y el uso eficiente de los recursos. Promover sectores económicos con un criterio de generar mayor número de empleos, puede generar ineficiencias en una economía de mercado. 


\subsection{Sostenibilidad del recurso}

\subsubsection{Varianza anual de pesca de juveniles}

Para mantener la existencia del recurso en el tiempo, se debe evitar que los especímenes de menor edad (juveniles) sean depredados, puesto que de estos depende la reproducción de la especie. En tal sentido, este indicador evalúa la desviación del porcentaje anual de pesca de juveniles respecto al promedio anual.

Como se puede apreciar en el gráfico 3.20, el grado de pesca mensual de juveniles es errático; sin embargo, la varianza del promedio anual (gráfico 3.21) presenta dos picos marcados (2005 y 2011) y un periodo de estabilidad (2006-2010). Dichos picos pueden deberse a un efecto rebote ocasionado por eventos climatológicos que incrementan la probabilidad de pesca de juveniles o deficiencias en la regulación de dicha pesca.

El hecho de que a partir de la vigencia del RISPAC, que regula de forma efectiva el cumplimiento del máximo de juveniles permitidos a pescar por embarcación mediante sanciones/multas, la desviación respecto al promedio de pesca de juvenil sea mínima sugiere dos posibles opciones: 1) esta normativa ha determinado la reducción de la pesca desmedida de juveniles y así promueve la reproducción sostenible de la especie o 2) los armadores (pescadores), conscientes de la sanción/multa en la que incurrirían (detallado en el TUO-RISPAC) si los fiscalizadores verifican el exceso de pesca de juvenil, habiendo pasado el límite asignado (más del 10\% del número de pescados extraídos), deciden descartar el recurso nuevamente al mar; lo cual genera un impacto negativo en la sostenibilidad de igual manera porque dichos juveniles no podrán reproducirse en un siguiente periodo.

Al respecto, Elena Conterno (presidenta de la SNP) en la entrevista realizada para esta investigación (Anexo 1) comenta las 
siguientes falencias en la fiscalización y en la tecnología usada en el sector:

a. Se sigue construyendo embarcaciones que no se destinan a reemplazar embarcaciones con cuota o a dar de baja; es decir, están destinadas a pescar por fuera de lo permitido.

b. No hay control de veinticuatro horas en los muelles, a diferencia de las plantas de harina.

c. El Sonar (equipo utilizado para detección de los cardúmenes), según las indicaciones del manual, puede presentar errores de medición en caballas, cuya longitud es superior al de la anchoveta; es decir, los propios armadores no pueden determinar la composición de tallas del cardumen que pescarán y se ven desfavorecidos por un sistema de sanciones/multas que tiene por supuesto lo contrario.

Ante este inconveniente PRODUCE ha desarrollado un reporte oportuno a la unidad respectiva de la entidad, mediante el cual se evalúa el cierre de la zona de pesca.

d. No todas las embarcaciones destinadas a CHD cuentan con el sistema de GPS activo. Con la norma de las 10 millas esta disposición se hizo aplicable también a las embarcaciones de menor escala; sin embargo, compraban el aparato, contaban con el contrato, pero no activaban el dispositivo.

Esta deficiencia está en potestad de PRODUCE regularizar, pues les es posible detectar las embarcaciones que no lo activan. Entonces, a aquellas que no muestran un trayecto no se debe permitir la descarga de la pesca y se les debe multar.

En suma, la evolución de la varianza de la pesca de juveniles indica una baja significativa de la desviación respecto al promedio; sin embargo, no asegura que esta mejora sea efectiva, dado que la data no recoge necesariamente la realidad del sector por falta de trazabilidad completa de la cadena, expresado en falta de monitoreo durante el zarpe, construcción de embarcaciones sin 
permiso de pesca, falta de control permanente en muelles, falta de activación de GPS en muchas embarcaciones, entre otros.

Gráfico 3.20 : Porcentaje mensual de pesca de juveniles

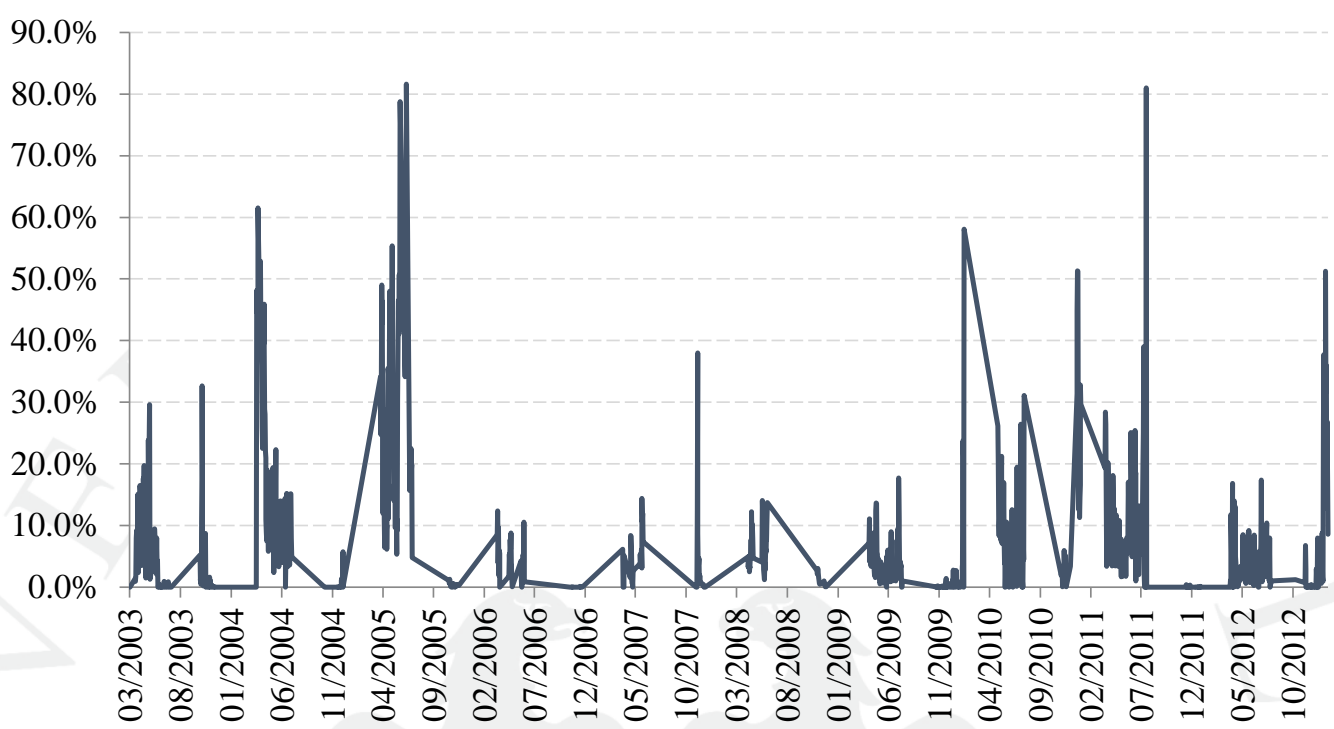

Fuente: PRODUCE, revisado 03-junio-2014

Gráfico 3.21 : Varianza anual del porcentaje de pesca de juveniles

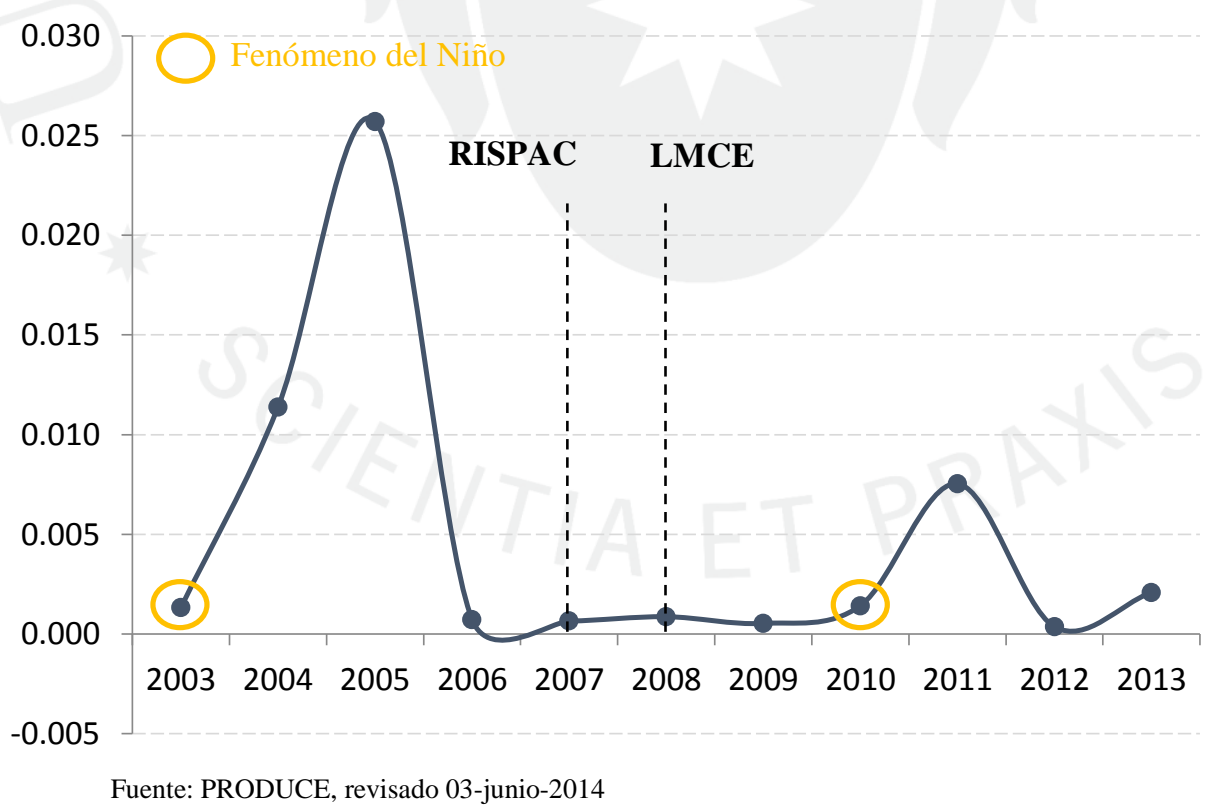




\section{CAPÍTULO IV: PROSPECTIVA DE LA INDUSTRIA DE LA ANCHOVETA EN BASE A LA NORMATIVA PESQUERA}

La normativa del sector presenta espacios de mejoras y de discusión. En tal sentido, en este capítulo se presentan dos temas de relevancia.

\subsection{Asignación de cuotas}

La asignación de cuotas de pesca responde a la problemática, explicada en el Marco Conceptual, sobre la no exclusividad pero sí rivalidad que caracteriza al recurso pesquero (tragedia de los comunes) y que conlleva a la denominada "carrera olímpica"; es decir, a la sobre explotación por encima del nivel sostenible y la sobre inversión en esfuerzo pesquero. En tal sentido, esta respuesta (asignación de cuotas) busca brindar una solución a las consecuencias de la falta de derecho de propiedad sobre la anchoveta.

Las cuotas pueden ser transferibles o no transferibles. En el caso peruano, como en el de varias pesquerías en países como Chile, Nueva Zelanda e Islandia, se utiliza el primer tipo; estando el caso peruano basado en una asignación histórica cuyos criterios fueron explicados en el Capítulo 1 dentro del Marco Normativo y están asociados a las embarcaciones.

Esto se debe a que la transferibilidad de las cuotas posibilita transar el dominio del derecho en forma permanente, lo cual mejora la eficiencia en el funcionamiento del sistema; basado en el del teorema de Coase (Chávez, Dresdner, Quiroga, Slagado, 2010).

Este teorema plantea que en los casos que los derechos de propiedad asignados inicialmente no permiten una solución económica eficiente, mientras que los costos de transacción sean bajos o inexistentes, se producirá una reasignación de los mismos hacia aquellos que los valoran más (Coase, 1960). 


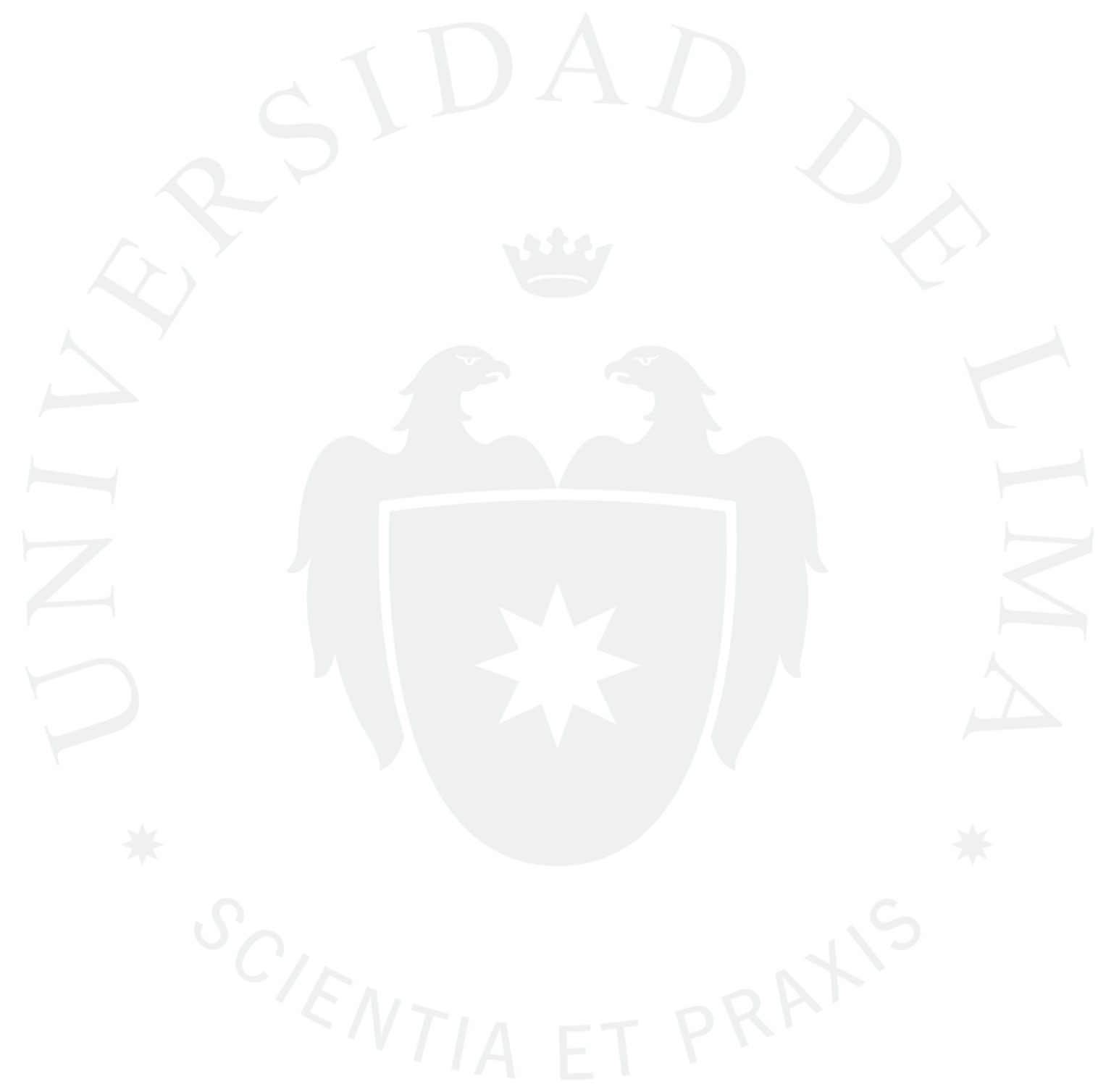


En tal sentido, se puede inferir que una limitación al cumplimiento de este teorema es la presencia significativa de costos de transacción, así como el de las asimetrías de información. En el teroema de Myerson-Satterthwaite (1983) argumentan que es imposible la existencia de un mecanismo eficiente de transacción, tras una asignación inicial dada, cuando hay presencia de asimetrías de información. Entonces, la validez del argumento para el uso de asignación inicial de las cuotas en base histórica radica en si existe presencia de costos de transacción significativos y asimetrías de información.

Bajo la estructura actual de asignación, las cuotas se encuentran asociadas a las embarcaciones; es decir, cualquier transacción de las mismas estará sujeta a la transacción de embarcaciones completas, lo cual es más complejo. Esto genera un incremento de los costos, debido a que se impone un tamaño mínimo en la transacción por la indivisibilidad de la embarcación y se restringe los periodos de la transacción a un año o más. Análogamente, se intensifica la presencia de asimetrías de información, puesto que no solo hay diferencias entre las valoraciones de las cuotas por parte de los interesados, sino que también el bien asociado a la cuota es heterogéneo y genera diferentes valoraciones por las partes y limitaciones adicionales de acceso a la información (Montero,2012).

En tal sentido, la estructura actual del sistema de cuotas genera limitaciones a la transferibilidad que intensifican los costos de transacción y las asimetrías de información, pudiendo invalidar la aplicación del teorema de Coase y, consecuentemente, la conveniencia de la asignación en base histórica.

Sin embargo, los miembros del sector privado de pesca en el Perú entrevistados para esta investigación (Anexo 1 y 2) comentaron que dadas las condiciones de este mercado pareciera ser la mejor alternativa posible. Afirmaron que sí existe un mercado de cuotas en el Perú y efectivamente este está concentrado en ciertas empresas; pero no por falta de transferibilidad, sino por los costos fijos altos que tiene el sector (por ejemplo la necesidad de contar con plantas que cumplan con los lineamientos de calidad). 
Un mecanismo de asignación alternativo es el de las subastas, que permite obtener la cuota a quien anuncia estar dispuesto a pagar más y cumple con los requisitos, sin los límites que presenta que la cuota esté sujeta a una embarcación. Sin embargo, presenta una serie de desventajas que reducen su atractivo en comparación a la asignación histórica: 1) oposición política basada en argumentos de expropiación de rentas cuyo origen está en inversiones históricas efectuadas en el sector; 2) probabilidad que no se logre recaudación fiscal extra a la finalidad de financiar los costos de administrar el sistema de cuotas; 3) probabilidad de colusión entre las firmas dominantes ya establecidas; entre otros.

Dos países que cuentan con el sistema de cuotas y que ejemplifican estas limitantes son Nueva Zelanda e Islandia. Tal como lo relata James N. Sanchirico, Daniel Holland, Kathryn Quigley y Mark Fina (2005), el sistema de gestión de cuotas (SGC) de Islandia y Nueva Zelanda tuvo su origen en 1986, con la creación de asignaciones de cuotas de varias especies marinas (entre 9 y 17 especies), inicialmente con una metodología basada en las capturas históricas, para luego implementar mecanismo de subastas.

El manejo de cuotas fue sumamente complejo para estos países, dado que se amplió el sistema para un significativo mayor número de especies (93 especies solo en Nueva Zelanda), con el objetivo de incluir todos los recursos marinos vivos (incluidos los invertebrados y algunas algas) que son de gran valor comercial o podían plantar problemas futuros de sostenibilidad como resultado de la pesca. Actualmente, Islandia y Nueva Zelanda han establecido un esquema de intercambio de cuotas dentro de un "mercado central", siendo el propio Estado el gestor del intercambio y venta de las cuotas.

Nueva Zelanda cuenta con un mecanismo de intercambio en el que se hace pública la información básica de la cuota, con el detalle sobre los armadores que están dispuestos a vender su cuota, intermediarios y compradores, disponible previo a la materialización de la transacción. A partir de ello, se esquematiza y se ordena la información con la que se hará la transacción de la cuota de pesca. En el 2004 se dio la primera subasta por una cuota anual a través de la página www.acetrader.maori.nz . A la fecha este sistema ha tenido un éxito limitado. 
La propuesta de Islandia fue el brindar información ex ante la realización de la subasta a todos los interesados, con el detalle del valor de la cuota a ser usado por los armadores (precio base); es decir los postores de la cuota presentarán la oferta por la cuota por encima de dicho valor. Se observó que el esquema era limitado, dado que las transacciones no se daban solo en las subastas, sino en un mercado paralelo y privado con adquisiciones y fusiones de empresas.

Entonces, el factor clave para el adecuado funcionamiento de esta opción es que su diseño se estructure en base a los temas centrales de la organización industrial; es decir, las barreras de entrada, la colusión o la predación. Entonces, se debe tener presente los siguientes criterios: 1) asignación de cuotas individuales de pesca a quienes más las valoran, relacionado a eficiencias en la producción; 2) promoción del mayor número posible de actores; 3) dificultar la colusión entre participantes; y 4) simplicidad de la subasta (Saavedra y Willington, 2012).

$\mathrm{Al}$ respecto, las entrevistas (en los Anexos 1 y 2 respectivamente) realizadas a Elena Conterno, presidenta de la SNP, y Raúl Salazar, miembro del directorio de Diamante, contemplaron la opinión sobre esta alternativa de método de asignación.

Mientras el representante de Diamante enfatizaba que algo más importante es la vigencia remanente de las cuotas asignadas y que posteriormente la alternativa de subasta es algo válido a evaluarse; la presidente de la SNP presentó una posición en contra basada en los siguientes 3 puntos:

a. Falta de éxito según experiencia internacional.- menciona que en países como Chile, Rusia, Estonia no se tuvo éxito e inclusive en los últimos dos se optó por cambiarlo.

b. No es un método de duración. Por otro lado, sí se está de acuerdo a que se realice una evaluación técnica que determine el costo del recurso.

c. Existe una relación de dependencia entre las embarcaciones y las plantas, siendo estas últimas de elevados costos fijos por las disposiciones de PRODUCE. En tal sentido, una subasta del recurso que busca permitir la entrada de nuevos actores, que no contarían con plantas, sería injusto ya 
que estas empresas han realizado dicha inversión bajo el supuesto de contar con la cuota. Por otro lado, si se realiza una subasta solicitando que los postulantes cuenten con plantas excluiría a los vikingos.

En síntesis, la estructura actual de asignación de cuotas en base histórica, al ligar la negociación de la cuota con la embarcación, genera problemas de costos de transacción y asimetrías de información que genera dificultades para la transferencia de las cuotas y, consecuentemente, dificultades para la corrección de la asignación inicial hacia la eficiente en base al teorema de Coase; sin embargo, en base a comentarios de representantes del gremio privado, esta es una buena alternativa dadas las condiciones de este mercado particular. Por otro lado, si bien la subasta es una alternativa que alivia la problemática de la relación de la cuota a las embarcaciones, tiene fuertes condiciones para su funcionamiento apropiado que de no cumplirse podrían generar más problemas que los de una asignación inicial sub-óptima.

Entonces, si bien el método de subastas indica en el plano teórico una mejor asignación del recurso, en el práctico, dadas las condiciones de funcionamiento descritas, no ha tenido éxito en grado tal que el sector privado está de acuerdo con el método que asocia la cuota a la embarcación. Por tanto, no sería recomendable que se imponga el cambio del método hasta verificar el cumplimiento de las condiciones mencionadas y que se haya consensuado con los actores privados el procedimiento.

\subsection{Trazabilidad de la cadena productiva}

A través de la normativa analizada en esta investigación, se ha introducido en el sector de pesca de anchoveta una serie de disposiciones de ordenamiento en términos de captura, calidad, entre otros; cuyo incumplimiento incide en sanciones establecidas en el RISPAC. Sin embargo, para que esto sea efectivo los factores principales son las autoridades, las herramientas con que cuentan y el alcance que se tiene sobre la cadena. 
En base al Reglamento del Sistema de Seguimiento Satelital para embarcaciones pesqueras -SISESAT (Decreto Supremo $\mathrm{N}^{\circ}$ 001-2014) el Reglamento del Programa de Vigilancia y Control de las actividades pesqueras y acuícolas en el ámbito nacional-PVCPDAM (Resolución Ministerial 0902015) y las acotaciones al respecto en el trabajo de la Universidad Cayetano Heredia en "La pesquería peruana de anchoveta" (2011) y de Carlos Paredes y Úrsula Letona en "Contra la corriente: La anchoveta peruana y los retos para su sostenibilidad" (2013), a continuación se detalla el estado de cada uno de estos factores clave.

\subsubsection{Autoridades involucradas}

Como se ha descrito en el capítulo 2 sobre la organización institucional, si bien la dirección del sector se concentra en PRODUCE, este coordina con diversas otras entidades. En cuanto al proceso de control y fiscalización, lo actores que más resaltan son PRODUCE, a quien se le rinde cuentas sobre las inspecciones realizadas y quien finalmente determina la medida en base a las disposiciones vigentes; la Dirección General de Capitanías y Guardacostas (DICAPI), la cual centraliza la información referida a las naves en el ámbito fluvial y lacustre; y las empresas privadas certificadas como inspectores tanto en puntos de desembarque, como transporte y plantas. A la fecha las seleccionadas son SGS del Perú SAC y Certificaciones del Perú SA (CERPER).

Respecto a estas últimas, el financiamiento de sus operaciones, cuya gran parte se destina a contratación de personal calificado, proviene de los propios agentes objeto de la regulación. Además, el monto a pagar por este servicio está relacionado con la cantidad de toneladas descargadas en la planta. 


\subsubsection{Herramientas para el control y fiscalización}

\section{a. Sistema de seguimiento satelital (SISESAT)}

Es un instrumento de georreferencia que deben utilizar los titulares de embarcaciones pesqueras de mayor y menor escala obligatoriamente, el cual brinda a las capitanías la ubicación de la embarcación y su velocidad.

Si se verifica que la embarcación presenta una imitación, ha instalado el sistema en otra embarcación emitiendo señal falsa y/o se congela la posición geográfica, la sanción es la cancelación del permiso de pesca. Sin embargo, no hay un registro.

Hace menos de cinco años un limitante de esta tecnología es que era unidireccional y se transmitía señal cada sesenta minutos.

Sin embargo, a la fecha es bidireccional (mediante DS $\mathrm{N}^{\mathrm{o}}$ 001-2014-PRODUCE), lo que según la norma implica que cada embarcación reporte: a) el número de lances realizados por faena de pesca, b) la cantidad de pesca extraída, c) el lugar y hora de desembarque de su pesca (mediante mensajes internos); y que las autoridades: a) modifiquen los intervalos del registro de la posición satelital de la embarcación en altamar y b) se comuniquen con las embarcaciones en casos de emergencia, facilitándoles información relacionada con la entrada a los puertos según su condición, mal tiempo, etc. Además, a marzo 2015 se implementó un nuevo software que según declaraciones en Gestión ${ }^{8}$ del viceministro de Pesquería, Juan Carlos Requejo, emitirá información cada diez minutos.

Dado que es uno de los principales mecanismos de monitoreo y es una herramienta de tecnología, se ha dispuesto que la revisión técnica sea cargo de la empresa proveedora del servicio, bajo supervisión de un inspector de la dirección regional de la producción de la localidad.

\footnotetext{
${ }^{8}$ http://gestion.pe/economia/produce-lanza-sistema-satelital-fiscalizar-1200-embarcaciones-2127796
} 


\section{b. Balanza gravimétrica}

En esta se realiza el control de peso y se envía un reporte en tiempo real por correo electrónico registrando las principales características de la descarga (nave, matrícula, hora de inicio, hora de fin y peso).

Actualmente, esta balanza es de pesaje por tolva, la cual cuenta con un sistema electrónico que es calibrado al menos dos veces al año por empresas acreditadas ante el Instituto de Defensa de la Competencia y Propiedad Intelectual (INDECOPI).

Para asegurar la veracidad de los datos, no está permitida la manipulación de la balanza por personajes ajenos, ni siquiera por los funcionarios de PRODUCE o por los inspectores de SGS o CERPER.

\subsubsection{Alcance sobre la cadena}

\section{a. Zarpe}

Las unidades del DICAPI realizan un control diario, con validez en el puerto donde se emite, en los que solo verifica la identificación de la nave (a través del número de matrícula) y que su tripulación esté debidamente acreditada; y un control trimestral, con validez en todo el litoral, en los que certifican si la embarcación se encuentra en buenas condiciones y que cumple con los requisitos exigidos por las normas.

Entre los principales puntos a monitorear se está el verificar que:

- La embarcación cuente con permiso de pesca vigente y un LMCE asignado.

- La embarcación encuentre operativa y cumpla con las características técnicas requeridas (de acuerdo con los requerimientos mínimos de seguridad recogidos en la Resolución Directoral 562-2003/DCG).

- El armador no tenga deudas pendientes de pago por derechos de pesca, FONCOPES y aportes sociales. 
- El armador cuente con una póliza de seguro de vida a favor de los tripulantes y la constancia de pago de seguro complementario de trabajo de riesgo y seguro social de salud.

- La embarcación se encuentre debidamente identificada, de acuerdo con los requisitos establecidos por la autoridad marítima.

Al respecto, cabe precisar que se han generado discrepancias cuando en el pesaje levantan reportes de ocurrencias en los que señalan que la nave no se encuentra bien identificada.

\section{b. Descarga (desembarcadero pesquero, muelles, chatas)}

Las empresas contratadas del PVCPDMA se encargan de verificar:

- La embarcación pesquera

- La vigencia del permiso de pesca

- El correcto estado del sistema SISESAT

- La nominación para realizar actividad extractiva

- La legalidad de la recepción de materia prima destinada a CHI

- El uso de los medios/sistemas y estado de conservación dispuestos por ley en el caso de CHD.

- El estricto cumplimiento del LMCE y de las tallas y pesos permitidos, restricciones de la pesca incidental y disposiciones legales que regulan las actividades extractivas de los recursos destinados a CHD.

En base a ello, deben informar a PRODUCE, DICAPI y demás autoridades competentes sobre las actividades ilegales, así como coordinar las actividades de control y fiscalización. 


\section{c. Transporte del recurso, descarte, residuos o producto terminado}

Las empresas contratadas del PVCPDMA se encargan de:

- Inspeccionar los vehículos y carga verificando que porten certificado de procedencia.

- Verificar que la guía de remisión consigne: embarcación, lugar de desembarque, descripción del recurso movilizado, número de cajas/contenedores y peso total.

- Verificar volumen, condiciones de estiba y medio de presentación adecuado del recurso.

\section{d. Plantas}

En este punto es importante recordar que del total de pesca intencionada para CHD, aquella que no es apta para este fin (por estándares de calidad), se deriva a plantas especializadas (residual y de reaprovechamiento) en procesar el porcentaje descartado.

Los armadores de las embarcaciones de menor escala pueden destinar directamente para el CHI el 10\% de su pesca, bajo el estandarte de pesca no apta para consumo humano. Luego, ya en planta, los titulares de las plantas de CHD pueden destinar el $40 \%$ del recurso recibido para la producción de harina de pescado. Con el $50 \%$ de lo supuestamente capturado para CHD, se inicia el proceso de transformación de la anchoveta hacia productos de CHD. De este proceso se producen residuos (hasta un 30-40\% de lo que entra a línea de producción, dependiendo del tipo de producto que se haga), que también se destinan a la producción de harina.

En tal sentido, para que se respete las disposiciones que establecen el porcentaje de anchoveta destinado a CHD, en el control de plantas es de suma importancia que las empresas contratadas del PVCPDMA identifiquen la procedencia de la 
anchoveta y que su peso en la balanza gravimétrica guarde relación con la producción (se estima un factor de 4 TM de anchoveta por unidad de harina de pescado).

A continuación se detalla las labores que realizan estas empresas por planta:

\section{- Plantas de procesamiento pesquero $\mathrm{CHI}$}

- Verificar procedencia, pesaje y registro.

- Evaluación biométrica del recurso a no menos del $70 \%$ del total de embarcaciones que descarguen en dichas plantas. El cumplimiento de ello se evalúa mensualmente.

- Verificar los límites de tolerancia de ejemplares en tallas y pesos permitidos, captura incidental.

Durante de veda se realizará de forma aleatoria mediante visitas inopinadas por supervisores de las oficinas locales de cada zona pudiendo apoyarse en inspectores verificados.

\section{- Plantas de procesamiento pesquero CHD}

- Verificar procedencia, pesaje y registro, y el peso de los descartes y residuos que se generen.

- Verificar vigencia y cumplimiento de los convenios de abastecimiento.

- Evaluación físico-sensorial y biométrica del recurso a no menos del $100 \%$ del total de embarcaciones.

- De realizarse en un mismo punto de control varias descargas, imposibilitando la evaluación del $100 \%$, el inspector, en base al resultado de un test con relación peso-longitud, composición de captura y porcentaje del recurso no apto de una muestra, debe seleccionar cuál unidad será inspeccionada.

- Verificar procedencia del recurso, destino del descarte y residuos.

- Verificar cumplimiento de los límites de descarte y residuos, así como que el proceso sea de acuerdo a las disposiciones 
legales vigentes y en función a los resultados de la evaluación físico-sensorial y biométrica.

- Reportar a PRODUCE mediante los Reportes de Ocurrencia y consolidados de información semanal cuando la producción de harina de pescado supere la capacidad autorizada o sea mayor a la proporción a la cantidad de recursos descargados según el ratio de producción (estimado en alrededor de 4) o se realicen modificaciones estructurales a la planta sin autorización.

\section{- Plantas de reaprovechamiento}

- Verificar vigencia y cumplimiento de los convenios de abastecimiento.

- Verificar pesaje, registro y, a través de guía de remisión, que procedan únicamente de las tareas previas en los desembarcaderos pesqueros artesanales. En el caso de que procedan de plantas de CHD, estas además de no tener planta de harina residual deben ubicarse en un departamento que no tenga alguna.

- Realizar la evaluación físico-sensorial y biométrica del recurso, para verificar que no cuente con condición apta para CHD

- Reportar a PRODUCE mediante los Reportes de Ocurrencia y consolidados de información semanal cuando la producción de harina de pescado supere la capacidad autorizada o sea mayor a la proporción a la cantidad de recursos descargados según el ratio de producción (estimado en alrededor de 4) o se realicen modificaciones estructurales a la planta sin autorización.

\section{- Plantas de harina de pescado residual}

- Verificar pesaje, registro, procedencia con las guías de remisión y convenios de abastecimiento.

- Realizar la evaluación físico-sensorial y biométrica del recurso, para verificar que no cuente con condición apta para CHD 
- Reportar a PRODUCE mediante los Reportes de Ocurrencia y consolidados de información semanal cuando la producción de harina de pescado supere la capacidad autorizada o sea mayor a la proporción a la cantidad de recursos descargados según el ratio de producción (estimado en alrededor de 4) o se realicen modificaciones estructurales a la planta sin autorización. 
Con respecto a la situación de la fiscalización actual descrita, las investigaciones mencionadas (Universidad Cayetano Heredia en "La pesquería peruana de anchoveta" y Carlos Paredes y Úrsula Letona en "Contra la corriente: La anchoveta peruana y los retos para su sostenibilidad”) presentan las siguientes opciones de mejora:

1. Mejorar la tipificación y coordinación de las instituciones, públicas y privadas, y los distintos niveles de gobierno (nacional y regional) involucrados.

2. Exigencia gradual del sistema SISESAT a las embarcaciones artesanales y consolidarlo en las embarcaciones de menor escala.

3. Seguir mejorando la automatización del sistema de peso en base a adelantos en la tecnología e implementar un monitoreo del software y sistemas de equipos de pesaje en plantas de harina y aceite de pescado, para evitar manipulación.

4. Para evitar los conflictos de intereses entre empresas supervisoras y agentes regulados, los costos del servicio de SISESAT y PVCPDAM deberían financiarse a través de un fondo en forma de fideicomiso operado por PRODUCE, con lo que la información podría hacerse pública. Además, se debería establecer un monto fijo a pagar, por planta y por temporada, que cubra los costos de ejecución del programa, para que las empresas ejecutoras den un trato equitativo a todas las empresas.

Además, Elena Conterno en la entrevista (Anexo 1) mencionó las siguientes falencias, relacionadas al CHD:

1. No hay control de veinticuatro horas en los muelles, donde se genera del desembarque y es donde debe comenzar la cadena de trazabilidad.

2. No hay control de veinticuatro horas en las plantas de residuos y de reaprovechamiento, que deberían servir para hacer harina de pesca de baja calidad en base a los desperdicios de la anchoveta destinada a CHD, lo cual incluye cabeza, cola vísceras y la anchoveta que llegó machucada que en suma representa aproximadamente el $80 \%$ de lo que arriba. Inclusive, enfatizó que el segundo tipo es el de mayor incidencia, puesto que no cuenta con una planta de CHD asociada; sino que surgieron como una 
alternativa en ciudades en que las plantas de harina residual no tenían la capacidad para procesar los residuos y en la práctica están operando de forma ilegal.

3. Falta de control sobre la harina, puesto que se exporta más de lo que se produce legalmente. Está establecido que un factor de conversión de TM de anchoveta a harina de pescado es aproximadamente de cuatro. Por tanto, argumenta que vía SUNAT se debe evaluar lo exportado por empresa y en harina de pescado y multiplicarlo por este factor para investigar aquella TM de anchoveta que sea de exceso.

4. La tecnología actual no permite diferenciar el rango de longitud dentro del cardumen, dado que la anchoveta es una especie de talla reducida. Además, esta tecnología no es compartida por todas las embarcaciones del sector; por ejemplo, los vikingos no cuentan con ella. Este es un punto importante, puesto que el sistema de sanciones/multas especificado en el RISPAC penaliza al armador por la pesca de juveniles que exceda el diez por ciento del total; sin embargo, él no puede determinar a priori el nivel de juveniles en el cardumen.

5. Hay embarcaciones de menor escala que cuentan con el GPS; sin embargo no lo activan sino que solo cuenta con el contrato y esto no es monitoreado por la entidad. Por otro lado, las embarcaciones artesanales no cuentan con este sistema y no les exige la norma. 


\section{CONCLUSIONES}

A continuación se detallan las conclusiones a las que se han llegado a partir de la investigación:

- La normativa tiene un impacto positivo en la eficiencia económica; puesto que reduce el esfuerzo pesquero, su impacto es neutral en términos de distribución y positivo en la sostenibilidad del recurso.

- La normativa tiene un impacto positivo en la reducción del esfuerzo pesquero, mientras que el valor agregado tanto de Consumo Humando Directo (CHD) como de Consumo Humano Indirecto (CHI) presenta una tendencia alcista (gráfico 3.18) y por ende en la eficiencia económica. El desincentivo de la carrera olímpica (depredación de la anchoveta por la pesca desmesurada causada por competencia no regulada) en base a este marco ha generado un cronograma de desembarque más eficiente por temporada de pesca (gráfico 3.3); una reducción del sobredimensionamiento de embarcaciones asociado a un incremento de la capacidad por embarcación (gráfico 3.13); y posiblemente una reducción del nivel de empleados (evidenciado en el uso del programa FONCOPES del cuadro 3.5). En términos de planta, la normativa no tiene un efecto directo, pues el incremento de la capacidad respecto al número de plantas puede deberse a factores de tecnología y/o ampliaciones de las plantas existentes (cuadro 3.2).

- En términos prácticos, el impacto de la normativa es nulo en la distribución, puesto que, si bien la normativa enfatiza la promoción del CHD, el incremento que ha experimentado la producción de los productos asociados a este tipo de consumo (desde el año 2000) no se relaciona a la emisión de la normativa (años 1990, 2007 y 2008). Más aún, casi la totalidad de la dotación de anchoveta se destina a CHI, evidenciando una preferencia revelada del productor por el destino de la anchoveta hacia este tipo de consumo. Sin embargo, sí se puede concluir que la prohibición para la negociación del desembarque de anchoveta en favor del CHD distorsiona las decisiones del productor y desfavorece la 
eficiencia económica, ya que el valor agregado de la harina de pescado es mayor que el de la elaboración y preservación de la anchoveta (gráfico 3.18).

- La normativa tiene un impacto positivo en la sostenibilidad y por ende sobre la eficiencia económica, dado que se observa una reducción de la volatilidad de la pesca de juveniles a partir de la vigencia del RISPAC (expresado en la baja de la varianza anual del porcentaje de pesca de juveniles del gráfico 3.21). Cabe precisar que esta afirmación está limitada a posibles eslabones en la recolección de la data, dado que no existe control sobre la posibilidad de que el pescador pesque un juvenil más allá del límite permitido y lo descarte al mar, previo al control realizado en los puertos. Además, la normativa que genera sanciones/multas para desincentivar la depredación de juveniles funciona bajo el supuesto de que el armador tiene conocimiento del nivel de juveniles por cardumen lo cual en la práctica no sucede (Anexo 2). Sin embargo, la implementación de un reglamento que verifique el cumplimiento de la normativa mediante mecanismos de supervisión y fiscalización (RISPAC), aun cuando presente espacios de mejora, y una ley que vuelva aún más riguroso el cumplimiento de la cuota global (LMCE), basada en la opinión de IMARPE que busca la sostenibilidad de la pesca, es un avance importante hacia la preservación de la especie y por tanto hacia la eficiencia económica del sector.

- En consecuencia a lo descrito, el sistema de cuotas implementado en el Perú, a través del LMCE y reforzado por el RISPAC, ha demostrado un impacto positivo en la eficiencia económica. Sin embargo, el hecho de que su estructura relacione la cuota a las embarcaciones genera una problemática en las negociaciones, en términos de costos de transacción y asimetrías de información, tal que es posible dificulte o imposibilite la reasignación de las cuotas a su punto óptimo acorde a lo planteado en el teorema de Coase. Por tanto, el esquema empleado de asignación histórica puede no ser el más recomendable.

Por otro lado, la alternativa del uso de subastas presenta condiciones en su diseño, que de no cumplirse, puede generar mayor problemática que las de la asignación histórica, tanto así que la presidenta de la Sociedad Nacional de Pesca (SNP) no está de acuerdo con esta alternativa. 
Por tanto, no sería recomendable que se imponga el cambio del método hasta verificar el cumplimiento de las condiciones mencionadas y que se haya consensuado con los actores privados el procedimiento.

- Si bien el impacto de la normativa sobre la eficiencia económica del sector es positiva, su implementación aún es limitada dadas las falencias en el mecanismo de control y fiscalización descritos en el capítulo 4. Entonces, es necesario que PRODUCE genere las modificaciones pertinentes para su perfeccionamiento, considerando que a la fecha, según estudios y opinión del sector privado, las principales falencias son: i) descoordinación entre los entes reguladores; ii) limitación de los programas de control y fiscalización (Sistema de Seguimiento Satelital para Embarcaciones Pesqueras- SISESAT y del Programa de Vigilancia y Control de las actividades pesqueras y acuícolas en el ámbito nacional-PVCPDAM) en las embarcaciones de menor escala y nulidad en las embarcaciones artesanales; iii) conflicto de intereses en el método de financiamiento de los programas de control y fiscalización así ; iv) falta de transparencia en los resultados de los programas SISESAT y PVCPDAM; v) desigualdad en la rigurosidad del control y fiscalización entre CHI y CHD; vi) falta de control sobre la exportación de harina de pescado respecto a la producción; vii) normativa de control sobre pesca de juveniles en base al supuesto equívoco de que el armador tiene conocimiento sobre el nivel de juveniles por cardumen. 


\section{RECOMENDACIONES}

A continuación se detallan las recomendaciones:

- Si bien sería favorable para la sociedad un mayor consumo de la anchoveta debido a sus propiedades favorables para la nutrición humana, dado que lo mejor es no distorsionar las decisiones de los productores, la normativa no debería orientarse hacia políticas de oferta como hasta la fecha. Sino, a políticas de demanda que promuevan la orientación del recurso hacia productos de CHD. Por ejemplo, mediante campañas publicitarias (programa a comer pescado) y reducciones de costos de transacción en la penetración del mercado (problema logístico para comercialización de la anchoveta como CHD referente a la cadena de frío).

- En base a los impedimentos para controlar si efectivamente la embarcación no pescó más allá de su límite de juveniles en el periodo previo a su arribo al puerto, podría obtenerse mayor información al ofrecer el primer día de pesca de cada embarcación por temporada un porcentaje adicional al máximo de pesca de juvenil, el cual no sería multado.

- Si bien, teóricamente la relación de la cuota con la embarcación genera dificultades en las transacciones, antes de tomar una decisión respecto al cambio de la estructura actual, se debería verificar la facilidad de las negociaciones (bajos costos de transacción y asimetrías de información). Entonces, antes de implementar la alternativa de las subastas, se debe hacer un estudio de los factores clave de la organización industrial para determinar el diseño apropiado que debe presentar y verificar que este garantice los aspectos mencionados en el Capítulo 4. Además, se debe determinar si el ente regulador posee la capacidad de implementar esta alternativa adecuadamente y concertar con los actores privados al respecto, dado los niveles de inversión ya realizados. 
- PRODUCE debería iniciar un proceso de diálogo con los agentes regulados e investigadores del tema para poder determinar cómo perfeccionar el proceso de control y fiscalización sobre la cadena productiva, siendo ideal iniciar por los puntos ya evidenciados en la opinión de estudios en el tema y del mismo sector privado : i) la mejor estipulación y coordinación entre las entidades involucradas en el control y fiscalización; ii) la ampliación de las medidas del Sistema de Seguimiento Satelital para Embarcaciones Pesqueras (SISESAT) y del Programa de Vigilancia y Control de las actividades pesqueras y acuícolas en el ámbito nacional (PVCPDAM) en forma gradual a las embarcaciones artesanales y la consolidación en las embarcaciones de menor escala; iii) financiar los servicios de SISESAT y PVCPDAM mediante un fideicomiso de monto fijo (que incluya planta y temporada) administrado por PRODUCE para evitar conflicto de intereses, que la información se pública y que las empresas ejecutoras den un trato equitativo a todas las empresas; iv) dar igual importancia al control de CHD como al de CHI, especialmente en las plantas de residuos y de reaprovechamiento; v) generar un mejor control entre lo que se exporta como harina de pescado y lo que se produce legalmente, en base a la mejora en la automatización del pesaje mediante la balanza gravimétrica; vi) redefinir la normativa de sanciones por pesca de juvenil por encima del rango permitido, de forma que el supuesto no recaiga en que el armador tendrá conocimiento a priori sobre el nivel de juveniles por cardumen. 


\section{FUENTES}

- Banco Central de Reserva del Perú http://www.bcrp.gob.pe/

- Instituto del Mar del Perú http://www.imarpe.pe/imarpe/

- Instituto Nacional de Estadística e Informática Perú http://www.inei.gob.pe/

- Food and Agriculture Organization of the United Nations http://www.fao.org/home/en/

- Ministro de la Producción http://www.produce.gob.pe/ 


\section{REFERENCIAS}

- Aguilar L., V. (2008). Eficiencia, Sostenibilidad Ambiental y Equidad Intergeneracional en los Modelos de Generaciones Traslapadas. Lecciones de Política. En: Cuestiones Económicas, Revista de Quito. Banco Central de Ecuador, enero-junio de 2008, Vol. 24, № 1, página 63-110

- Aguilar, A., Reid, C., Thorpe, A. (2000). The Political Economy of Marine Fisheries Development in Peru, Chile and Mexico. Journal of Latin American Studies, 32(2), 503-5027

- Arévalo, A. (1955). Historia y Fundamentos de la pesquería de Perú. Lima: Las Hormigas.

- Bowles, S. (2004). Microeconomía: Comportamiento, Instituciones, y Evolución. Princeton University Press, 689 páginas.

- Coase, Ronald H. (1960). El problema del costo social. The Journal of Law and Economics, 1-44

- Dupont, Diane P. y Phipps, Shelley A. (1991). Distributional Consequences of Fisheries Regulations. Canadian Journal of Economics, 24 (1), 206-208

- Gordon, H. Scott. (1954) The Economic Theory of a Common-Property Resource: The Fishery. The Journal of Political Economy, 62(2), 124-142.

- Hardin, G. (1968). The Tragedy of the Commons. En: Science Magazine, diciembre 1968, Vol. 162, N³859, página 1243-1248

- Jaisuño A. (1973). Libro de La Industria Pesquera en el Perú: Génesis, Apogeo y crisis. Lima: 96 páginas.

- Montero, Juan Pablo (2012). Cuotas de pesca y libre competencia: Consideraciones para la nueva ley de pesca. Centro de Estudios Públicos, 127, $1-51$. 
- Paredes Lanatta, C., Letona Pereya, U. (2013). Contra la corriente: La anchoveta peruana y los retos para su sostenibilidad ( $1^{\mathrm{a}}$ ed.). Perú: WWF, USMP.

- Peña T., J. (1966). Regulación pesquera chilena: Una perspectiva histórica. Santiago: Universidad de Chile, Cuadernos de Economía, diciembre 1996, N 100, página 367-395

- Prochaska J., F. (1978). Theoretical and Empirical Considerations for Estimating Capacity and Capacity Utilization in Commercial Fisheries. American Journal of Agricultural Economics, 60(5), 1020-1025.

- Saavedra, Eduardo, Willington, Manuel (2012). Eficiencia en asignación de cuotas individuales de pesca: Teorema de Coase y asimetrías de información. Centro de Estudios Públicos, 127, 54-85

- Sociedad Nacional de Pesquería (2013). Aportes al debate en pesquería. № 32013

- Sociedad Nacional de Pesquería (2003). Libro de Oro de la Pesquería Peruana. Lima: Sociedad Nacional de Pesquería, 402 páginas.

- Stavins Robert N. (2011). The Problem of the Commons: Still Unsettled after 100 Years. The American Economic Review, 101(1), 81-108.

- Universidad Cayetano Heredia (2011). La pesquería peruana de anchoveta (1era. ed.). Lima: Cancha y Media

- Williamson, O. (2002). The Theory of the Firm a Governance Structure: From Choice to Contract. Journal of Economic Perspective, 16(3), 171-195.

- Varian, H. (2007). Microeconomía Intermedia. Barcelona: 789 páginas. 
ANEXOS 


\section{ANEXO 1: NORMATIVA}

\section{Ley General de la Pesca y su Reglamento}

El 7 de diciembre de 1992 y el 14 de marzo de 2001 respectivamente, se aprobó la Ley General de Pesca (Decreto Ley N²5977) y el Reglamento de la misma (Decreto Supremo N ${ }^{\circ}$ 012-2001-PE. Su emisión constituye el punto de partida del ordenamiento pesquero del Perú, ya que previamente, a pesar de la importancia del sector desde la década de los cincuentas, las disposiciones de regulación no habían sido significativas para una normalización del sector en términos de una economía de mercado.

- Ordenamiento pesquero y objetivo de la ley

En tal sentido, esta ley define al ordenamiento pesquero como "el conjunto de normas y acciones que permiten administrar una pesquería, sobre las bases del conocimiento actualizado de sus componentes biológico pesqueros, económicas y sociales”. Para lograrlo, de acuerdo con el artículo 1 de la Ley, se busca promover el desarrollo sostenido del sector, como fuente de alimentación, empleo e ingresos, así como asegurar un aprovechamiento responsable de los recursos hidrobiológicos, optimizando los beneficios económicos, en armonía con la preservación del medio ambiente y la conservación de la biodiversidad.

- Rol del Estado

Por tanto, la Ley establece el rol y competencias del sector público en búsqueda del objetivo mencionado. El Estado, en lo referente a la promoción de la comercialización del sector, conforme a los artículos 3 y 21 de la mencionada ley, promueve preferencialmente las actividades extractivas de recursos hidrobiológicos destinados al CHD y fomenta la inversión extranjera, con sujeción a las disposiciones pertinentes de la legislación peruana, mediante 1) medidas que contribuyan a alentar la investigación, conservación, extracción, cultivo, procesamiento y comercialización de los recursos pesqueros; 2) incrementar la construcción y modernización de la infraestructura y servicios pesqueros; 3) estimular las innovaciones tecnológicas propiciando la modernización de la industria pesquera y por ende optimizando la utilización de los recursos hidrobiológicos a través de la obtención de un producto pesquero 
con mayor valor agregado; y 4) facilitar la adquisición de bienes destinados a la actividad pesquera.

En cuanto al desarrollo de la actividad pesquera, promueve e incentiva la investigación y capacitación pesquera que realizan los organismos públicos especializados del sector y las universidades, así como la que provenga de la iniciativa de personas naturales o jurídicas del sector privado, cuyos resultados deberán ser oportunamente difundidos por medios apropiados. En forma general, conforme al artículo 11, según el tipo de pesquería y la situación de los recursos que se explotan, establecerá el sistema de ordenamiento que concilie el principio de sostenibilidad de los recursos pesqueros o conservación en el largo plazo, con la obtención de los mayores beneficios económicos y sociales.

- Rol del Ministerio de Pesquería (actualmente Viceministerio de Pesquería)

Análogamente, el Ministerio de Pesquería, para fines de la regularización del sector, según el artículo 9, determinará, según el tipo de pesquerías, los sistemas de ordenamiento pesquero, las cuotas de captura permisible, las temporadas y zonas de pesca, la regulación del esfuerzo pesquero, los métodos de pesca, las tallas mínimas de captura y demás normas que requieran la preservación y explotación racional de los recursos hidrobiológicos. En base a lo mencionado, el desarrollo de la actividad pesquera desde la vigencia de esta norma se encontró supeditado a:

$\checkmark$ Concesión.- Para 1) administración y usufructo de la infraestructura pesquera del Estado y/o 2) acuicultura que se realice en terrenos públicos, fondos o aguas marinas o continentales.

$\checkmark$ Autorización.- Para 1) desarrollo de la acuicultura en predios de propiedad privada, 2) realizar actividades de investigación, 3) incremento de flota y/o 4) instalación de establecimientos industriales pesqueros.

$\checkmark$ Permiso de Pesca.- Para 1) operación de embarcaciones pesqueras de bandera nacional y/o 2) operación de embarcaciones pesqueras de bandera extranjera.

$\checkmark$ Licencia.- Para operación de plantas de procesamiento de productos pesqueros. 
Para promover el desarrollo del sector, según el artículo 15, determina los correspondientes mecanismos de financiación y propicia la cooperación internacional, en procura de la provisión suficiente y oportuna de fondos, que posibiliten el eficiente cumplimiento de los planes y programas destinados a investigación y capacitación; además, según el artículo 17, destinará un porcentaje de los derechos que graven el otorgamiento de las concesiones, autorizaciones, permisos de pesca y licencias.

Por otro lado, en línea con la búsqueda de promoción del CHD por parte del Estado, conforme al artículo 62 del Reglamento, el Ministerio de la Pesquería por intermedio del Fondo Nacional de Desarrollo Pesquero FONDEPES, promueve y desarrolla la construcción de infraestructura básica y el equipamiento para el desarrollo de la pesquería artesanal, mediante la entrega en administración, uso u otra modalidad legal, de los bienes siguientes:

$\checkmark \quad$ Muelles, desembarcaderos y otros sistemas de desembarque

$\checkmark$ Módulos para el manipuleo, lavado y fileteo de pescado

$\checkmark$ Plantas o cámaras de hielo o frío, así como camiones isotérmicos y otros vehículos de transporte refrigerado

$\checkmark$ Plantas de transformación o procesamiento primario y otros equipos, tales como ahumado-res y secadores.

Además, conforme al artículo 63 del Reglamento, se estableció la zona reservada para la actividad pesquera artesanal y de menor escala, entre las cero y cinco millas marinas. En dicha área reservada, está prohibido el uso de artes y aparejos de pesca que modifiquen las condiciones bioecológicas del medio marino, tales como redes de arrastre de fondo, redes de cerco industriales, rastras y chinchorros mecanizados.

En cuanto al medio ambiente, según el artículo 78 del Reglamento, los titulares de las actividades pesqueras y acuícolas son responsables de los efluentes, emisiones, ruidos y disposición de desechos que generen o que se produzcan como resultado de los procesos efectuados en sus instalaciones, de los daños a la salud o seguridad de las personas, de efectos adversos sobre los ecosistemas o sobre la cantidad o calidad de los recursos naturales en general y de los recursos hidrobiológicos en particular, así como de los efectos o impactos resultantes de sus actividades. En este sentido, están obligados a ejecutar de 
manera permanente planes de manejo ambiental y, en consecuencia, a realizar las acciones necesarias para prevenir las consecuencias negativas de los hechos mencionados. Asimismo, están obligados a adoptar medidas destinadas a la conservación de los recursos hidrobiológicos y de los ecosistemas que les sirven de sustento. Para monitorear el cumplimiento de las responsabilidades mencionadas, se realizaran programas de monitoreo de efluentes, emisiones entro otros, en función a la frecuencia que fije el Programa de Adecuación y Manejo Ambiental y conforme a los protocolos aprobados por el Ministerio de Pesquería. Los resultados de los programas de monitoreo serán presentados a la Dirección Nacional de Medio Ambiente para su evaluación y verificación.

- Prohibiciones, infracciones y sanciones

Para asegurar la efectividad de las medidas establecidas en la presente ley, en la misma se detallaron las prohibiciones, infracciones y sanciones.

En tal sentido, los actores que participen de la actividad pesquera se encontraban imposibilitados de 1) realizar actividades pesqueras sin la concesión, autorización, permiso o licencia correspondiente, o contraviniendo las disposiciones que las regulan; 2) extraer, procesar o comercializar recursos hidrobiológicos declarados en vedas o de talla o peso menores a los establecidos; 3) utilizar implementos, procedimientos o artes y aparejos de pesca no autorizados, así como llevar a bordo o emplear aparejos o sistemas de pesca diferentes a los permitidos; 4) contravenir o incumplir las normas de sanidad, higiene y seguridad industrial calidad y preservación del medio ambiente en el procesamiento y comercialización de productos pesqueros; etc. De lo contrario, serán sancionados administrativamente, sin perjuicio de las acciones civiles o penales a que hubiere lugar, mediante 1) multa, 2) suspensión de la concesión, autorización, permiso o licencia, 3) decomiso o 4) cancelación definitiva de la concesión, autorización, permiso o licencia.

- $\quad$ Síntesis y aportes

En síntesis, se especifican los parámetros de la actividad del sector, referidas a investigación y capacitación, extracción, procesamiento, y comercialización; en base a consideraciones relacionadas a regímenes de acceso, captura total permisible, magnitud del esfuerzo de pesca, temporadas de pesca, 
tallas mínimas de captura, zonas prohibidas o de reserva, artes, aparejos, métodos y sistemas de pesca, así como las necesarias acciones de monitoreo, control y vigilancia, a ser respetadas según lo establecido en el punto de prohibiciones, infracciones y sanciones.

El aporte de la presente ley es normalizar y ordenar el sector pesquero en un marco general de explotación y sostenibilidad del recurso; además, se favorece el CHD mediante programas de promoción y establecimientos de zonas de reserva para uso exclusivo de este tipo de consumo.

\section{Reglamento de Inspecciones y Sanciones Pesqueras y Acuícolas - RISPAC}

En el 2007 se prosigue con la labor de regularizar el sector y se publica el Reglamento de Inspecciones y Sanciones Pesqueras y Acuícolas - RISPAC (Decreto Supremo $\mathrm{N}^{\circ}$ 016-2007). En este se establecen las facultades y procedimiento del fiscalizador, así como los parámetros de los decomisos de recursos hidrobiológicos destinados al CHD y CHI; se nombra a los órganos administrativos sancionadores (Comisiones Regionales de Sanciones, Gobiernos Regionales, Dirección General de Seguimiento, Control y Vigilancia - DIGSECOVI y el Comité de Apelación de Sanciones del Ministerio de la Producción); y el procedimiento. En cuanto a las multas, estas se basan en un sistema de sanción por factor respecto al recurso sobre el cual es materia.

Actualmente, este Reglamento se encuentra modificado sujeto a las nuevas Leyes del sector. En tal sentido, las infracciones se dividen en:

- Infracciones vinculadas al incumplimiento de los LMCE.

- Infracciones vinculadas al desarrollo de las actividades extractivas.

- Infracciones vinculadas al Fondo de Compensación para el Ordenamiento Pesquero. 


\section{Ley sobre Límites Máximos de Captura por Embarcación y su Reglamento}

Un año después, entra en vigencia la Ley sobre Límites Máximos de Captura por Embarcación (Decreto Supremo $N^{\circ}$ 1084) y su respectivo Reglamento (Decreto Legislativo $\mathrm{N}^{\circ}$ 1084), los cuales tienen por objetivo establecer un mecanismo de ordenamiento referido a la extracción de los recursos de anchoveta y anchoveta blanca con fines de CHI.

- Cálculo del LMCE

Según la Ley, los límites se descomponen en dos aspectos: temporadas de pesca y embarcaciones. Por cada temporada, el Ministerio fijará el Límite Máximo Total de Captura Permisible del recurso anchoveta para Consumo Humano Indirecto (LMCTP), basado en el informe científico de la biomasa del recurso publicado por el Instituto del Mar del Perú (IMARPE). Su multiplicación el Porcentaje Máximo de Captura por Embarcación (PMCE) asignado por el Ministerio otorgará el Límite Máximo de Captura por Embarcación (LMCE). El PMCE es calculado dividiendo el índice de participación de dicha embarcación entre la suma total de índices de participación que corresponden a todas las embarcaciones. Estos índices se basan en la ponderación de la mejor participación de capacidad de bodega y/o la captura histórica de anchoveta por embarcación según al Régimen del Decreto Ley al que pertenezcan y sus excepciones (contemplado en los artículos 8 y 9 del Reglamento).

- Re-cálculo del PMCE

Debido a su importancia para el sistema planteado y para asegurar el cumplimiento del mismo, se plantearon las siguientes causales del recálculo del PMCE (artículo 11 del Reglamento):

$\checkmark$ Durante cuatro temporadas de pesca consecutivas su porcentaje no ejecutado del LMCE asignado supera el $20 \%$ en cada período. La reducción corresponde al porcentaje promedio no capturado durante las cuatro (4) Temporadas de Pesca. Cabe destacar que, para desincentivar este punto, las cantidades no extraídas en ejecución de un LMCE asignado para una temporada de pesca no podrán ser transferidas a ninguna otra temporada, extinguiéndose el derecho del armador sobre los saldos no 
extraídos en la fecha de expiración de la Temporada de Pesca correspondiente (artículo 13 del Reglamento).

$\checkmark$ Cuando se declara la caducidad o extinción del PMCE como consecuencia de haberse caducado o extinguido el permiso de pesca de una Embarcación.

$\checkmark$ Cuando lo disponga una resolución administrativa o judicial firme que implique (i) la modificación de los PMCE asignados por el Ministerio; (ii) el otorgamiento de un permiso de pesca que se encontraba en trámite por sustitución de igual capacidad de bodega; (iii) el reconocimiento de un derecho de incremento de flota por sustitución de igual capacidad de bodega, saldos o cualquier otro derecho otorgado con posterioridad a la aprobación del Listado de PMCE; o, (iv) la modificación de un permiso de pesca.

$\checkmark$ Cuando se aplique una penalidad o una sanción de reducción del PMCE, de acuerdo a lo establecido en los Convenios de Fiel y Cabal Cumplimiento de Obligaciones, el Reglamento de Inspecciones y Procedimiento Administrativo Sancionador - RISPAC, sus normas ampliatorias y modificatorias.

- Transferencia del PMCE

Cabe destacar que, conforme al artículo 7 del Reglamento, El PMCE no podrá ser transferido de manera independiente de la embarcación que sirvió de base para su cálculo y determinación inicial. En el caso de que la embarcación que sirvió de base para su cálculo y determinación inicial sea desmantelada (desguazada), dedicada de manera definitiva a otra pesquería u obtenga una autorización de incremento de flota para operar la embarcación mediante la sustitución de igual volumen de capacidad de bodega de la flota existente, en la extracción de recursos plenamente explotados, en recuperación y subexplotados, o el armador acredite que dicha embarcación ha sido modificada para ser utilizada para otros fines y no realizará actividades pesqueras, el total PMCE podrá ser asociado e incorporado a otra u otras embarcaciones del mismo armador de manera definitiva. 
- Incremento de flota y participación de la actividad de procesamiento

Este punto resulta de importancia, puesto que para el caso de anchoveta y anchoveta blanca, conforme a la segunda disposición final de la Ley, queda prohibido el otorgamiento de autorizaciones de incrementos de flota y permisos de pesca salvo que se sustituya igual capacidad de bodega de la flota existente correspondiente a dichos recursos. Análogamente, se prohíbe el acceso a la actividad de procesamiento para consumo humano indirecto, así como la instalación y aumento de capacidad de las plantas de harina de pescado estándar y de alto contenido proteínico, salvo la instalación de plantas de harina de pescado residual, de conformidad con las disposiciones sectoriales.

- Fondo de Compensación para el Ordenamiento Pesquero

Este sistema, que tiene implicancias sobre los aspectos de sostenibilidad y de esfuerzo pesquero del CHI, impacta directamente en el salario de los pescadores, pues las jornadas laborales requeridas por cada empresa disminuyen al asignársele un máximo de captura por sus embarcaciones. Es así que la Ley introduce el aspecto social mediante su artículo 11, el cual establece la creación del Fondo de Compensación para el Ordenamiento Pesquero (FONCOPES), financiado por los aportes obligatorios correspondientes a los titulares de permisos de pesca incluidos dentro de la medida. Este tiene como fin el financiamiento exclusivo de los Programas de Beneficios destinados a los trabajadores de los armadores considerados en la presente ley.

Los trabajadores tuvieron la posibilidad de acceder al Programa de Jubilación Adelantada si contaban con cincuenta años de edad a la finalización de la campaña de difusión. De lo contrario, pudieron y pueden acogerse al Programa de Incentivos a la Reconversión Laboral hacia otras actividades pertinentes o al Programa de Desarrollo y Promoción de Mypes, por el cual se favorece el inicio de micro y pequeñas empresas por parte de los beneficiarios.

- Infracciones y sanciones

En el caso de sobrepasar el LMCE autorizado y el margen de tolerancia aprobado, el artículo 27 de la Ley establece que al implicado se le descontará el triple del volumen del exceso detectado del LMCE correspondiente a la 
siguiente temporada, expresado en toneladas métricas, sin perjuicio de la multa aplicable por el exceso de captura considerado dentro del margen de tolerancia.

Según la gravedad del caso, de acuerdo al artículo 28 de la Ley, las sanciones para las infracciones de la Ley contemplan medidas de multa, reducción del PMCE o cancelación del permiso de pesca; independientemente de la responsabilidad penal o civil. Además, el cumplimiento de la medida de sanción no significará la convalidación de la situación irregular, debiendo el infractor cesar de inmediato los actos que dieron lugar a la sanción.

\section{Zona de Reserva para el Consumo Humano Directo}

Finalmente, el 14 de diciembre de 2013 se publica el Decreto Supremo 0112013, ratificando el D.S.005-2012, denominado "Establece Zona de Reserva para el Consumo Humanos Directo del recurso anchoveta y anchoveta blanca aplicable desde el extremo norte del dominio marítimo hasta los $16^{\circ} 00^{\prime} 00^{\prime \prime}$ Latitud Sur, el cual define que la zona que abarca entre las 0 y 10 millas marinas se reservan para el Consumo Humano Directo, siendo la zona de entre 0 y 5 millas marinas de uso exclusivo para la actividad pesquera artesanal y la zona de entre 5 a 10 millas marinas de uso exclusivo para la actividad pesquera de menor escala.

Como se puede apreciar, la normativa detallada establece disposiciones que impactan sobre el esfuerzo pesquero, distribución del recurso y la sostenibilidad; por ende, tienen un impacto sobre la eficiencia económica del sector.

Antes de realizar la evaluación del impacto, desarrollado en el Capítulo 3, se especificará la composición de la organización la industria de la anchoveta, cuyos componentes son parte del análisis de indicadores del siguiente capítulo. 


\section{ANEXO 2: METODOLOGÍA VALOR AGREGADO}

Para determinar si el impacto de la normativa es positivo sobre la eficiencia económica, teniendo en cuenta que el enunciado de esta normativa busca promover la oferta de consumo humano directo, se tomó en consideración dentro de los indicadores propuesta al Valor Agregado generado por tipo de Consumo.

A continuación se detalla la metodología empleada para su cálculo, expuesta en el trabajo del INEI “Matrices Especiales de la Tabla de Insumo Producto 2007” del año 2009, cuya data se obtiene a través de encuestas dirigidas a empresas de comercio.

\section{Matriz de Producción a Valores Básicos}

Esta matriz muestra la disponibilidad de bienes y servicios nacionales, registrando en sus filas las categorías de Productos y en sus columnas las Actividades Económicas.

En tal sentido, está compuesta por:

- Producción Principal

Representa la producción homogénea del establecimiento para el que ha sido creado; es decir, se obtiene de la intersección del mismo tipo de producto (fila) y actividad económica (columna).

En tal sentido, la producción principal total se obtiene de la diagonal de la matriz, que constituye los ingresos percibidos por la producción principal por cada actividad económica.

- Producción Secundaria

Representa la producción no homogénea de la actividad; es decir, se obtiene de la suma de los ingresos percibidos por actividad económica (columna) relacionado a productos no principales de la misma.

En tal sentido, la producción secundaria total se obtiene de la resta de todos los elementos de la matriz de producción respecto a la diagonal de la misma. 
Habiendo definido los elementos de la matriz, se obtiene que la Oferta Nacional es la sumatoria de las filas; la Producción Típica es la sumatoria de la diagonal; y la Producción No Típica es la sumatoria de las producciones secundarias.

Tabla 12: Esquema de una Matriz de Producción (a valores básicos)

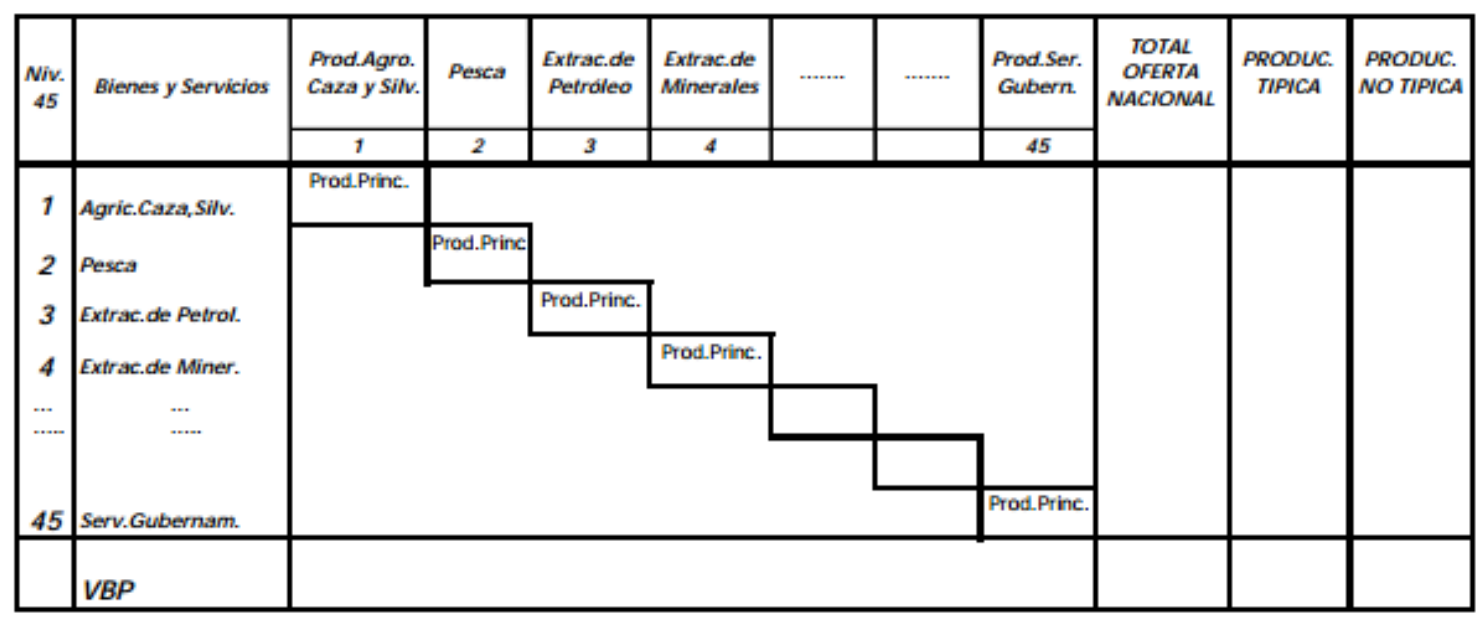

Fuente: INEI “Matrices Especiales de la Tabla de Insumo Producto 2007” (2009)

\section{Matriz de Demanda Intermedia}

Esta matriz muestra el total de productos utilizados por las diferentes actividades económicas para realizar la producción que los caracteriza. Al registrar los flujos interindustriales de los productos en las diferentes actividades, representa el uso de los productos en la elaboración o producción de otros.

En tal sentido, la sumatoria del valor por producto en cada actividad; es decir, la sumatoria por cada fila representa la demanda intermedia total por producto. Por otro lado, la sumatoria del valor por producto en una misma actividad; es decir, la sumatoria por cada columna representa el consumo intermedio de la respectiva actividad económica. 


\section{Matriz de Valor Agregado}

Esta matriz muestra la diferencia entre la valoración de la producción final de los bienes y la valoración de los insumos intermedios utilizados, con lo cual se debe cargar los factores productivos que participaron en la generación de la producción; es decir, representa las rentas generadas por estos factores (remuneración, otro impuestos a la producción, consumo de capital fijo y excedente neto de explotación).

Es en base a esta composición del VA que ofrece la data de INEI es que se determinó la intensidad en trabajo por cada componente del VA Pesca Total (Pesca y Acuicultura, Elaboración y preservación de pescado, y Elaboración de harina y aceite de pescado).

Dado que la data de las Tablas Insumo Producto (TIP) de INEI tienen como corte 2007 y no hay un histórico, asumiendo que en la producción de este tipo de productos no se ha generado un cambio tecnológico de impacto significativo, la evolución del VA por tipo de consumo se obtiene de la multiplicación del VA por tipo de consumo respecto a Total Pesca del 2007 (33\% CHI y 20\% CHD) con la participación de la Pesca respecto al PBI Nacional por cada uno de los años desde 1999, dado que previamente la producción de CHD era prácticamente nula. 


\section{ANEXO 2: ENTREVISTA A ELENA CONTERNO}

\section{Hoja de vida}

Economista de la Universidad del Pacífico y Master en Administración Pública de la Universidad de Harvard, actualmente se desempeña como presidenta del directorio de la Sociedad Nacional de Pesquería.

También ha sido miembro de directorio de entidades públicas como Fondo MiVivienda, Cofide y Foncodes, así como consultora de USAID, Banco Mundial, BID y GTZ.

\section{$\underline{\text { Entrevista }}$}

\section{Asignación de cuotas:}

\section{Derechos de propiedad/Costos de transacción}

- ¿Cree que realmente existe un mercado de cuotas pesqueras en el Perú?

La alternativa seleccionada ha sido asignar la cuota a la embarcación, porque la opción de dárselo a las plantas excluía a los más pequeños, por lo que los vikingos desaparecerían. Lo que se hizo fue asegurar que se mantuviera la capacidad de los vikingos, dado que se discierne entre madera y acero.

Sí hemos tenido adquisiciones. Se compran barcos y/o empresas. Es decir, mercado hay a nivel de lo que es cuota.

- ¿Es transable dicho producto o hay barreras administrativas o de mercado; es decir, costos de transacción, que hace que no sea un activo líquido?

Siempre el valor de la embarcación será la cuota. Muchos lo que hacen es comprar la embarcación, la dan de baja y la cuota la ponen a otra embarcación. Es parte de las reglas de juego. No se me ocurre que pudiese ser de otra manera.

A nivel de consumo humano directo algunas plantas se quejan de no tener abastecimiento. Nuestro mensaje es "compra", ya que nada te impide salir al mercado y comprar embarcaciones de menor escala. 
Lo que se debe evitar es que haya más permisos. Ya en el año 1997 se estableció que era una pesquería plenamente explotada, por lo que ya no podemos concebir nuevos permiso. Como hicieron mucho en consumo humano indirecto, probablemente tendrán que dar de baja lo comprado y hacer una embarcación modelo con frío y todas las características asociadas.

\section{Adquisición hostil}

- ¿La necesidad de un tamaño mínimo de compra de cuotas pesqueras es lo que genera que la única opción de entrada de nuevas empresas es la adquisición de una existente o "amenaza de adquisición hostil"?

No necesariamente hostil dado que son pocas las que cotizan en bolsa, que son Exalmar y Austral. Las demás tienen que ser por acuerdo. Además de empresa pueden ser armadores independientes que también hay, tanto de madera como de acero. Lo que sí es que tiene que ser dentro de lo que ya existe.

Algo importante es que el acceso se cerró en 1997 por la característica de plenamente explotada. De allí en adelante lo que tenemos es que hay que racionalizar; es decir, debemos tener menos esfuerzo pesquero.

Un segundo punto es que se ha empezado a exigir a las plantas varios requisitos, determinando al sector como de elevado costos fijos. Las empresas existentes han tenido que invertir mucho en esto, y muchos de los nuevos han tenido que comprar como CFG Investment. Tuvo que hacerse de lo que ya había y tuvo que invertir de manera significativa en flota y plantas para ser un actor calificado en este mercado.

\section{Subastas}

- ¿Qué problemas generaría una futura subasta de cuotas pesqueras por parte de Produce?

En primer lugar, a nivel internacional en ningún lado han funcionado las subastas para la pesquería. En Chile hicieron hacer unos años les fue pésimo. En Rusia lo hicieron e inmediatamente cambiaron. Si no me equivoco, Estonia también lo hizo y también lo dejaron de lado. Acá que quisieron hacerlo con el atún están en un enredo, porque lo precios que han subastado difieren en proporción 1 a 30, generando que el que pagó como 30 ya no quiere los contratos. En general, no es un instrumento usual a nivel pesquería. 
En segundo lugar, en referente a cuánto pagar, estamos de acuerdo con un análisis técnico de cuánto es el pago de hacerse por estos recursos; pero la subasta no es un instrumento que dure.

En tercer lugar, hay que reconocer que la industria existe por las plantas. La embarcación sin planta no sirve y estas plantas tienen varias exigencias (tipos de tratamientos, tipo de tecnología, etc.), ya que creo que es al único sector al que se le exigió cierta innovación tecnológica. Esta es una industria de elevados costos fijos, por lo que salir a licitar y que el Estado al postor no le exija planta en realidad es injusto. Si dejas a un actor existente sin cuota la planta no le sirve de nada, porque el poder lo tienen los armadores. Sin embargo, si se exige que todos deben tener planta, los vikingos son dejados de lado, generando su desaparición.

En cuanto a cuándo se realizaría la posibilidad de un cambio en las cuotas, hay que tener claro que la ley no cambia. Lo que tiene un plazo es los convenios de permanencia. En la ley se da vigencia al convenio por diez años. Entonces, estando la mayoría suscritos en el 2010, la permanencia del régimen está garantizada hasta el 2020. En este año lo que podría hacerse es discutir cuál es el pago por el recurso y en buena cuenta si es que volvemos a la carrera olímpica.

\section{Trazabilidad:}

\section{Produce como fiscalizador}

- ¿Por qué cree que Produce no tiene capacidad para conocer toda la trazabilidad de la cadena productiva de la pesca de anchoveta?

Nosotros creemos que en el consumo humano indirecto, tanto planta como armadores, sí hay full trazabilidad o control.

Más bien en el consumo humano directo es donde hay bastantes puntos sin control.

Día a día me reportan por ejemplo que en Pisco hay embarcaciones de menor escala desembarcando anchoveta y que se van a Pampa de secado y tengo videos. De igual forma en Chimbote. 
En primer punto, por más de que ya está prohibido, siguen construyendo embarcaciones. Si construyen embarcaciones y saben que no se van a dar más permisos es porque saben que van a poder pescar impunemente.

Produce explica que ya les han exigido convenio de abastecimiento; sin embargo, lo más importante es el punto de desembarque porque es ahí donde debe comenzar la cadena de trazabilidad. El problema es que el control en los muelles es bastante relativo, puesto que no controlan las veinticuatro horas, a diferencia de las plantas de harina que inclusive en temporada de vedas son custodiadas a tiempo completo, aunque con menor cantidad de personal.

En segundo punto, se debe mejorar el control sobre la harina. Se está exportando más harina de la que se produce legalmente. Vía SUNAT se debe hacer el ejercicio de evaluar lo exportado por empresa. Se realiza un ratio simple y multiplicado por cuatro se obtiene la tonelada de anchovetas. En base a eso cuestionar de dónde se obtuvieron para así evaluar la licitud de las mismas.

La harina ilícita no se hace en las plantas de harina de aceite de pescado. Se hacen en las plantas de harina residual, que deberían abastecerse solo de residuos (cabeza, cola vísceras y la anchoveta que llegó machucada), y las plantas de reaprovechamiento. Respecto a la primera, al desembarcar se tiene un diez por ciento de permiso para descarte. Una vez que se lleva a la planta se puede descartar en la entrada cuarenta por ciento. Como parte del proceso se saca cabeza, cola y vísceras y en buena cuenta le quitas la mitad. Por ende, legalmente se puede obtener del desembarque veinte por ciento de CHD y ochenta por ciento de harina residual. Sin embargo, no se obtiene ni ese porcentaje y están haciendo cien por ciento de harina residual. Referente a la segunda, nosotros y la Sociedad Nacional de Industrias concordamos en que son la madre del problema, ya que estas no tienen siquiera una planta de CHD adscrita. Simplemente se crearon en ciudades en que no había la capacidad de plantas de harina residual para procesar los residuos; pero se han convertido en plantas ilegales que hacen harina de pescado y es lamentable. Nosotros hemos venido reclamando que sean mucho más feroces con ellos. Justamente en estas plantas no se impone un control de veinticuatro horas y se quejan de que les ejercen demasiado control cuando no son de harina de pescado y son consumo humano directo. 


\section{Pesca de juveniles}

- Los mecanismos de fiscalización se generan mediante mecanismos de multas que dan incentivos perversos para no dar información de "pesca de juveniles" a las autoridades, ¿Cómo cree que podría mejorarse?

Me parece que lo que está haciendo PRODUCE en este punto es premiar el reporte oportuno.

Para comenzar, no todas las embarcaciones tienen SONAR. Nosotros tenemos como cincuenta embarcaciones que cuentan con un SONAR último modelo y ni si quiera con eso se puede saber ex - ante el nivel de juveniles en el cardumen a pescar. Inclusive el manual especifica que puede tener errores en el caso de caballa, cuyo mínimo es veintinueve centímetros, mientras que la anchoveta es aún más pequeño. Y esto es para aquellas que tienen el SONAR. En las demás es mucho más manual. Digamos, los vikingos no tienen instrumentos como para darse cuenta. De hecho, nosotros tenemos un porcentaje de juveniles mucho más bajo que los vikingos.

Ante ello, lo que está haciendo PRODUCE es enfatizar que se debe reportar a la unidad de reporte oportuno. Si te das cuenta que has pescado demasiados juveniles repórtalos y eso va a significar que se cierre la zona. PRODUCE lo que hace es inmediatamente cerrar la zona en forma preventiva creo que por tres día y cuando se encuentra mucha incidencia y con un informe de IMARPE lo cierran por cinco días más.

La mejor forma es tener el reporte oportuno para cerrar la zona.

Yo creo que lo más importante de sostenibilidad es que las cuotas se respetan. Si comparas lo que se viene pescando una vez implementada el sistema de cuotas individuales es por debajo de la cuota global y ya no hay todas estas embarcaciones clonadas.

Por otro lado, poner GPS a las embarcaciones de CHD no es tan caro y al día de hoy ya es exigible. Desde que salió la norma de las 10 millas se especifica que era exigible, pero no lo estaban haciendo y nosotros hemos presionado para que se logre. Lo siguiente fue que compraban el aparato, pero no lo prendían. 
No puede ser que sólo se exijan tener un contrato. Se tiene que verificar en tiempo real. Si en el muelle se verifica pesca, pero no se evidencia un trayecto, no se debe permitir esa descarga y se debe multar.

Hoy en día supuestamente sí tienen control satelital y está operativo a nivel de la menor escala. Artesanal aún no.

\section{Competencia / OPEP}

- ¿Cree que existe una competencia efectiva entre empresas pesqueras? ¿Perú y Chile al ser uno de los principales productores de harina de pescado, no podrían generar una suerte de OPEP de la anchoveta?

En general más que harina de anchoveta es harina de pescado, y en este Perú y Chile son importantes.

En anchoveta tenemos un stock sólo en Perú y otro que compartimos con Chile, del sur del Perú que se comparte con el norte de Chile.

Este tema de cartel es algo que se cree que pasa. En China creen que productores peruanos se coluden con la autoridad por los problemas que hemos tenido; pero es algo que no sucede porque se tienen muchos actores.

Nosotros concentramos cincuenta y seis por ciento de la cuota. Veinte por ciento son de acero independiente y veinte por ciento de madera. Son aproximadamente cuatrocientas empresas, por lo que nos es viable pensar en que se van a coludir.

Acá no se acuerda nada comercial justamente para una libre competencia. No se conversan precios, calidades, etc. Es un tema de oferta y demanda. 
- ¿A nivel de Produce, qué considera que hace falta para mejorar en el corto plazo?

Se tiene como doscientas diez embarcaciones de menor escala con su permiso. Estas en promedio que puedan pescar diez metros cúbicos ya son dos mil toneladas diarias, operando doscientos días al año son cuatrocientos mil toneladas. El año que más se ha tenido se ha demandado ciento veinticinco mil toneladas de anchoveta.

Sólo considerando las de menor escala tienen más que suficiente capacidad de pescar; pero las plantas de consumo humano directo afirman que no lo están desembarcando a ellas; es decir, se va a otro lado. Se está yendo a la harina a estas otras plantas que comentaba o a Pampas de secado que también las usan.

Cuando se pesca se debe demostrar que el esfuerzo que se hace es esfuerzo pesquero. A estas solo se les debe contabilizar cuando llegue a la planta.

¿De qué sirve que sea para CHD si no llega a una planta de CHD?

Esa trazabilidad es de suma importancia; de lo contrario, habrá que caducarles porque no están usando su permiso para lo que es y dárselo a otro. Si bien no tienen tan buen control en desembarque sí se tiene a nivel de plantas. Si te declaran que sí está pescando para CHD, pero no llega a la planta o está desviándolo y está cometiendo una ilegalidad o está pescando otra cosa. Hay que darle el permiso a alguien que si quiera.

Estamos conversándolo con PRODUCE. Ellos incluso contemplaban la posibilidad de dar nuevos permisos, pero no pueden hacer eso. Todos dicen que lo que se tiene que hacer es racionalizar. Además, que vas a hacer con los que ya tienen permiso. En el momento que des a nuevos, los que ya tienen no tendrían razón de ser. A las que ya tienen permisos y hasta tienen capacidad por el triple de lo necesario hay que generar que lleven el pescado a las plantas. Una forma es que justamente las plantas que demandas compren estos permisos.

Lo que proponemos es que a los que no usen para lo destinado se le caduque. En el momento que se caduque a uno van a empezar a pescar para el CHD o van a abrir su mercado. 


\section{ANEXO 3: ENTREVISTA A RAÚL SALAZAR}

\section{Hoja de vida}

Economista de profesión, es actualmente director Scotiabank Perú, Química del Pacífico, British American Tobbaco, Pesquera Diamante y Profuturo AFP. Además, es socio director y fundador de Macroconsult, firma consultora de la temática de regulación, social y macroeconomía.

Ha sido Presidente del Banco Wiese Sudameris y Director de Sindicato Pesquero, Peruplast, Royal \& Sun Alliance Vida, Royal \& Sun Alliance-Seguros Fénix, Banco de Lima-Sudameris, Banco de Lima, Unión Metalúrgica, Agroindustrial Lima SAC, Banco Agrario del Perú y la Empresa de Saneamiento de Lima.

Se le considera experto en asuntos económicos, monetarios y financieros con más de treinta años de experiencia profesional.

\section{$\underline{\text { Entrevista }}$}

\section{Asignación de cuotas:}

\section{Derechos de propiedad/Costos de transacción}

- ¿Cree que realmente existe un mercado de cuotas pesqueras en el Perú?

De que existe, existe. Como sabes, la cuota está asignada a la embarcación de pesca. De hecho, la embarcación tiene un valor fundamentalmente por la cuota que está asignada a ella. Muchas veces son embarcaciones antiguas que simplemente se desechan, pero se compra porque tiene la cuota. Desde ese punto de vista existe un mercado de cuota. Yo diría, sin embargo, que ese mercado es cada vez más pequeño porque el sistema se está consolidando en un grupo de empresas grandes que está acumulando todas las cuotas que están dispersas. Pero que el mercado existe, sí existe. 
- ¿Es transable dicho producto o hay barreras administrativas o de mercado; es decir, costos de transacción, que hace que no sea un activo líquido?

Originalmente asociar la cuota a una embarcación fue una forma práctica de llevar a cabo la asignación de las cuotas. En realidad, debía de asignarse por empresa y creo que a eso se está llegando. No me extrañaría que en el futuro cuando se revise cuotas lo que prime es la empresa.

La embarcación es cada vez menos significativa. Lo que se ve es que una empresa que adquiere cuota la une a otra para hacer embarcaciones más eficientes y modernas. Entonces, la asignación individual se está consolidando. Ahora las embarcaciones tienen cuotas originales de tres o dos embarcaciones.

Cada vez hay menos embarcaciones libres. En estos momentos la cuota es muy cara porque se tiene derecho a un recurso natural que en estos momentos es muy escaso.

Los que tienen cuotas que no están utilizando directamente o la utilizan de manera no eficiente en su óptimo tienen incentivos muy fuertes para venderla, puesto que la cuota vale mucho.

\section{Adquisición hostil}

- ¿La necesidad de un tamaño mínimo de compra de cuotas pesqueras es lo que genera que la única opción de entrada de nuevas empresas es la adquisición de una existente o "amenaza de adquisición hostil"?

Para mí eso es parte de un mercado. En el Perú, la adquisición hostil no es un medio muy eficaz para lograr adquisiciones, porque la mayor de las empresas no está listada en bolsa. Son de propiedad individual o de muy pocos socios.

La única empresa que debe tener accionariado difundido es la listada en Noruega. Con la plata obtenida compró CAMPOSOL.

Va a ser un mercado de 5 o 6 empresas que van a competir entre ellas, pero nada más. 


\section{Subastas}

- ¿Qué problemas generaría una futura subasta de cuotas pesqueras por parte de Produce?

La gran discusión hoy día es cuánto tiempo durará las cuotas asignadas ahora. Una vez que se dé solución a eso, la siguiente es cómo se hace para asignarlas nuevamente.

En ese caso, la subasta es uno de los tantos mecanismos que existen. Pero antes debe resolverse el problema de si las cuotas son permanentes o por cuánto tiempo duran.

Hasta ahora no se ha resuelto y en realidad esa es la gran pregunta.

\section{Trazabilidad:}

\section{Produce como fiscalizador}

- ¿Por qué cree que Produce no tiene capacidad para conocer toda la trazabilidad de la cadena productiva de la pesca de anchoveta?

PRODUCE es un ente estatal, es un ministerio, que trata de normar. Norma entre comillas en función del interés público. No necesariamente esto es verdad.

Yo siempre he creído que tiene que haber un equilibrio entre lo que es la norma y lo que es verdaderamente el interés público.

Para mí al final siempre se impone los verdaderos intereses económicos. Los pesqueros-industriales en el pasado han sido gente primitiva que no ha tenido capacidad para mirar más allá de sus narices y el corto plazo. Hubieran depredado el mar si les hubieran dejado. Pero entonces se creó un IMARPE que les comenzó a imponer cuotas. Sin embargo, justamente este se crea por iniciativa privada, luego de la barbaridad que hace el Estado con Pesca Perú, porque unos pocos empresarios pesqueros se dan cuenta que se va a acabar su materia prima. Yo creo que esos pocos han ido aumentado y hoy en día tienes varios que están mirando a futuro.

Yo sostengo que el sector privado ya debería tener un instituto de investigación pesquera igual que el IMARPE, manejado independientemente, que haga estudios y mediciones para aumentar la diversidad del mar. 


\section{Pesca de juveniles}

- Los mecanismos de fiscalización se generan mediante mecanismos de multas que dan incentivos perversos para no dar información de "pesca de juveniles" a las autoridades, ¿Cómo cree que podría mejorarse?

En estos momentos hay un conflicto serio entre el gobierno y el sector de pesca industrial. Mi opinión es que el conflicto no es por razones técnicas; sino por razón ideológica. En estos momentos hay un criterio muy fuerte que es el que está marcando la política pesquera y es la ideología de la conservación.

Lo que debiera promover cualquier política pesquera es el aumento de la diversidad y el aumento de las especies, contrario a lo que en estos momentos se ha venido aplicando.

Hay una biomasa de la anchoveta que lo que tiene es que preservarse para que tenga una continuidad, una permanencia. Por eso es que se hacen prospecciones antes de decir cuánto se va a pescar.

La controversia está en que los conservacionistas dicen que no se debe pescar nada porque lo que se tiene que hacer es aumentar la biodiversidad. Yo creo que, como en todos los casos, este es un extremo que está mal.

¿Es el óptimo haber reducido la cuota, que hace unos cinco años era de 6 millones de tonelada de anchoveta por año, a la mitad? Yo creo que eso es el punto. Promover el aumento de la cantidad de especies migrantes que salen de nuestro mar territorial para que la capturan los chinos, los coreanos o los chilenos que están esperando. Eso es parte de los que queremos definir.

Ha diferencia de lo que ha pasado en el resto del mundo, que se ha depredado los mares, por ejemplo Estados Unidos y Europa, cuyos pesqueros depredaron la pesca, Perú ha conservado sus especies. Inclusive, Chile ha actuado de la manera más irresponsable posible. E una especie migrante que sale de Nueva Zelanda, pasa por las costas chilenas, pasa por las peruanas y después se va Ecuador. El año pasado han capturado 200 mil toneladas. No hay más, se han acabado el jurel.

Con Chile compartimos una biomasa de anchoveta. El Perú no deja que se capturen los juveniles, pero esos crecen y una vez que crecen migran a Chile. Una vez que llegan a Chile, lo pescan todo, no tienen cuota. Entonces, nosotros lo que necesitamos es definir una política de largo plazo. 
Mi posición como director de una empresa pesquera es que el Perú en un conjunto de actividades ya llegó a utilizar en pleno las ventajas comparativas naturales. Eso es lo que ha pasado por ejemplo con la anchoveta.

Una empresa en el Perú ya no puede aumentar de valor por capturar la anchoveta, porque ya hay una cuota máxima que te permiten. Tu eficiencia ya llegó al máximo por la cuota. Antes se salía de manera caótica a capturar ineficientemente. Entonces, la única forma en que una empresa pesquera puede aumentar su valor ahora es a través de dos vías: consumo humano directo y/o indirecto.

Se puede pescar especies que se puedan consumir directamente; es decir, no anchoveta sino las otras como jurel, caballa, atún, pota. Lo que se encuentra en este aspecto es que la rentabilidad de esa actividad es lejos superior a la del negocio de hacer harina. Ahora las principales empresas pesqueras están invirtiendo cada vez más en pesca para consumo humano directo. El problema es que no se puede pescar para llevar al mercado, que es lo que hacen los artesanos y pierden plata porque una vez que se llega a la cantidad de pesca el precio se va abajo y si no se vende se malogra el pescado. Lo que se tiene que tener es una red de frío. El pescado se enfría y sigue siendo fresco y dura varios días. Las grandes empresas están armando en todas las grandes ciudades, especialmente en la sierra, sus cadenas de frío. Entonces, se pesca y no va al mercado, sino a los depósitos de conserva y cada día se saca lo que cada mercado requiere. El principal competidor del pollo en estos momentos en el Perú es el pescado fresco, pero no lo traen los artesanos, lo traen las grandes empresas. Además, eso les permite buenas ganancias, que son proporcionalmente mayores que las de la anchoveta. Entonces, uno de los que debiera estar promoviendo la diversidad de la riqueza marina son las empresas pesqueras y cada vez son más conscientes de ello.

Yo creo que de aquí a los próximos cinco años vas a tener una transformación total de la industria pesquera. Para ello se tiene que unir los intereses de los pesqueros con los ecologistas y yo creo que van en la misma dirección. 


\section{Competencia / OPEP}

- ¿Cree que existe una competencia efectiva entre empresas pesqueras? ¿Perú y Chile al ser uno de los principales productores de harina de pescado, no podrían generar una suerte de OPEP de la anchoveta?

Chile usa la harina para su propio salmón y nos compran a nosotros la harina, pero no pueden competir con los chinos, puesto que pagan más por la harina. Chile por ejemplo usaba el jurel para hacer harina lo que es un crimen. Ahora ellos pasan por una crisis. 